\title{
Parental influences on child snacking
}

Citation for published version (APA):

Gevers, D. W. M. (2016). Parental influences on child snacking: advancing research. [Doctoral Thesis, Maastricht University]. https://doi.org/10.26481/dis.20160629dg

Document status and date:

Published: 01/01/2016

DOI:

$10.26481 /$ dis.20160629dg

Document Version:

Publisher's PDF, also known as Version of record

\section{Please check the document version of this publication:}

- A submitted manuscript is the version of the article upon submission and before peer-review. There can be important differences between the submitted version and the official published version of record.

People interested in the research are advised to contact the author for the final version of the publication, or visit the DOI to the publisher's website.

- The final author version and the galley proof are versions of the publication after peer review.

- The final published version features the final layout of the paper including the volume, issue and page numbers.

Link to publication

\footnotetext{
General rights rights.

- You may freely distribute the URL identifying the publication in the public portal. please follow below link for the End User Agreement:

www.umlib.nl/taverne-license

Take down policy

If you believe that this document breaches copyright please contact us at:

repository@maastrichtuniversity.nl

providing details and we will investigate your claim.
}

Copyright and moral rights for the publications made accessible in the public portal are retained by the authors and/or other copyright owners and it is a condition of accessing publications that users recognise and abide by the legal requirements associated with these

- Users may download and print one copy of any publication from the public portal for the purpose of private study or research.

- You may not further distribute the material or use it for any profit-making activity or commercial gain

If the publication is distributed under the terms of Article $25 \mathrm{fa}$ of the Dutch Copyright Act, indicated by the "Taverne" license above, 


\section{Parental influences on child snacking: advancing research}




\section{Colophon}

Cover: Ridderprint BV

Printing: Ridderprint BV

(C) Dorus Gevers, 2016

ISBN: 978-94-6299-358-7

The research presented in this thesis was conducted at the Department of Health Promotion at Maastricht University, the Netherlands. The work in this thesis was performed within the NUTRIM School of Nutrition and Translational Research in Metabolism, Maastricht University Medical Center+.

All rights are reserved. No part of this book may be reproduced or transmitted in any form or by any means, without the written permission from the author or, where appropriate, the publisher of the article. 
PARENTAL INFLUENCES ON CHILD SNACKING: ADVANCING RESEARCH

\section{Proefschrift}

ter verkrijging van de graad van doctor aan de Universiteit Maastricht, op gezag van de Rector Magnificus, Prof. dr. L.L.G. Soete volgens het besluit van het College van Decanen, in het openbaar te verdedigen op woensdag 29 juni 2016 om 12:00 uur

door

Dorus Wilhelmus Maria Gevers

geboren op 10 november 1987 te Heesch, Nederland 


\section{Promotores}

Prof. dr. Stef Kremers

Prof. dr. Nanne de Vries

\section{Copromotor}

Dr. Patricia van Assema

\section{Beoordelingscommissie}

Prof. dr. Dike van de Mheen (voorzitter)

Prof. dr. Benedicte Deforche, Universiteit Gent

Prof. dr. Gerjo Kok

Dr. Christina Niermann, Karlsruhe Institute of Technology

Dr. Anne Roefs 


\section{Contents}

$\begin{array}{lll}\text { Chapter } 1 & \text { General introduction } & 7\end{array}$

Chapter 2 Intake of energy-dense snack foods and drinks among Dutch children aged 7-12 years: how many, how much, when, where and which?

Chapter 3 Clarifying concepts of food parenting practices. A Delphi study with an application to snacking behavior

Chapter 4 Development of the Comprehensive Snack Parenting Questionnaire: test-retest reliability and discriminative value of constructs

Chapter 5 Patterns of food parenting practices and children's intake of energydense snack foods

Chapter 6 Associations between general parenting, restrictive snacking rules, and adolescent's snack intake. The roles of fathers and mothers and interparental congruence

Chapter 7 Explaining food parenting practices: the importance of predisposing factors and parental cognitions

Chapter 8 General discussion

References

Appendices

Summary

Samenvatting

Curriculum Vitae 



\section{Chapter 1}

General introduction 
The main purpose of the studies reported in this dissertation was to advance research and the development of theory around parental influences - in particular food parenting practices (FPPs) - on children's consumption of energy-dense snack foods (EDSFs). The ultimate goal of the six studies that are presented was to identify priorities and starting points for intervention developers aiming at promoting healthy diets among children. The focal populations of the dissertation were mainly primary school children and their parents. The current introductory chapter describes the overall rationale and aims of the research project. It ends with an outline and presentation of the general research framework.

\section{Children's intake of energy-dense snack foods}

A high intake of EDSFs is undesirable as such foods tend to be high in sugars or fat and low in micronutrients, and thus of little nutritional value (World Health Organization, 2003). Excessive intakes of snack foods may result in harmful physical conditions and diseases: although there are some contradictory empirical findings on the link between children's intake of snacks and body fatness (Larson \& Story, 2013), experts consulted by the World Health Organization (WHO, 2003) reported that the available evidence is convincing enough to state that excessive intakes of snack foods promote weight gain and obesity. Obesity in childhood, in turn, is associated with several unhealthy physical (e.g. cardiovascular diseases) and psychosocial conditions (e.g. depression) (Daniels, 2006). Research also points out that obese children are at risk for becoming obese adults (Singh et al., 2008). Yet, the large variety in definitions of snacking (and snacks foods) in the literature continues to complicate the relationship between snacking and obesity (Johnson \& Anderson, 2010), thereby stressing the importance of a strict definition to be provided from the outset of research (Gregori \& Maffeis, 2007). The following definition of EDSFs was used in the current dissertation: EDSFs are any non-core foods meant for consumption between main meals. It is based on a definition introduced by multiple nutritional institutes, including the ones in Australia and the Netherlands (Netherlands Nutrition Centre, 2011; Smith et al., 1998). They have uniformly distinguished core foods from non-core foods. Core foods are defined as foods that are relatively high in nutrients and low in energy and contribute to a healthy dietary pattern (Johnson et al., 2011). In contrast, non-core foods are relatively low in nutrients and high in energy (Johnson et al., 2011). By definition, non-core foods are superfluous to a healthy diet and their intake should be limited (Bell et al., 2005). According 
to the Netherlands Nutrition Centre, EDSFs all fall within the non-core foods category and refer to any food meant for consumption between main meals, such as potato chips, nuts, savory snacks, deep-fried snacks, cookies, pastry, sweets, chocolate, and ice creams. The current dissertation will use this definition (i.e. non-core foods meant for consumption between main meals), but foods which often constitute or are part of a meal in the Netherlands, such as pizza, deep-fried snacks, including French fries and hamburgers, and ice creams, were considered to be EDSFs only when consumed between meals. The terms EDSFs, snack foods, and snacks are used interchangeably throughout this dissertation and all denote the foods as defined above.

Among U.S. children, an increase in snacking was observed for the last several decades (Larson \& Story, 2013). It is crucial to invert this trend and establish healthy dietary patterns in childhood since there is evidence to indicate that children's dietary behaviors track into adulthood (Craigie et al., 2011). The figures from the U.S. might be indicative of other Western countries. In the Netherlands, several researchers investigated EDSF intake among children (e.g. Rodenburg et al., 2014; Van Strien et al., 2009), but the samples (e.g. small samples or samples taken from a specific subpopulation) and measures (e.g. measures consisting of a few food frequency questions) prevent generalization of the results and drawing sound conclusions on the actual intake of Dutch children. The Dutch Nutrition Institute recommends a maximum daily intake of non-core foods of 200 kcals for girls aged 4 to 12 and for boys aged 4 to 8 and to a maximum of $300 \mathrm{kcal}$ for boys aged 9-13 (NNC, 2011). Figures about the number of children that meet these guidelines when it comes to their snack consumption are also lacking.

\section{General parenting and food parenting practices}

Researchers increasingly recognize the critical importance of parents in shaping children's dietary behaviors. In the literature, a distinction is made between general parenting and FPPs. The current project investigates both general parenting and FPPs, but the main focus will be on the latter. General parenting reflects an emotional climate of attitudes in which communication toward the child takes place and in which parental behaviors are expressed (Darling \& Steinberg, 1993) and is commonly conceptualized as consisting of two dimensions, i.e. responsiveness and demandingness (Maccoby \& Martin, 1983). Parents who are both responsive and demanding are referred to as authoritative and are found to have 
children with more desirable energy-balance related outcome measures, compared to children of parents with other parenting styles (Sleddens et al., 2011). The two-dimensional model seems not entirely valid and complete. The Comprehensive General Parenting Questionnaire (CGPQ) is a recently developed instrument to measure five general parenting factors (i.e. nurturance, structure, behavioral control, coercive control, and overprotection) (Sleddens et al., 2014). Parenting practices are goal-directed parental behaviors directed at influencing children's behaviors (Darling \& Steinberg, 1993). These practices apply to various domains (e.g. food, physical activity, alcohol) and are defined accordingly. As such, parenting practices around children's dietary behaviors might be referred to as FPPs. The research in this dissertation will concentrate on FPPs in the context of snacking.

Several questionnaires have been developed to assess FPPs, of which the Child Feeding Questionnaire (CFQ) (Birch et al., 2001) is the most widely used (Corsini et al., 2008). Other well-known instruments in this field include the Parental Feeding Style Questionnaire (PFSQ) (Wardle et al., 2002), and the Comprehensive Feeding Practices Questionnaire (CFPQ) (Musher-Eizenman \& Holub, 2007). A comparison of these instruments reveals inconsistencies with regard to the terminology and operationalization of constructs (Vaughn et al., 2013). In addition, most instruments have concentrated on a limited set of practices, mostly on parenting practices designed to control a child's food intake (Baranowski et al., 2013a). For instance, the CFQ only includes the constructs of restriction, pressure to eat, and monitoring to measure FPPs (Birch et al., 2001). However, a large variety of parental behaviors may be regarded as potentially influential practices, such as modeling of healthy food intake, teaching about food, and involvement (Musher-Eizenman \& Holub, 2007). As a result, empirical evidence of the relationship between FPPs and children's dietary behaviors and BMI is relatively limited and difficult to consolidate. Nevertheless, some consistent associations have been found across studies. For instance, parental modeling, encouragement, and the home availability and accessibility of foods (i.e. foods that are similar to the outcome measures used in each study) have been found to be positively associated with the intake of fruit, vegetables, and soft drinks (Gerards \& Kremers, 2015).

Still, several remarks can be made concerning the present knowledge base on parenting practices around food. First, most researchers included just a few FPPs as independent predictors of a child's dietary intake or BMI, implying that only the main effects of single parenting practices were studied. However, parents rather employ multiple FPPs, 
which might have synergistic (Rodenburg et al., 2013) or opposing effects. Instead of using isolated observations, such effects might be revealed by examining patterns. Second, most of the evidence about FPPs (e.g. their impact on children's dietary behavior and weight) is based on research in mothers (Hughes et al., 2013). Furthermore, there is only limited evidence about paternal and maternal differences regarding parenting practices. Yet, the interaction between both parents within a family may form an independent risk factor for a child to become overweight (Power et al., 2013). To the best of our knowledge, studies investigating parenting congruence in the context of children's dietary behavior are absent. Third, most studies around FPPs focused on their relationship with child energy-balance related outcome measures (e.g. child's dietary behavior and weight), and not on their determinants. More research on the precursors of parenting practices is essential in order to develop evidence-based interventions aimed at improving FPPs. So far, research has mainly linked demographic factors with food parenting practices. Other potentially important precursors include the general parenting style (Collins et al., 2014) and personality of parents. Besides these distal factors, more proximal determinants of parenting practices might include factors from socio-cognitive theories of health behavior. For instance, the Social Cognitive Theory (Bandura, 1986) describes the importance of self-efficacy and outcome expectations in shaping behavior while subjective norms (Fishbein \& Ajzen, 1975) is one of the constructs within the Theory of Planned Behavior that also may predict the use of FPPs.

\section{Study aims}

The following aims have been formulated:

- to assess the intake of EDSFs and drinks among children in the Netherlands.

- to bring consensus regarding terminology and conceptualization of FPP in the context of snacking.

- to develop a questionnaire that can be used to assess a wide range of FPPs.

- to assess the co-occurrence of FPPs (i.e. patterns of FPPs) within parents and its association with the snack intake of children of those parents.

- to assess the impact of parental congruence concerning general parenting and restrictive snacking rules on the intake of snack foods in adolescents. 
- to identify correlates of parent's pattern of FPPs, including predisposing factors (e.g. personality and general parenting) and parental cognitions (e.g. attitude and self-efficacy).

\section{Outline of the dissertation}

The general research framework, which outlines the chapters of this dissertation, is presented in figure 1.1. Chapter 2 describes the intake of EDSFs and drinks among Dutch children using 24-hour dietary recall data from the Dutch National Food Consumption Survey 2007-2010. Chapter 3 aims to clarify concepts of FPPs in the context of snacking and reach consensus on terminology using an international Delphi study. Chapter 4 describes the development and initial test of reliability and discriminative value of constructs from a questionnaire to measure a wide range of FPPs around snacking. This questionnaire was based on the FPPs derived from the Delphi study reported in the preceding chapter. Chapter 5 examines whether groups of parents can be distinguished according to these parenting practices using data from a cross-sectional questionnaire survey and links the resulting patterns with children's snack intake. Chapter 6 uses child-report data and investigates both fathers' and mothers' parenting with regard to adolescents' snack intake. In particular, it explores if incongruence between both caregivers within one family influences the associations between parenting (i.e. general parenting and the use of restrictive food rules) and adolescents' snack intake. Based upon previous research and socio-cognitive models of health behavior, a research framework was developed for the prediction of the FPP patterns found in chapter 5 . In chapter $\mathbf{7}$, this model is empirically tested. Finally, chapter $\mathbf{8}$ provides an overview of the main findings and limitations from the studies presented in this dissertation and a discussion on the studies' contribution to research, theory, and practice. 


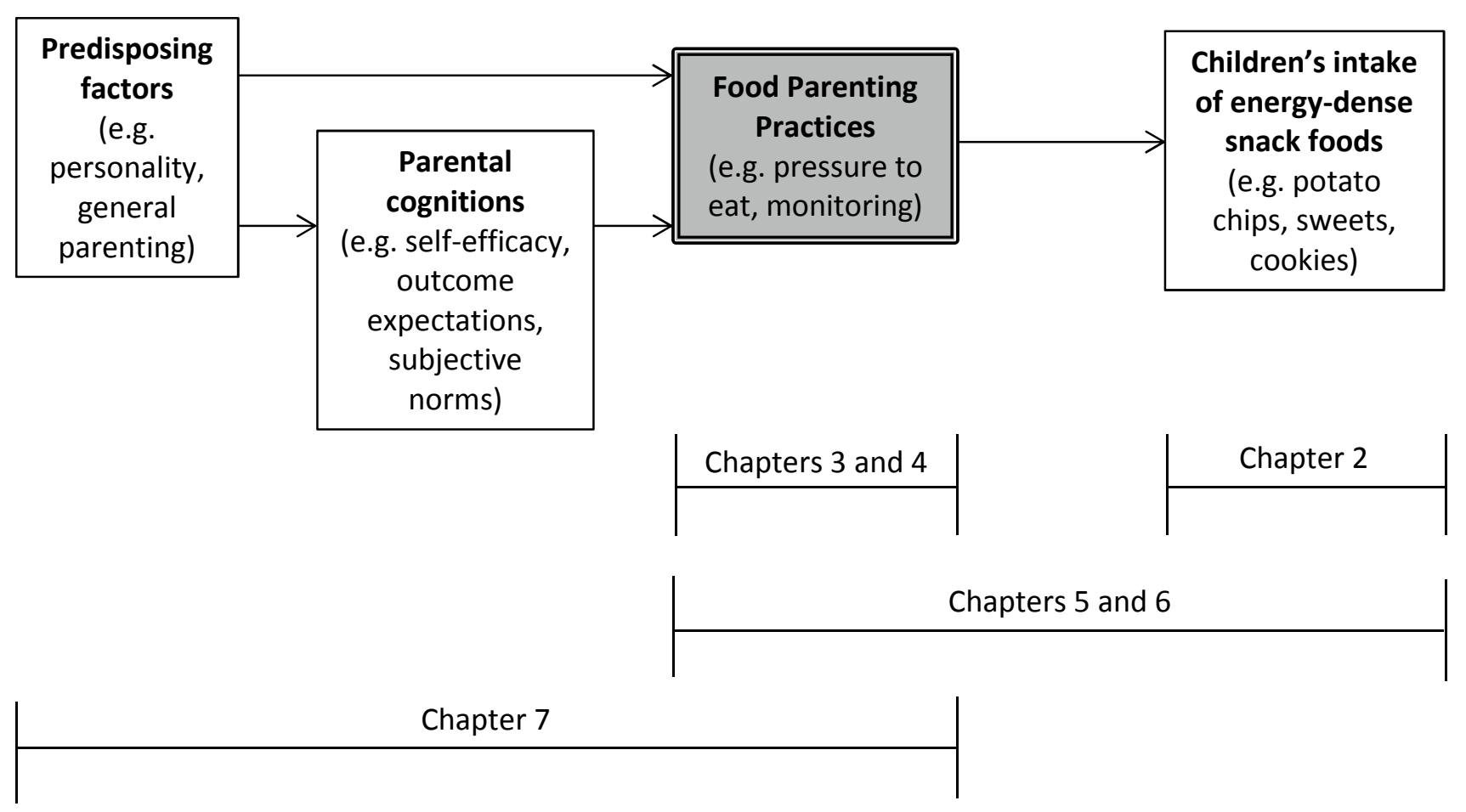

Figure 1.1: general research framework 


\section{Chapter 2}

Intake of energy-dense snack foods and drinks among Dutch children aged 7-12 years: how many, how much, when, where and which?

This chapter has been published as: Gevers D.W.M., Kremers S.P.J., de Vries N.K., van Assema P. (2015). Intake of energy-dense snack foods and drinks among Dutch children aged 7-12 years: how many, how much, when, where and which? Public Health Nutrition 8, 1-10.

Acknowledgement: Data analyzed were from FCS2010_Core_20111125; part of the Dutch National Food Consumption Survey, performed by the National Institute for Public Health and the Environment (RIVM), Bilthoven. 


\begin{abstract}
Objective: To describe the energy-dense snack food (EDSF) and energy-dense drink (EDD) consumption of children in the Netherlands and investigate subgroup differences. The amounts consumed, eating occasions, places of consumption and consumed types are reported.
\end{abstract}

Design: Twenty-four hour dietary recall data were used to describe the EDSF and EDD consumption. Subgroup differences concerning these intakes were identified with ANCOVA. Setting: Dutch National Food Consumption Survey 2007-2010.

Subjects: Children ( $\mathrm{n} 860$ ) aged 7-12 years.

Results: The mean number of EDSF events was 3.3 ( $S D=1.6)$ per day, yielding 1569.7 $(\mathrm{SD}=928.7) \mathrm{kJ}$. Average EDD consumption was $594.2(\mathrm{SD}=342.3) \mathrm{ml} / \mathrm{d}$, yielding 737.2 $(S D=495.9) \mathrm{kJ}$. Over $90 \%$ of the children consumed more energy from non-core foods per day than recommended. Differences in EDSF and EDD consumption were found between several subgroups. Most importantly, we found higher intakes among older children and children with low educated mothers. Almost half of the EDSF events took place in the afternoon and at home. Cookies and sweets were consumed during half of the EDSF events. Almost one-third of the EDD were consumed in the afternoon. The majority of these drinks were consumed at home and most were soft drinks.

Conclusions: The results demonstrate that snack food and drink consumption is highly prevalent among Dutch children. Health promotion efforts addressing these behaviors are warranted and the present study could accelerate these initiatives. Focusing on children with low educated parents and on snacking at home after school offers the greatest potential to reduce snack food and drink intakes. 


\section{Introduction}

The WHO and the FAO have identified high intake of energy-dense micronutrient-poor foods as a 'convincing causative factor of weight gain' (WHO, 2003). This category typically includes snack foods such as potato chips, chocolate and cookies. According to the WHO, a high intake of sugar sweetened soft drinks may also increase body weight and promote obesity (WHO, 2003). Overweight in childhood is associated with short-term and long-term physical and psychological morbidity (Reilly \& Kelly, 2011; Reilly et al., 2003) and is likely to track into adulthood (Singh et al., 2008). Independent of a high energy intake, high intakes of fat, sugar and salt from energy-dense snack foods (EDSF) or energy-dense drinks (EDD) may also result in harmful physical conditions (e.g. high blood pressure and high LDL-cholesterol) and diseases (e.g. diabetes, CVD and dental caries) (WHO., 2003). There are indications that these dietary habits persist over time (Pearson et al., 2011; Totland et al., 2013a).

Although there is no universally accepted definition of snack foods (Gregori et al., 2011; Gregori \& Maffeis, 2007; Johnson \& Anderson, 2010), several nutrition institutes, including the Netherlands Nutrition Centre (NNC), distinguish core foods (e.g. fruit, vegetables and bread) from non-core foods (e.g. soft drinks, sauces and snacks) (NNC, 2011). Due to the inconsistencies in definitions, some studies on snacking included the intake of all foods, including fruit and vegetables (e.g. Kerr et al., 2009), while others focused on noncore foods only (e.g. Macdiarmid et al., 2009). The EDSF and EDD investigated in the present study belong to this non-core foods category. The NNC recommends a maximum daily consumption of 837-1255 kJ (200-300 kcal) from non-core foods, depending on age and sex (NNC, 2011).

Policy makers and health promotion practitioners would benefit from information on the amounts of EDSF and EDD consumed and on risk groups, eating occasions, places of consumption and consumed types of food and drink. For several dietary behaviors, this information is available (e.g. Piernas et al., 2014), but few studies focus on EDSF and EDD and use representative samples of children and recent data. Macdiarmid et al. (2009) used national survey data collected in 2006 to investigate snacking patterns among Scottish children. They found a median number of 2.0 snacks/d (Macdiarmid et al., 2009). Bell et al. (2005) reported that in 1995 the average proportion of energy from non-core foods and drinks in the daily energy intake of Australian children aged 5-12 years was over $40 \%$ for non-core foods and over $30 \%$ for non-core drinks. A recent European study reported that 
soft drink consumption among Dutch children aged 10-12 years was higher than that of their peers in six other European countries (Brug et al., 2012b). A recent report on the Dutch National Food Consumption Survey demonstrated that children aged 7-11 years consume almost $600 \mathrm{~g}$ of sugar-sweetened beverages daily (Buurma-Rethans et al., 2012). Studies among various Dutch samples have shown means of nine to ten EDSF events per week (Rodenburg et al., 2014; Van Strien et al., 2009).

Children from low socio-economic backgrounds have been found to be at risk for high EDSF and EDD consumption (Craig et al., 2010; Totland et al., 2013b). Differences in intakes between boys and girls and age groups have also been investigated (Brug et al., 2012b; Macdiarmid et al., 2009; Rangan et al., 2008), but results are contradictory. Information concerning the occasions at which food is consumed has been reported in several studies. In particular, dietary patterns on weekdays have been compared with weekend days (Rockell et al., 2011a; Rothausen et al., 2013) and the importance of after-school snacking has been highlighted (Gilbert et al., 2012; Rockell et al., 2011b). There is little information available on the places where EDSF and EDD are consumed, although home and school seem most common (Briefel et al., 2009; Kerr et al., 2010). Some studies have reported the most commonly consumed types of EDSF and EDD, but their results are hard to compare due to differences of categorization (Kerr et al., 2009; Rangan et al., 2008).

The current study aimed to describe the EDSF and EDD consumption of children aged 7-12 years in the Netherlands. Results can inform public health policies and interventions, and contribute to the international literature. The specific research aims of the study were to: 1. Describe what quantities of EDSF and EDD children consume per day in terms of events, amounts and energy; 2. Test if there are differences in EDSF and EDD consumption between sociodemographic subgroups and BMI subgroups; and 3. Describe at what type of eating occasions and in what places children consume EDSF and EDD, and which types of EDSF and EDD are consumed.

\section{Methods}

Data were derived from the most recent Dutch National Food Consumption Survey, the DNFCS 2007-2010 (Van Rossum et al., 2011). That survey was commissioned by the Dutch Ministry of Health, Welfare and Sport and coordinated by the Dutch National Institute for Public Health and the Environment. Initially, 5502 members of a consumer panel aged 7-69 
years were invited to participate and data collection took place through a market research agency (GfK Panel Services). In total, 3819 persons participated, 860 of whom were 7-12 years old.

\section{Data collection}

Data on food consumption were collected by trained dietitians by means of two $24 \mathrm{~h}$ dietary recalls using the EPIC-Soft software program (Slimani et al., 2000). Food products were matched with products from the Dutch Food Composition Database (NEVO) (Rijksinstutuut voor Volksgezondheid en Milieu, 2011). Children were interviewed face-to face at home twice, in the presence of at least one parent or caregiver. There was an interval of about 4 weeks between the two interviews. Data collection was evenly distributed over the seasons and days of the week. In addition to the interviews, the children were given written questionnaires to assess demographic variables including age, sex, height and weight, employment status and country of birth of both parents, household income and household size. Information on respondents' place of residence (in terms of region and degree of urbanization) and the educational level of the head of the household was already known to the marketing research agency. A report on the full DNFCS 2007-2010, including the data collection method, is available (Van Rossum et al., 2011).

\section{Definitions of energy-dense snack foods and energy-dense drinks}

EDSF were defined using the type of eating occasion (during meals or between meals), as self-designated by the study participants, and using a food classification (Bell et al., 2005) from the NNC. First, all foods classified as 'snacks' according to the NNC were identified as EDSF. The NNC defines snacks as foods that are meant for consumption between main meals. They include potato chips, nuts, savory snacks, deep-fried snacks, cookies, pastry, sweets, chocolate, ice creams and certain types of dessert. Second, the type of eating occasion was taken into account for foods which often constitute or are part of a meal in the Netherlands, such as pizza, deep-fried snacks, including French fries and hamburgers, and ice creams. Hence, these types of food were defined as EDSF only when consumed between meals. Third, similar EDSF consumed within 60 min were considered to be part of the same snacking event and coded as such. Fourth, foods (both core foods and noncore foods) eaten in conjunction with an EDSF (e.g. hamburger with bun) were also considered to be part of 
the same snacking event and the total energy involved in this snack event was counted. EDD included in the present study were soft drinks and squash (drinks prepared from concentrated fruit syrups mixed with water), irrespective of the type of eating occasion. These drinks are included in the 'soft drinks' category of the non-core food group. Soft drinks with both sweeteners and added sugars were only included if the carbohydrate content was more than $2 \mathrm{~g}$ per $100 \mathrm{~g}$ (Buurma-Rethans et al., 2012). Sugar-free beverages and fruit juices were not included in the definition of EDD.

\section{Data analysis}

BMI was calculated according to age- and sex-specific cutoff values (Hirasing et al., 2001; van Buuren, 2004) and divided into underweight, normal weight and overweight (including obese). Based on definitions from Statistics Netherlands, the variables ethnicity, educational level of mother and education level of father were created (Statistics Netherlands, 2015; Keij, 2000). Ethnicity consisted of three categories: native Dutch, Western immigrants and non-Western immigrants. Educational levels were defined as follows: low (primary school, lower vocational, low or intermediate general education), intermediate (intermediate vocational education and higher general education) and high (higher vocational education and university). Household income was assessed by nineteen categories of net income per month, which were reduced to three categories by splitting into tertiles (i.e. low, $<€ 1700$ net monthly; intermediate, $\geq € 1700$ to $<€ 2500$ net monthly, high, $\geq € 2500$ net monthly). Degree of urbanization was indicated by the number of addresses per square 20ilometer (i.e. low, $<1000$ addresses $/ \mathrm{km}^{2}$; intermediate, $\geq 1000$ and $<1500$ addresses $/ \mathrm{km}^{2} ;$ high, $\geq 1500$ addresses $/ \mathrm{km}^{2}$ ).

Descriptive analyses were used to describe the sample according to demographics and consumption in terms of the types of EDSF and numbers of EDSF events, types and amounts of EDD, energy intake from EDSF and EDD, the type of eating occasion and place of consumption. Descriptive statistics for the amount of, and energy from, EDSF and EDD were weighted for small deviations from the general Dutch population regarding sociodemographic characteristics (i.e. region where household is located, urbanization of household location and educational level of the household head), as well as for day of the week and the season of data collection. The weighing factor was derived by using census data from Statistics Netherlands. 
Differences in intakes (mean number of EDSF events per day, mean EDD intake in millilitres per day, and mean energy intake from EDSF and EDD events per day) according to age, sex, BMI, ethnicity, household income, degree of urbanization, educational level of the mother and father, employment status of the mother and father, and household size were identified using ANCOVA with age as a covariate while weighing for small deviations from the general Dutch population and moment of data collection. If the $F$ test showed a $P$ value $<0.05$, Bonferroni post hoc tests were performed. Cohen's d effect sizes for significantly different subgroups were calculated using group means and standard errors produced by the ANCOVA. Effect sizes were termed according to the classification of Lipsey (1990): small $(\leq 0.32)$, medium $(0.33-0.55)$ and large $(>0.56)$. In order to determine the relative importance of the sociodemographic factors in explaining total EDSF and EDD intake and EDSF and EDD intake at home, weighted backward linear regression analyses were performed. To investigate determinants of intake at home, we created two new dependent variables called 'relative EDSF consumption at home' and 'relative EDD consumption at home', to rule out the influence of total consumption. These new variables were calculated by dividing the consumption at home by the total consumption. The intakes over two days were averaged for the analyses related to the amount of foods and drinks consumed. All analyses were conducted using the statistical software package IBM SPSS Statistics for Windows, version 20.0 . 
Table 2.1: Sample characteristics

\begin{tabular}{|c|c|c|}
\hline & $\mathbf{N}$ & Mean (SD) or \% \\
\hline Mean age, years (standard deviation) & 860 & $9.42(1.75)$ \\
\hline \multicolumn{3}{|l|}{ Age (\%) } \\
\hline 7 or 8 years & 304 & 35.3 \\
\hline 9 or 10 years & 265 & 30.8 \\
\hline 11 or 12 years & 291 & 33.8 \\
\hline \multicolumn{3}{|l|}{ Gender $(\%)(n=860)$} \\
\hline Male & 433 & 50.3 \\
\hline Female & 427 & 49.7 \\
\hline \multicolumn{3}{|l|}{ BMI group (\%) (n=859) } \\
\hline Underweight & 82 & 9.5 \\
\hline Normal weight & 608 & 70.8 \\
\hline Overweight and obese & 169 & 19.7 \\
\hline \multicolumn{3}{|l|}{ Ethnicity (\%) $(n=840)$} \\
\hline Native Dutch & 756 & 90.0 \\
\hline Western immigrant & 32 & 3.8 \\
\hline Non-Western immigrants & 52 & 6.2 \\
\hline \multicolumn{3}{|l|}{ Household income $(n=860)$} \\
\hline Low & 297 & 34.5 \\
\hline Intermediate & 268 & 31.2 \\
\hline High & 295 & 34.3 \\
\hline \multicolumn{3}{|l|}{ Degree of urbanization $(\%)(n=860)$} \\
\hline Low & 351 & 40.8 \\
\hline Intermediate & 150 & 17.4 \\
\hline High & 359 & 41.7 \\
\hline \multicolumn{3}{|l|}{ Educational level of mother $(n=852)$} \\
\hline Low & 290 & 34.0 \\
\hline Intermediate & 383 & 45.0 \\
\hline High & 179 & 21.0 \\
\hline \multicolumn{3}{|l|}{ Educational level of father( $n=758)$} \\
\hline Low & 221 & 29.2 \\
\hline Intermediate & 319 & 42.1 \\
\hline High & 218 & 28.8 \\
\hline \multicolumn{3}{|l|}{ Employment status of mother $(n=849)$} \\
\hline Employed & 614 & 72.3 \\
\hline Non-employed & 235 & 27.7 \\
\hline \multicolumn{3}{|l|}{ Employment status of father $(n=754)$} \\
\hline Employed & 719 & 95.4 \\
\hline Non-employed & 35 & 4.6 \\
\hline \multicolumn{3}{|l|}{ Household size $(n=860)$} \\
\hline 2 & 42 & 4.9 \\
\hline 3 & 163 & 19.0 \\
\hline 4 & 383 & 44.5 \\
\hline$\geq 5$ & 272 & 31.6 \\
\hline \multicolumn{3}{|l|}{ Region of household location ( $n=860$ ) } \\
\hline North & 96 & 11.2 \\
\hline East & 192 & 22.3 \\
\hline South & 207 & 24.1 \\
\hline Three largest cities in the West & 115 & 13.4 \\
\hline West (other) & 250 & 29.1 \\
\hline
\end{tabular}


Table 2.1: continued

\begin{tabular}{lll}
\hline & N & Mean (SD) or \% \\
\hline Season of interviews $(\mathbf{n}=\mathbf{8 6 0})$ & 197 & 22.9 \\
Spring & 216 & 25.1 \\
Summer & 222 & 25.8 \\
Autumn & 225 & 26.2 \\
Winter & & \\
Day assessed by 24-hour dietary recall (n=860*2 times) & 230 & 13.4 \\
Monday & 297 & 17.3 \\
Tuesday & 242 & 14.1 \\
Wednesday & 283 & 16.5 \\
Thursday & 246 & 14.3 \\
Friday & 202 & 11.7 \\
Saturday & 220 & 12.8 \\
Sunday & & \\
\hline
\end{tabular}

\section{Results}

The sample consisted of 860 children, with fewer respondents in the 9-10 years category than in the youngest and oldest age categories (Table 2.1). Boys and girls were evenly distributed, and $71 \%$ of the sample had a normal weight, while $20 \%$ were overweight and $10 \%$ were underweight. Overweight children and children of Dutch native ethnicity were somewhat over-represented, compared with the general Dutch population (Schönbeck et al., 2011; Statistics Netherlands, 2014). Compared with the general Dutch population, mothers and fathers with a high educational level were over-represented, while fathers and mothers with a low educational level were underrepresented (Statistics Netherlands, 2014). About 70 $\%$ of the mothers and more than $90 \%$ of the fathers were employed. Almost half of the households consisted of four persons. The distribution of households across regions was comparable to that of the general Dutch population (Statistics Netherlands, 2014).

\section{Consumption of energy-dense snack foods and energy-dense drinks}

The mean number of EDSF events for the total sample was 3.3 ( $S D=1.6)$ per day (Table 2.2). The mean daily energy intake from EDSF was 1569.7 (SD=928.7) $\mathrm{kJ}$ for the total sample. The average amount of EDD consumed by the total sample was $594.2(\mathrm{SD}=342.3) \mathrm{ml} / \mathrm{d}$. The mean energy intake from EDD for the total sample was $737.2(\mathrm{SD}=495.9) \mathrm{kJ} / \mathrm{d}$.

The mean total energy intake from EDSF and EDD was 2306.8 (SD=1113.8) kJ/d (about $550 \mathrm{kcal} / \mathrm{d}$ ) and $91.1 \%$ of the children did not comply with the recommendation of the NNC (a maximum of 837-1255 kJ (200-300 kcal) from non-core foods per day, depending on age and sex (NNC, 2011). 


\section{Subgroup differences in energy-dense snack food and energy-dense drink consumption}

The 9- and 10 -year-olds $(P<0.001)$ and the 11 - and 12 - year-olds $(P=0.038)$ had significantly more events than the 7- and 8-year-olds. Girls had significantly more events per day than boys $(P=0.018)$. Children of native Dutch ethnicity had significantly more events per day than non-Western immigrants $(P=0.020)$ and children living in low-urbanization areas had more EDSF events than children living in highly urbanized areas $(P=0.005)$. Cohen's $d$ values of these differences were small to medium (ranged from 0.16 to 0.40 ; Table 2.2).

Children from the two older age categories had higher energy intakes from EDSF than children from the youngest age category (both $\mathrm{P}<0.001$ ). Children of mothers with a low educational level consumed significantly more EDSF in $\mathrm{kJ} / \mathrm{d}$ than children of highly educated mothers $(P=0.007)$. Children of fathers with low and intermediate educational levels consumed significantly more energy EDSF in $\mathrm{kJ} / \mathrm{d}$ than children of highly educated fathers ( $P=0.012$ and $P=0.004$, respectively). Cohen's $d$ values of these differences were small to medium (ranged from 0.28 to 0.45 ; Table 2.2).

Children of mothers with a low educational level consumed significantly more EDD in $\mathrm{ml} / \mathrm{d}$ than children of mothers with a high educational level $(P=0.027$, Cohen's $d=0.25$; Table 2.2).

More energy from EDD was consumed by children aged $11-12$ years $(P=0.037)$ than by the youngest children. Children with a normal weight had higher energy intakes from EDD $(P=0.008)$ than underweight children. Children of mothers with a low and intermediate educational level ( $P=0.001$ and $P=0.041$, respectively), children of employed mothers $(P=0.034)$ and children from three-person households $(P=0.024)$ consumed relatively more energy from EDD. Cohen's d values of these differences were small to medium (ranged from 0.16 to 0.35 ; Table 2.2).

Age and the degree of urbanization were found to be significant correlates of the number of EDSF events after backward linear regression analyses (Table 2.3). With regard to energy intake from EDSF, the most important sociodemographic factors were age and the mother's educational level. Educational level of the mother was also a significant correlate of EDD consumption together with household size, both in terms of amount and energy. Energy intake from EDD was additionally explained by the child's BMI and mother's employment. 


\section{Type of eating occasions, places of consumption and consumed types}

Almost half of the EDSF events took place in the afternoon and at home (Table 2.4). Cookies were consumed in one-third of all EDSF events and sweets in one-fifth of all EDSF events. Cookies included for instance Dutch raisin cookies, chocolate cookies and spiced cookies (i.e. Dutch windmill cookies). Sweets included mainly wine gums, Dutch liquorice, lollipops and boiled sweets. Almost one-third of the EDD were consumed in the afternoon. The majority of these drinks were consumed at home. The majority of EDD consumed were soft drinks, which included sodas such as coke and orangeade, fruit juice drinks, sports drinks and energy drinks.

Backward linear regression analyses showed that children living in large households (i.e. five persons) consumed a greater proportion of EDSF at home than children living in small households (i.e. two persons; $\beta=-0.11, P=0.002, R^{2}=0.01$ ). These analyses also showed that children of unemployed mothers consumed a greater proportion of EDD at home than children with employed mothers $\left(\beta=0.07, P=0.03, R^{2}=0.01\right)$ and that children living in low urbanized areas consumed a greater proportion of EDD at home than children living in high urbanized areas $\left(\beta=0.02, P=0.03, R^{2}=0.01\right)$. 
Table 2.2: Mean consumption of EDSF and EDD by sample characteristics among children aged 7-12 years

\begin{tabular}{|c|c|c|c|c|}
\hline & $\begin{array}{l}\text { EDSF events } \\
\text { (number/day) }\end{array}$ & $\begin{array}{l}\text { Energy intake from } \\
\text { EDSFs (kJ/day) }\end{array}$ & $\begin{array}{l}\text { EDD } \\
\text { consumption } \\
\text { (ml/day) }\end{array}$ & $\begin{array}{l}\text { Energy intake } \\
\text { from EDDs } \\
\text { (kJ/day) }\end{array}$ \\
\hline & Mean (SD) & Mean (SD) & Mean (SD) & Mean (SD) \\
\hline Total sample & $3.3(1.6)$ & $1569.7(928.7)$ & $594.2(342.3)$ & 737.2 (495.9) \\
\hline \multicolumn{5}{|l|}{ Age } \\
\hline (1) 7 or 8 years & $3.0(1.4)$ & $1320.7(709.6)$ & $568.4(315.7)$ & $674.2(456.9)$ \\
\hline (2) 9 or 10 years & $3.5(1.8)$ & $1668.3(957.9)$ & $630.9(323.5)$ & $763.4(450.3)$ \\
\hline (3) 11 or 12 years & $3.4(1.7)$ & $1729.9(1045.0)$ & $585.9(383.3)$ & $776.4(567.8)$ \\
\hline Post hoc Bonferroni ${ }^{a}$ & $2>1 * * * *, 3>1 *$ & $2>1 * * * *, 3>1 * * * *$ & & $3>1 *$ \\
\hline Cohen's $d^{b}$ & $0.30,0.21$ & $0.38,0.45$ & & 0.21 \\
\hline \multicolumn{5}{|l|}{ Gender } \\
\hline (1) Boys & $3.2(1.6)$ & $1572.0(957.0)$ & $610.9(355.5)$ & 747.9 (519.9) \\
\hline \multirow[t]{2}{*}{ (2) Girls } & $3.4(1.7)$ & $1567.2(1411.6)$ & $576.4(327.8)$ & $725.7(470.2)$ \\
\hline & $2>1 *$ & NS & NS & NS \\
\hline Cohen's d $d^{\mathbf{b}}$ & 0.16 & & & \\
\hline \multicolumn{5}{|l|}{ BMI } \\
\hline (1) Underweight & $3.4(1.7)$ & $1532.1(822.8)$ & $527.8(298.6)$ & $588.6(398.4)$ \\
\hline (2) Normal weight & $3.3(1.7)$ & $1595.1(960.2)$ & $603.3(334.6)$ & $763.9(500.3)$ \\
\hline (3) Overweight or obese & $3.2(1.6)$ & $1501.2(872.3)$ & $595.2(389.3)$ & $714.8(516.3)$ \\
\hline Post hoc Bonferroni & NS & NS & NS & $2>1 * *$ \\
\hline Cohen's $d^{b}$ & & & & 0.35 \\
\hline \multicolumn{5}{|l|}{ Ethnicity } \\
\hline (1) Native Dutch & $3.4(1.6)$ & $1583.8(922.2)$ & $592.4(330.0)$ & $733.4(495.0)$ \\
\hline (2) Western immigrant & $3.4(1.7)$ & $1731.0(1056.8)$ & $616.2(358.5)$ & $828.4(524.3)$ \\
\hline $\begin{array}{l}\text { (3) Non-Western } \\
\text { immigrant }\end{array}$ & $2.7(1.8)$ & $1376.2(935.4)$ & $534.4(411.0)$ & $654.4(450.5)$ \\
\hline Post hoc Bonferroni & $1>3^{*}$ & NS & NS & NS \\
\hline Cohen's d $\mathrm{d}^{\mathrm{b}}$ & 0.40 & & & \\
\hline \multicolumn{5}{|l|}{ Household income } \\
\hline (1) Low & $3.3(1.5)$ & $1642.4(915.0)$ & 621.5 (359.7) & $752.6(479.3)$ \\
\hline (2) Intermediate & $3.4(1.9)$ & $1588.3(958.3)$ & $566.6(340.1)$ & $710.4(517.5)$ \\
\hline (3) High & $3.2(1.5)$ & $1476.8(914.6)$ & $592.1(326.4)$ & 746.4 (495.3) \\
\hline Post hoc Bonferroni & NS & NS & NS & NS \\
\hline \multicolumn{5}{|l|}{ Degree of urbanization } \\
\hline (1) Low & $3.5(1.7)$ & $1613.7(938.8)$ & $602.1(333.2)$ & $727.5(473.2)$ \\
\hline (2) Intermediate & $3.2(1.8)$ & $1502.6(1001.4)$ & $582.2(292.7)$ & 717.9 (467.1) \\
\hline (3) High & $3.1(1.5)$ & $1561.6(887.0)$ & $592.8(373.3)$ & 755.2 (531.1) \\
\hline Post hoc Bonferroni & $1>3^{* *}$ & NS & NS & NS \\
\hline Cohen's $d^{b}$ & 0.24 & & & \\
\hline
\end{tabular}




$\begin{array}{llll}\begin{array}{l}\text { EDSF events } \\ \text { (number/day) }\end{array} & \begin{array}{l}\text { Energy intake from } \\ \text { EDSFs (kJ/day) }\end{array} & \begin{array}{l}\text { EDD } \\ \text { consumption } \\ \text { (ml/day) }\end{array} & \begin{array}{l}\text { Energy intake } \\ \text { from EDDs } \\ \text { (kJ/day) }\end{array} \\ \text { Mean (SD) } & \text { Mean (SD) } & \text { Mean (SD) } & \text { Mean (SD) }\end{array}$

\section{Educational level of} mother
(1) Low
(2) Intermediate
(3) High
Post hoc Bonferroni
Cohen's d $\mathrm{d}^{\mathbf{b}}$
Educational level of
father

$3.4(1.7)$
$3.3(1.7)$
$3.1(1.4)$
NS
1668.3 (947.7)
$1593.6(946.8)$
$1373.9(843.4$
$1>3^{* *}$
0.29
(1) Low
(2) Intermediate
(3) High
Cohen's d ${ }^{b}$

$3.4(1.7)$

1630.7 (930.0)

$607.9(330.1) \quad 760.3(485.5)$

Employment of mother

(1) Employed

(2) Non-employed

Cohen's $d^{\text {b }}$

\section{Employment of father}

(1) Employed

(2) Non-employed

\section{Household size}

$\begin{array}{ll}\text { (1) } 2 & 3.2(1.8) \\ (2) 3 & 3.1(1.4) \\ \text { (3) } 4 & 3.3(1.6) \\ \text { (4) } \geq 5 & 3.4(1.8) \\ \text { Post hoc Bonferroni } & \text { NS }\end{array}$

$3.4(1.6)$

$3.1(1.7)$

NS

$2.8(1.3)$
NS

$1613.1(879.8)$

1380.2 (911.4)

$1>3^{*}, 2>3^{* * *}$

$0.28,0.29$

$3.3(1.6)$
$3.3(1.7)$
NS

$$
\begin{aligned}
& 1593.4(926.9) \\
& 1518.2(941.9) \\
& \text { NS }
\end{aligned}
$$

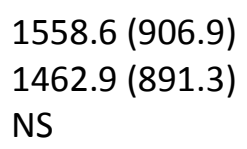
1559.4 (1475.3)
$1692.5(987.2)$
1540.1 (908.7)
1539.3 (927.0)
NS

$\begin{array}{ll}625.1(347.4) & 802.0(535.6) \\ 600.9(341.3) & 744.0(490.1) \\ 540.8(334.1) & 630.2(429.0) \\ 1>3^{*} & 1>3^{* * *}, 2>3^{*} \\ 0.25 & 0.34,0.22\end{array}$

$607.7(357.4) \quad 759.3(531.3)$

553.8 (308.9) $662.4(444.3)$

NS

NS

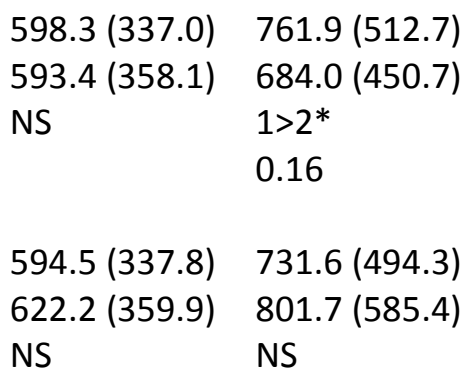

Cohen's d

Note: Analyses were weighted for small deviations in socio-demographic characteristics, day of the week and season of data collection; age was included as a covariate, $* P<0.05, * * P<0.01, * * * P<0.005, * * * * P<0.001$, ${ }^{a}$ ANCOVAs without age as a covariate, ${ }^{b}$ Cohen's d values calculated from subgroup means and standard errors produced by ANCOVAs (with age as a covariate):

Cohen's $d=\bar{x}_{a}-\bar{x}_{b} /\left(\sqrt{\left.\left(\left(n_{a}-1\right)\left(S E_{a} \sqrt{n}_{a}\right)^{2}+\left(n_{b}-1\right)\left(S E_{b} \sqrt{n}_{b}\right)^{2}\right) /\left(n_{a}+n_{b}\right)\right)}\right.$ 
Table 2.3: Relative importance of child background characteristics in explaining EDSF and EDD consumption

\begin{tabular}{|c|c|c|c|c|c|c|c|c|}
\hline & \multicolumn{2}{|c|}{$\begin{array}{l}\text { EDSF events } \\
\text { (number/day) } \\
n=860\end{array}$} & \multicolumn{2}{|c|}{$\begin{array}{l}\text { Energy intake } \\
\text { from EDSFs } \\
\text { (kJ/day) } n=852\end{array}$} & \multicolumn{2}{|c|}{$\begin{array}{l}\text { EDD } \\
\text { consumption } \\
\text { (ml/day) } n=852\end{array}$} & \multicolumn{2}{|c|}{$\begin{array}{l}\text { Energy intake } \\
\text { from EDDs } \\
\text { (kJ/day) } n=847\end{array}$} \\
\hline & $B$ & $\begin{array}{c}\mathrm{p}- \\
\text { value }\end{array}$ & B & $\begin{array}{c}\mathrm{p}- \\
\text { value }\end{array}$ & ß & $\begin{array}{c}\mathrm{p}- \\
\text { value }\end{array}$ & ß & $\begin{array}{c}\mathrm{p}- \\
\text { value }\end{array}$ \\
\hline Age & 0.08 & 0.03 & 0.17 & $<0.01$ & & & & \\
\hline \multicolumn{9}{|l|}{ Gender } \\
\hline \multicolumn{9}{|c|}{ Boys (reference) } \\
\hline \multicolumn{9}{|l|}{ Girls } \\
\hline \multicolumn{9}{|l|}{ BMI } \\
\hline Underweight & & & & & & & -0.10 & $<0.01$ \\
\hline \multicolumn{9}{|c|}{ Normal weight (reference) } \\
\hline Overweight & & & & & & & -0.05 & 0.16 \\
\hline \multicolumn{9}{|l|}{ Ethnicity } \\
\hline \multicolumn{9}{|c|}{ Native Dutch (reference) } \\
\hline \multicolumn{9}{|c|}{ Western immigrant } \\
\hline \multicolumn{9}{|c|}{ Non-Western immigrant } \\
\hline \multicolumn{9}{|c|}{ Household income } \\
\hline \multicolumn{9}{|c|}{ Low (reference) } \\
\hline \multicolumn{9}{|l|}{ Intermediate } \\
\hline \multicolumn{9}{|l|}{ High } \\
\hline \multicolumn{9}{|c|}{ Degree of urbanization } \\
\hline \multicolumn{9}{|c|}{ Low (reference) } \\
\hline Intermediate & -0.07 & 0.05 & & & & & & \\
\hline High & -0.11 & $<0.01$ & & & & & & \\
\hline \multicolumn{9}{|c|}{$\begin{array}{l}\text { Educational level of mother } \\
\text { Low (reference) }\end{array}$} \\
\hline Intermediate & & & 0.03 & 0.39 & -0.04 & 0.36 & -0.08 & 0.04 \\
\hline High & & & -0.12 & $<0.01$ & -0.10 & $<0.01$ & -0.17 & $<0.01$ \\
\hline \multicolumn{9}{|c|}{ Educational level of father } \\
\hline \multicolumn{9}{|c|}{ Low (reference) } \\
\hline \multicolumn{9}{|l|}{ Intermediate } \\
\hline \multicolumn{9}{|l|}{ High } \\
\hline Employment of & & & & & & & & \\
\hline Employed (refe & & & & & & & & \\
\hline Non-employed & & & & & & & -0.09 & 0.01 \\
\hline Employment of & & & & & & & & \\
\hline Employed (refe & & & & & & & & \\
\hline Non-employed & & & & & & & & \\
\hline Household size & & & & & & & & \\
\hline 2 & & & & & -0.03 & 0.44 & $<0.01$ & 0.99 \\
\hline 3 & & & & & 0.07 & 0.07 & 0.09 & 0.03 \\
\hline 4 & & & & & 0.08 & 0.05 & 0.09 & 0.02 \\
\hline$\geq 5$ (reference) & & & & & & & & \\
\hline $\mathbf{R}^{2}$ & 0.02 & & 0.04 & & 0.02 & & 0.05 & \\
\hline
\end{tabular}

Note: Analyses were weighted for small deviations in sociodemographic characteristics, day of the week and season of data collection 
Table 2.4: Proportions of EDSF and EDD consumed according to eating occasion, place and type

\begin{tabular}{|c|c|c|}
\hline & $\begin{array}{l}\text { Proportion of } \\
\text { total EDSF } \\
\text { consumption \% }\end{array}$ & $\begin{array}{l}\text { Proportion of } \\
\text { total EDD } \\
\text { consumption \% }\end{array}$ \\
\hline \multicolumn{3}{|l|}{ Type of eating occasion } \\
\hline Before breakfast & 0.5 & 0.6 \\
\hline During breakfast & 1.6 & 5.7 \\
\hline During the morning (between breakfast and lunch) & 23.0 & 20.5 \\
\hline During lunch & 4.9 & 10.3 \\
\hline During the afternoon (between lunch and dinner) & 45.3 & 31.9 \\
\hline During dinner & 1.7 & 11.3 \\
\hline During the evening/at night & 23.0 & 19.7 \\
\hline \multicolumn{3}{|l|}{ 3Weekdays vs. weekend days ${ }^{\dagger}$} \\
\hline Weekdays & 47.4 & 49.1 \\
\hline Weekend days & 52.6 & 50.9 \\
\hline \multicolumn{3}{|l|}{ Place of consumption } \\
\hline At home & 49.3 & 58.0 \\
\hline At school & 17.1 & 17.7 \\
\hline At a friend's home & 15.2 & 12.4 \\
\hline $\begin{array}{l}\text { Other (i.e. street, sports centre, car/boat/train/airplane, and } \\
\text { cafe/restaurant, }<5 \% \text { per group) }\end{array}$ & 18.4 & 11.9 \\
\hline \multicolumn{3}{|l|}{ Type of EDSF } \\
\hline Cookies (e.g. Dutch raisin cookies, chocolate cookies) & 30.9 & \\
\hline Sweets (e.g. wine gums, Dutch liquorice) & 21.2 & \\
\hline Potato chips & 8.5 & \\
\hline Chocolate (excluding candy bars) & 7.3 & \\
\hline Pastry & 6.0 & \\
\hline Chewing gum and mints & 6.0 & \\
\hline Ice cream & 4.5 & \\
\hline Savory snacks (e.g. pretzel sticks) and nuts (e.g. coated peanuts) & 4.3 & \\
\hline Ginger cake & 2.5 & \\
\hline Candy bars & 2.0 & \\
\hline Deep-fried snacks (e.g. French fries) & 1.8 & \\
\hline Other & 5.0 & \\
\hline \multicolumn{3}{|l|}{ Type of EDD } \\
\hline $\begin{array}{l}\text { Soft drink (e.g. sodas, sports drinks, energy drinks, and fruit } \\
\text { juice drinks) }\end{array}$ & & 60.7 \\
\hline Squash (concentrated fruit syrups mixed with water) & & 39.3 \\
\hline
\end{tabular}

Note: $\uparrow$ percentages based on cases with one recall day during the week and one recall day during the weekend $(n=294)$ 


\section{Discussion}

The current study examined the consumption of EDSF and EDD among Dutch children in terms of the amounts consumed, type of eating occasions, places of consumption and consumed types. The results demonstrated that, on average, Dutch children aged between 7 and 12 years consumed more than three EDSF per day, yielding over $1500 \mathrm{~kJ}$. The number of snacking events in the current study was higher than that found among Scottish children (Macdiarmid et al., 2009) and in Dutch studies investigating specific sub-populations (Rodenburg et al., 2014; Van Strien et al., 2009). On average, the children consumed almost $600 \mathrm{ml}$ of EDD daily, which is comparable to the outcomes of the European study by Brug et al. (2012b). In the current study, the average energy intake from EDD was more than 730 $\mathrm{kJ} / \mathrm{d}$. There are no similar studies available with which to compare our results concerning the energy intake from EDSF and EDD. Nevertheless, these results indicate that efforts to promote healthy dietary behaviors in Dutch children are justified and necessary, as their energy intakes from EDSF and EDD exceed the recommendations from the NNC (2011). The total mean intake from these foods and drinks was over $2300 \mathrm{~kJ} / \mathrm{d}$ (about $550 \mathrm{kcal} / \mathrm{d}$ ) and as many as $90 \%$ of the children exceeded the recommendation (a maximum of 837-1255 kJ (200-300 kcal) from non-core foods per day, depending on age and sex (NNC, 2011).

Older children had higher intakes of EDSF and EDD than younger children. Older children are generally likely to have higher total daily energy intakes than younger children, while the proportion of snack foods to the total daily energy intake may increase with age as well (Rangan et al., 2008). Intervening just before the age of 9 years might be the most effective option to reduce EDSF and EDD consumption, as we found a steep rise in these behaviors from this age onwards, indicated by medium sized effects (Lipsey, 1990). Considering all factors included in the present study, age appeared to be one of the most important predictors of EDSF consumption. Girls, children of native Dutch ethnicity and children living in low-urbanization areas had relatively more EDSF events. Macdiarmid et al. (2009) did not find differences in the number of snacking events between Scottish boys and girls. Future studies should examine sex differences in the portion sizes and types of EDSF and EDD consumed. We found no other studies that reported results concerning urbanization, and we have no a clear explanation for the difference we observed. The finding that non-Western immigrants had fewer EDSF events may be explained by the underrepresentation of this group in the sample, as non-Dutch speaking persons were 
excluded from the study. Brug et al. (2012a) found no differences in soft drink consumption between children of non-native ethnicity and native ethnicity in the Netherlands, which is in agreement with the current findings. The finding that overweight and obese children did not differ from normal-weight or underweight children in their intakes of EDSF and EDD may be caused by under-reporting (Fisher et al., 2000), dieting behavior (Hill \& Pallin, 1998) or low levels of energy expenditure (Rennie et al., 2005) by overweight children. Less favorable outcomes regarding EDSF and EDD consumption were found among children with lower educated parents. The mother's educational level was found to be the most important sociodemographic predictor of a child's EDD intake. Other studies have amply documented higher intakes of EDSF among children of low socioeconomic status compared with children of high socioeconomic status (Brug et al., 2012b; Craig et al., 2010). Hence, interventions to promote healthy eating should prioritize children with lower educated parents, taking into consideration the mechanisms that make these children consume more EDSF and EDD, such as food parenting practices, parental consumption and food availability at home (De Coen et al., 2012; Totland et al., 2013b; Zarnowiecki et al., 2014). Children with mothers in employment had higher energy intakes from EDD than children with non-employed mothers. Earlier studies have also acknowledged the role of mothers' working hours in children's diets and found a positive association between maternal working hours and intakes of soft drinks and fast food (Datar et al., 2014). The most plausible explanation for this finding is lack of time, as working mothers may have less time to prepare healthy meals (Datar et al., 2014) or monitor their child's dietary intake (Rennie et al., 2005). Children living in households consisting of three individuals had a higher energy intake from EDD than children living in the largest households. Ayala et al. (2007) did not find a relationship between household size and soft drink consumption, but found a positive relationship between household size and snack food intake. Neither their study nor ours collected data on family composition (e.g. one-parent families), so it is possible that relationships between household size and dietary intakes interact with other factors.

Half of all EDSF and a third of the EDD events occurred in the afternoon, most often at home. The importance of after-school snacking has also been found among children in other countries (Gilbert et al., 2012; Rockell et al., 2011b). Intervention objectives should therefore not be limited to reducing EDSF intake at schools. We found that children living in large households, children of unemployed mothers and children living in low urbanized areas 
had a relatively high proportional intake of EDSF or EDD at home. Probably, these children and their mothers spend more time at home. Still, research should pay more attention to factors underlying after-school snacking. Popular types of EDSF were cookies and sweets. These foods often contain nutrients that may have harmful effects, such as sugar and fat. Most EDD that were consumed consisted of soft drinks. Few studies have distinguished between snack food consumption during meals and consumption between meals. In the present study, there was a modest contribution of energy from snack foods consumed during meals and a moderate contribution of energy from EDD consumed during meals to the total consumption of these foods and drinks. Nevertheless, both could have unfavourable effects, as those foods and drinks may replace nutritious foods served at meals. The current study did not find major differences in intakes of EDSF and EDD between weekdays and weekend days, although several studies have observed such differences (Bjelland et al., 2011; Hart et al., 2011; Macdiarmid et al., 2009; Rothausen et al., 2013). In the current sample, differences between weekdays and weekend days might be present in the energy derived from these foods or drinks, or the types consumed. Additionally, differences in these behaviors could be captured in day-to-day variations, which might be explored in future studies.

It is likely that dietary patterns, and particularly the type of eating occasion and place of EDSF and EDD consumption, vary between countries due to differences in school hours and policies concerning school meals. In the Netherlands, primary schools usually start around 08:30 hours and end around 15:15 hours, with a short break in the morning and a one-hour break at lunchtime. Children may go home for lunch or may stay at school. The results of the present study should be interpreted in the light of this context.

The current sample is representative of the Dutch population in many characteristics. However, overweight children, children of native Dutch ethnicity and children with highly educated parents were somewhat overrepresented. The method of data collection in the current study carries a certain risk of memory and recording biases (Willet, 1998). However, these biases were minimized by using trained dietitians and a computer-based recording system. The data that were used probably do not fully represent habitual intake, as the habitual intake may deviate from reported recall days (Mackerras \& Rutishauser, 2005). However, reported intakes were based on two recall days, approaching habitual intake more accurately than a single $24 \mathrm{~h}$ recall (Guenther et al., 2006). 


\section{Conclusions}

The data from the present study demonstrate that snack food and drink consumption is highly prevalent among Dutch children. Health promotion efforts addressing these behaviors are warranted and can benefit from our findings regarding the specific groups at risk, eating occasions and places involving higher risks, and the types of foods and drinks that are frequently consumed. Particularly, focusing on children with low educated parents and on snacking at home after school offers the greatest potential to reduce snack food and drink intake. 


\section{Chapter 3}

Clarifying concepts of food parenting practices. A Delphi study with an application to snacking behavior

This chapter has been published as: Gevers D.W.M., Kremers S.P.J., de Vries N.K., van Assema P. (2014a). Clarifying concepts of food parenting practices. A Delphi study with an application to snacking behavior. Appetite, 79, 51-57. 


\begin{abstract}
Inconsistencies in measurements of food parenting practices continue to exist. Fundamental to this problem is the lack of clarity about what is understood by different concepts of food parenting practices. The purpose of this study was to clarify food parenting practice concepts related to snacking. A three round Delphi study among an international group of experts ( $n=63$ ) was conducted. In the first round, an open-ended survey was used to collect food parenting practice descriptions and concept labels associated with those practices. In the second round, participants were asked to match up descriptions with the appropriate concept labels. The third and final round allowed participants to reconsider how descriptions and concept labels were matched, taking into account the opinions expressed in round two. Round one produced 408 descriptions of food parenting practices and 110 different concept names. Round two started with 116 descriptions of food parenting practices and 20 concept names. On 40 descriptions, consensus regarding the underlying concept name was reached in round two. Of the remaining 76 descriptions, consensus on 47 descriptions regarding the underlying concept name was reached in round three. The present study supports the essential process of consensus development with respect to food parenting practices concepts.
\end{abstract}




\section{Introduction}

Considerable attention has been paid to investigating parental influences on children's diets (Ventura \& Birch, 2008), revealing that parents are pivotal in shaping children's dietary intake (Faith et al., 2004; Ventura \& Birch, 2008). Parents create their children's physical and social environment, for example, by buying foods, by setting rules about foods, by encouraging or discouraging their children to eat certain kinds of foods, and by modeling the consumption of foods (Pinard et al., 2012). Many researchers have tried to capture these food parenting practices (FPPs) to study their impact on children's dietary intake, food preferences, eating styles, or anthropometric outcomes. The ultimate goal of such investigations is to inform interventions to promote healthy eating among children.

Many different instruments to assess FPPs have been used, among which the Child Feeding Questionnaire (CFQ) (Birch et al., 2001) is predominant (Corsini et al., 2008). Other popular and validated instruments include the Comprehensive Feeding Practices Questionnaire (CFPQ) (Musher-Eizenman \& Holub, 2007) and the Parental Feeding Style Questionnaire (PFSQ) (Wardle et al., 2002). When comparing instruments to measure FPPs, several measurement inconsistencies can be noted. First, the names of FPP concepts differ between studies, while referring to the same concept (e.g. "food as a reward"; (MusherEizenman \& Holub, 2007) vs. "instrumental feeding"; (Wardle et al., 2002)). Second, the operationalization of similar concepts differs between studies, for example, pressure to eat has been operationalized as "if I did not guide or regulate my child's eating, she would eat much less than she should" (Birch et al., 2001), but also with the conceptually different item, "when he/she says he/ she is finished eating, I try to get my child to eat one more (two more, etc.) bites of food" (Musher-Eizenman \& Holub, 2007). Third, concepts differ in their level of specificity, both across and within studies. Restriction (e.g. Birch et al., 2001), for example, could be regarded as a concept at a general level while the concept of availability (e.g. Gattshall et al., 2008; Vereecken et al., 2010a) may be regarded as one of the multiple ways to restrict a child's unhealthy food intake. Fourth, concepts are operationalized at different dimensions, in which some items reflect behaviors (e.g. "I intentionally keep some foods out of my child's reach"), while other items reflect beliefs (e.g. "I have to be sure that my child does not eat too many high-fat foods") (Corsini et al., 2008). Aside from these inconsistencies, many instruments have concentrated on a limited number of FPPs, most of which are controlling practices (Clark et al., 2007). However, a wide range of FPPs seem to 
exist and FPPs related to concepts such as modeling, educating, and involving are often disregarded (Musher-Eizenman \& Holub, 2007). An instrument measuring all potentially important FPPs is lacking.

Fundamental to these issues is the lack of clarity about the full range of FPPs and about what is understood by different FPP concepts. Therefore, initiatives aiming at reaching consensus on FPP concepts are required to solve the inconsistencies in conceptualization and operationalization of concepts (Vaughn et al., 2013).

This study addresses the conceptualization of FPPs by consulting experts in the field of parenting. The focus of this study is on snacking-related FPPs, as a high intake of energydense snacks increases the risk of weight gain and obesity among children (WHO, 2003). Furthermore, snack related parent-child interactions are likely to occur on a daily basis and to involve a wide range of parenting behaviors (Brown \& Ogden, 2004).

\section{Methods}

\section{Overview}

A three round Delphi study was conducted using an international group of experts and a series of online surveys. The Delphi method is considered to be an appropriate method when aiming at reaching consensus and when experts are located distantly (Adler \& Ziglio, 1996). In addition, this method usually starts from a blank slate, without directing or narrowing the focus of the experts to frequently utilized concepts and thereby creating a wider perspective compared with a review of instruments. The standard characteristics of the Delphi method (e.g. iterative process, anonymity of participants, feedback of group responses, and opportunity to reconsider individual opinion) were respected (Landeta, 2006). The focus in the current study was on snacking as child feeding in general would generate a greater number of nonspecific, more global descriptions of food parenting behaviors.

In the first round of the current study, an open-ended survey was used to collect FPP descriptions and concept labels associated with those practices. For this study, snackingrelated FPPs were defined as follows: "any behavior of parents which may promote or inhibit the snack intake of their child (between 4 and 12 years old). Parents may engage in parenting practices with or without the explicit aim to influence the snack intake of their children." Snacks were defined as follows (NNC, 2011): "all savory products, sweet products, 
and ice creams that are meant to be consumed between meals." These "in between" products were also considered to be snacks when consumed during meals. After round one, these responses were summarized. In the second round, experts were asked to match up descriptions with the appropriate concept labels. The third and final round allowed experts to reconsider how descriptions and concept labels were matched, taking into account the opinions expressed in the previous round. All three questionnaires were pretested among a small sample of scientists in the field of Health Promotion.

\section{Procedures and participants}

Participants in this study represented an international group of experts in the fields of parenting styles and/or parenting practices related to nutrition and/or physical activity. In preparation for the first round, 20 experts were identified through a search in Medline and an additional 75 experts were identified from a preliminary list of attendees to the International Society for Behavioral Nutrition and Physical Activity (ISBNPA) preconference on "Parenting measurement: Current status and consensus reports" (held in Houston, TX May 2012; (Baranowski et al., 2013a). In April 2012, these 95 experts were invited by e-mail to participate in the study. The same experts were also invited for the second round in September 2012, complemented with additional 25 experts identified from the final list of attendees to the ISBNPA preconference and eight experts named by second round experts (128 in total). Experts in the second round were invited to participate in the third round in November $2012(n=53)$. Nonresponders received up to two reminder e-mail messages in each round.

\section{First round questionnaire and data-analysis}

At the outset of the first round questionnaire, participants were given the aim of the study, which was "to gain insight into specific FPPs which may promote or inhibit the snack intake of children between 4 and 12 years old". Then, experts were asked to write down descriptions of snacking-related FPPs and, subsequently, the names of the concepts they would use to label these practices (one or two words which covered the content of the description). Experts were allowed to provide more than one concept name for each description. The definitions of snacking related FPPs and snacks and four example descriptions of snack parenting practices (e.g. "consuming snacks in the presence of the 
child"), five example concept names (e.g. availability) and eight example snacks (e.g. biscuits, sweets)were included in the survey instructions.

Three questions were asked to assess the participants' expertise: "is the study on parenting practices one of your primary focus areas of research?" (yes, no); "for which health behavior(s) have you ever studied parenting practices?" (e.g. nutrition, smoking); and "what is your area of expertise?" (e.g. child nutrition, pediatrics). Experts could provide the names of other experts who, in their opinion, should participate, and in each round they were given the opportunity to write down comments.

In line with guidelines, the research team grouped similar descriptions together and provided one description for similar descriptions (Hasson et al., 2000). A similar procedure was followed for the concept labels. No descriptions or concept labels were added or disregarded and the wording used by participants was maintained as much as possible. Descriptions which reflected similar underlying concepts such as phrases with opposite evaluative connotations (positive-negative) were combined. Specific moments (e.g. "when spending time with friends", "during sedentary activities") which were mentioned once in descriptions were removed and specific foods mentioned in sole descriptions were categorized to represent snacks, healthy foods, and foods. Specific foods and moments which were mentioned multiple times were maintained in these descriptions, since it may be relevant to distinguish foods from food groups and moments from descriptions without moments. The descriptions of the FPPs from round one were formulated at different levels of specificity, for example: "restricting snack consumption" vs. "storing snacks in such a way that the child cannot see them." The latter description is an example of a specific act (i.e. a way to restrict snack consumption). Only FPPs described as specific acts were included in the second round. All descriptions were rephrased to start with a verb.

\section{Second round questionnaire and data-analysis}

In the second round, participants were asked to match one concept label to each description of a FPP. The exact question was "please, select one concept name per description of a FPP, the description should fall within the scope of the selected concept." Furthermore, experts could choose between $0 \%, 25 \%, 50 \%, 75 \%$, and $100 \%$ to indicate the extent to which the FPP fell within the scope of the concept they selected. Descriptions were shown in a random order, while concepts were shown in alphabetical order. 
Data-analysis in the second round consisted of calculating the percentage of participants who chose a concept name for a description, and calculating medians and Inter Quartile Deviations (IQDs) for the answer to the question on the extent to which the FPP fell within the scope of the concept. The IQD indicates the distance between the 25 th and the 75th percentile. The lower the IQD, the greater the consensus among participants. It was decided that consensus on descriptions was reached if a similar concept name was chosen by $\geq 70 \%$ of the experts with an IQD of $\leq 1$ (Rayens \& Hahn, 2000). Descriptions on which consensus was obtained in the second round were not included in the third round questionnaire.

\section{Third round questionnaire and data-analysis}

The questionnaire items and data-analysis in the third round were similar to the second round. In the third round, experts were additionally informed about the other experts' opinions as they were shown the percentages and IQD of each description of a FPP. They were also informed that FPPs on which consensus was reached in the second round were not included.

\section{Results}

\section{Response and participant characteristics}

In total, 36 experts participated in the first round (response rate $=38 \%$; Table 3.1 ). In the second round, 53 experts participated (response rate $=41 \%$ ), including 26 experts from the first round. Of these 53 experts, 43 completed both questions on all descriptions, and 10 experts partly filled in the questionnaire (ranging from both questions on 12 descriptions to both questions on 83 descriptions). Two experts did not share information on their expertise. In the third round, 39 experts participated (response rate $=74 \%$ ), of which 37 completed both questions on all descriptions. One participant filled in both questions on 23 descriptions, and one participant filled in both questions on 10 descriptions. The majority of participants indicated that the study of parenting practices is one of their primary focus areas of research, that they had previously studied parenting practices related to nutrition, worked in the field of Health Promotion, and lived in North America. 
Table 3.1: Participant information

\begin{tabular}{llll}
\hline & $\begin{array}{l}\text { First } \\
\text { round (n) }\end{array}$ & $\begin{array}{l}\text { Second } \\
\text { round (n) }\end{array}$ & $\begin{array}{l}\text { Third } \\
\text { round (n) }\end{array}$ \\
\hline $\begin{array}{l}\text { Invitations sent } \\
\text { Participants }\end{array}$ & 95 & 128 & 53 \\
$\begin{array}{l}\text { Study of parenting practices is primary focus area of } \\
\text { research }\end{array}$ & 36 & 53 & 39 \\
Yes & 29 & 32 & 28 \\
No & 7 & 9 & 6 \\
Health behavior for which parenting practices were & & & \\
studied & & & \\
Nutrition & 31 & 35 & 29 \\
If not nutrition, other domains (e.g. physical activity, & 5 & 5 & 4 \\
alcohol) & & & \\
None & 0 & 1 & 1 \\
Research area & & & \\
$\quad$ Health Promotion & 13 & 20 & 17 \\
Child Nutrition & 5 & 6 & 3 \\
$\quad$ Health Psychology & 3 & 5 & 4 \\
Pediatrics & 3 & 3 & 3 \\
Epidemiology & 0 & 2 & 2 \\
$\quad$ Other & 13 & 5 & 5 \\
Country & & & \\
North America & 23 & 32 & 22 \\
Europe & 10 & 17 & 14 \\
Australia & 3 & 4 & 3 \\
\hline
\end{tabular}

\section{FPP descriptions and concept names}

The first round produced 408 FPP descriptions and 110 different concept names. In total, 116 FPP descriptions and 20 concept names were included in the second round questionnaire (see Table A1.1 in appendix 1 for all descriptions of FPPs and concept names included in the second and third round). In round two, consensus was reached on 40 of the 116 FPP descriptions, including 13 unique concepts (Table 3.2). Of those 40 FPP descriptions, 27 had a median score of $5(100 \%)$ and 13 had a median score of 4 (75\%). In round three, 76 FPP descriptions and 20 concept names were included in the questionnaire. Consensus was reached on 47 additional FPP descriptions, involving 16 concept names (including 11 of the 13 names identified in round two). Of these FPP descriptions, two had a median score of 5 (100\%), 44 had a median score of $4(75 \%)$, and one had a median score of $3.5(62.5 \%)$. This left 29 FPP descriptions without consensus.

For instance, consensus was reached on five descriptions within the scope of the concept of accessibility. "Making healthy foods accessible to the child" reached consensus in 
the second round as it was matched to the concept of accessibility by $88 \%$ of the experts with a median score of 5 and an IQD of 0 . "Storing snacks in a location the child cannot access on his or her own" was matched to this concept in the third round by $95 \%$ of the experts with a median score of 5 and an IQD of 1 , implying consensus.

Consensus was reached regarding one or more descriptions within the scope of the concepts of accessibility, availability, discussing, educating, emotional feeding, encouragement, instrumental feeding, involving, meal routines, modeling, monitoring, permissiveness, pressure to eat, providing feedback, rewarding, rules, structure, and visibility. Each concept label was matched with 1-15 FPP descriptions (mean = 4.8 SD = 3.9). Within the concepts of persuasion and training, we found no descriptions that reached consensus among the experts. 
Table 3.2: Second- and third-round results for the descriptions of FPPs and concept names that reached consensus

\begin{tabular}{|c|c|c|c|c|c|c|}
\hline \multirow[b]{2}{*}{ Consensus reached in second or third round } & \multicolumn{3}{|c|}{ Second round } & \multicolumn{3}{|c|}{ Third round } \\
\hline & $\mathbf{N}(\%)$ & Mdn & IQD & $\mathbf{N}(\%)$ & Mdn & IQD \\
\hline \multicolumn{7}{|l|}{ ACCESSIBILITY: } \\
\hline Making healthy foods accessible to the child & $42(88 \%)$ & 5 & 0 & & & \\
\hline $\begin{array}{l}\text { Storing snacks in a location the child cannot } \\
\text { access on } \\
\text { his or her own }\end{array}$ & $35(81 \%)$ & 5 & 2 & $35(95 \%)$ & 5 & 1 \\
\hline Not giving the child money for snacks at school & $23(54 \%)$ & 4 & 2 & $30(81 \%)$ & 4 & 1 \\
\hline $\begin{array}{l}\text { Avoiding going to shops where snacks are } \\
\text { available }\end{array}$ & $25(49 \%)$ & 4 & 2 & $28(74 \%)$ & 4 & 0 \\
\hline Putting snacks on the table all day & $25(51 \%)$ & 5 & 1 & $27(73 \%)$ & 4 & 1 \\
\hline \multicolumn{7}{|l|}{ AVAILABILITY: } \\
\hline Having healthy foods at home & $36(82 \%)$ & 5 & 1 & & & \\
\hline Not having snacks at home & $35(71 \%)$ & 5 & 1 & & & \\
\hline Limiting the type of snacks available at home & $36(71 \%)$ & 4 & 1 & & & \\
\hline Offering healthy foods & $33(65 \%)$ & 4 & 0.50 & $36(95 \%)$ & 4 & 1 \\
\hline Providing appropriate options for breakfast & $40(76 \%)$ & 4 & 2 & $36(92 \%)$ & 4.50 & 1 \\
\hline $\begin{array}{l}\text { Providing the child with healthy foods as } \\
\text { alternatives to snacks (in different situations, } \\
\text { e.g. during family visits }\end{array}$ & $26(52 \%)$ & 4 & 1 & $34(90 \%)$ & 4 & 0.25 \\
\hline Making sure healthy foods are prepared & $24(56 \%)$ & 4 & 1 & $30(81 \%)$ & 4 & 0 \\
\hline $\begin{array}{l}\text { Serving snacks (in different situations, e.g. } \\
\text { when the child brings friends home) }\end{array}$ & $16(33 \%)$ & 4 & 1 & $28(76 \%)$ & 4 & 1 \\
\hline $\begin{array}{l}\text { Giving choice of several healthy foods for a } \\
\text { snack }\end{array}$ & $19(38 \%)$ & 4 & 2 & $27(71 \%)$ & 4 & 0 \\
\hline \multicolumn{7}{|l|}{ DISCUSSING: } \\
\hline Discussing availability of snacks with the child & $35(73 \%)$ & 4 & 1 & & & \\
\hline Talking about what kind of snacks the child eats & $34(67 \%)$ & 4 & 1.25 & $35(90 \%)$ & 4 & 0 \\
\hline $\begin{array}{l}\text { Discussing with the child snack choices and } \\
\text { preferences }\end{array}$ & $33(65 \%)$ & 4 & 1 & $30(77 \%)$ & 4 & 0.25 \\
\hline $\begin{array}{l}\text { Talking about the number of snacks the child } \\
\text { eats }\end{array}$ & $28(61 \%)$ & 4 & 1 & $27(73 \%)$ & 4 & 1 \\
\hline Discussing rules related to snacks with the child & $19(44 \%)$ & 4 & 2 & $26(70 \%)$ & 4 & 1 \\
\hline \multicolumn{7}{|l|}{ EDUCATING: } \\
\hline Teaching the child about healthy foods & $49(98 \%)$ & 5 & 1 & & & \\
\hline $\begin{array}{l}\text { Teaching the child the difference between } \\
\text { snacks and healthy foods }\end{array}$ & $47(94 \%)$ & 5 & 1 & & & \\
\hline $\begin{array}{l}\text { Teaching the child about making healthy food } \\
\text { choices }\end{array}$ & $41(93 \%)$ & 5 & 1 & & & \\
\hline $\begin{array}{l}\text { Talking to the child about the consequences of } \\
\text { eating healthy foods and snacks }\end{array}$ & $39(91 \%)$ & 4 & 1 & & & \\
\hline
\end{tabular}




\begin{tabular}{|c|c|c|c|c|c|c|}
\hline \multirow[b]{2}{*}{ Consensus reached in second or third round } & \multicolumn{3}{|c|}{ Second round } & \multicolumn{3}{|l|}{ Third round } \\
\hline & $\mathbf{N}(\%)$ & Mdn & IQD & $\mathbf{N}(\%)$ & Mdn & IQD \\
\hline \multicolumn{7}{|l|}{ EDUCATING continued } \\
\hline $\begin{array}{l}\text { Discussing with the child the importance of } \\
\text { eating healthy foods }\end{array}$ & $40(78 \%)$ & 4 & 1 & & & \\
\hline $\begin{array}{l}\text { Telling the child that eating healthy foods } \\
\text { instead of snacks is better }\end{array}$ & $41(84 \%)$ & 4 & 2 & $37(100 \%)$ & 5 & 1 \\
\hline $\begin{array}{l}\text { Telling the child that eating snacks is not } \\
\text { healthy }\end{array}$ & $36(77 \%)$ & 4 & 1.75 & $37(100 \%)$ & 4 & 1 \\
\hline $\begin{array}{l}\text { Teaching the child how to refuse a snack when } \\
\text { it is offered }\end{array}$ & $24(49 \%)$ & 4 & 2 & $30(81 \%)$ & 4 & 0 \\
\hline \multicolumn{7}{|l|}{ EMOTIONAL FEEDING: } \\
\hline $\begin{array}{l}\text { Using snacks in response to the child's } \\
\text { emotional distress }\end{array}$ & $44(96 \%)$ & 5 & 1 & & & \\
\hline Comforting the child with snacks & 45 (94\%) & 5 & 1 & & & \\
\hline Using food for emotional regulation & $45(90 \%)$ & 5 & 1 & & & \\
\hline \multicolumn{7}{|l|}{ ENCOURAGEMENT: } \\
\hline $\begin{array}{l}\text { Encouraging the child to eat a large variety of } \\
\text { foods }\end{array}$ & $42(88 \%)$ & 5 & 1 & & & \\
\hline $\begin{array}{l}\text { Encouraging the child to take enough healthy } \\
\text { foods during the meal }\end{array}$ & $38(88 \%)$ & 4 & 1 & & & \\
\hline Encouraging the child to try healthy foods & $38(87 \%)$ & 4 & 1 & & & \\
\hline Encouraging child's interest in foods & $32(73 \%)$ & 4 & 2 & $32(87 \%)$ & 4 & 1 \\
\hline $\begin{array}{l}\text { Encouraging the child to drink plenty of water } \\
\text { between main meals }\end{array}$ & $26(59 \%)$ & 4 & 2 & $30(81 \%)$ & 4 & 0.25 \\
\hline Making positive statements about foods & $21(42 \%)$ & 4 & 1.50 & $29(76 \%)$ & 4 & 1 \\
\hline Making eating a game or fun & $18(42 \%)$ & 3 & 1 & $29(78 \%)$ & 4 & 0.50 \\
\hline \multicolumn{7}{|l|}{ INSTRUMENTAL FEEDING: } \\
\hline $\begin{array}{l}\text { Using foods to persuade the child to do } \\
\text { something }\end{array}$ & $20(47 \%)$ & 5 & 1 & $31(84 \%)$ & 4 & 1 \\
\hline \multicolumn{7}{|l|}{ INVOLVING: } \\
\hline Allowing the child to assist in preparing snacks & $39(85 \%)$ & 4 & 1 & & & \\
\hline $\begin{array}{l}\text { Allowing the child to help pick out healthy } \\
\text { foods at the store }\end{array}$ & $45(85 \%)$ & 4 & 1 & & & \\
\hline Involving the child in food purchasing & $43(84 \%)$ & 4 & 1 & & & \\
\hline Engaging the child in preparing healthy foods & $41(82 \%)$ & 5 & 1 & & & \\
\hline $\begin{array}{l}\text { Giving the child control in selecting healthy } \\
\text { foods }\end{array}$ & $35(73 \%)$ & 4 & 2 & $37(100 \%)$ & 4 & 1 \\
\hline Letting the child choose the food at dinner & $26(59 \%)$ & 4 & 0.25 & $35(95 \%)$ & 4 & 0 \\
\hline $\begin{array}{l}\text { Allowing the child to help pick out snacks at the } \\
\text { store }\end{array}$ & $42(86 \%)$ & 4 & 1.25 & $35(95 \%)$ & 4 & 1 \\
\hline
\end{tabular}


Table 3.2 continued

\begin{tabular}{|c|c|c|c|c|c|c|}
\hline \multirow[b]{2}{*}{ Consensus reached in second or third round } & \multicolumn{3}{|c|}{ Second round } & \multicolumn{3}{|c|}{ Third round } \\
\hline & $\mathbf{N}(\%)$ & Mdn & IQD & $\mathbf{N}(\%)$ & Mdn & IQD \\
\hline \multicolumn{7}{|l|}{ INVOLVING continued } \\
\hline $\begin{array}{l}\text { Allowing the child to determine how much he } \\
\text { or she eats }\end{array}$ & $20(47 \%)$ & 3.50 & 2 & $34(92 \%)$ & 4 & 0 \\
\hline $\begin{array}{l}\text { Asking about the child's opinion on what kind } \\
\text { of snacks to eat and when }\end{array}$ & $29(55 \%)$ & 4 & 0 & $35(90 \%)$ & 4 & 0 \\
\hline $\begin{array}{l}\text { Asking the child's opinion on how many snacks } \\
\text { to eat and when }\end{array}$ & $29(55 \%)$ & 4 & 0 & $32(84 \%)$ & 4 & 0 \\
\hline \multicolumn{7}{|l|}{ MEAL ROUTINES: } \\
\hline Eating meals together as a family & $24(49 \%)$ & 5 & 1.75 & $27(73 \%)$ & 4 & 0 \\
\hline \multicolumn{7}{|l|}{ MODELING: } \\
\hline $\begin{array}{l}\text { Eating healthy foods in the presence of the } \\
\text { child }\end{array}$ & $43(100 \%)$ & 5 & 0 & & & \\
\hline Eating healthy foods with the child & $43(100 \%)$ & 5 & 0 & & & \\
\hline $\begin{array}{l}\text { Avoiding eating snacks when the child is } \\
\text { present }\end{array}$ & $42(97 \%)$ & 5 & 1 & & & \\
\hline Eating snacks with the child & $49(96 \%)$ & 5 & 1 & & & \\
\hline Being enthusiastic about eating healthy foods & $26(61 \%)$ & 4 & 1 & $27(73 \%)$ & 4 & 1 \\
\hline \multicolumn{7}{|l|}{ MONITORING: } \\
\hline $\begin{array}{l}\text { Keeping track of the number of snacks the child } \\
\text { eats }\end{array}$ & $42(98 \%)$ & 5 & 0 & & & \\
\hline $\begin{array}{l}\text { Keeping track of the kind of snacks the child } \\
\text { eats }\end{array}$ & $45(94 \%)$ & 5 & 0 & & & \\
\hline $\begin{array}{l}\text { Asking the child at the end of the day what he } \\
\text { or she ate during the day }\end{array}$ & $35(71 \%)$ & 5 & 1 & & & \\
\hline \multicolumn{7}{|l|}{ PERMISSIVENESS: } \\
\hline $\begin{array}{l}\text { Obeying the preference of the child without } \\
\text { setting limits }\end{array}$ & $38(88 \%)$ & 5 & 1 & & & \\
\hline $\begin{array}{l}\text { Allowing the child to eat as many snacks as he } \\
\text { or she wants }\end{array}$ & $36(84 \%)$ & 5 & 1 & & & \\
\hline Giving in to the child's pestering for snacks & $36(82 \%)$ & 4 & 1.75 & $36(97 \%)$ & 4 & 1 \\
\hline Allowing late night eating & $28(55 \%)$ & 4 & 1.75 & $27(71 \%)$ & 4 & 1 \\
\hline \multicolumn{7}{|l|}{ PRESSURE TO EAT: } \\
\hline Pressuring the child to eat more foods & $51(100 \%)$ & 5 & 1 & & & \\
\hline Pressuring the child to eat healthy foods & $48(96 \%)$ & 5 & 1 & & & \\
\hline $\begin{array}{l}\text { Pressuring the child to eat certain types of } \\
\text { snacks }\end{array}$ & $41(95 \%)$ & 5 & 1 & & & \\
\hline Forcing the child to finish a meal & $42(91 \%)$ & 5 & 1 & & & \\
\hline $\begin{array}{l}\text { Insisting the child to finish a healthy food even } \\
\text { if he or she is not hungry }\end{array}$ & 39 (91\%) & 5 & 1 & & & \\
\hline $\begin{array}{l}\text { Threatening to take something away from the } \\
\text { child if he or she does not eat the desired food }\end{array}$ & $18(41 \%)$ & 4 & 1 & $26(70 \%)$ & 4 & 1 \\
\hline
\end{tabular}


Table 3.2 continued

\begin{tabular}{|c|c|c|c|c|c|c|}
\hline \multirow[b]{2}{*}{ Consensus reached in second or third round } & \multicolumn{3}{|c|}{ Second round } & \multicolumn{3}{|c|}{ Third round } \\
\hline & $\mathbf{N}(\%)$ & Mdn & IQD & $\mathbf{N}(\%)$ & Mdn & IQD \\
\hline \multicolumn{7}{|l|}{ PROVIDING FEEDBACK: } \\
\hline Criticizing when the child eats snacks & $29(67 \%)$ & 3 & 1.50 & $34(92 \%)$ & 4 & 1 \\
\hline \multicolumn{7}{|l|}{ REWARDING: } \\
\hline Giving the child a reward for not eating snacks & $40(82 \%)$ & 5 & 1 & & & \\
\hline $\begin{array}{l}\text { Offering toys or other non-food rewards for } \\
\text { good eating }\end{array}$ & $29(63 \%)$ & 5 & 1 & 35 (95\%) & 4 & 1 \\
\hline \multicolumn{7}{|l|}{ RULES: } \\
\hline $\begin{array}{l}\text { Setting explicit rules about what kind of snacks } \\
\text { the child is allowed to eat }\end{array}$ & 45 (94\%) & 5 & 1 & & & \\
\hline $\begin{array}{l}\text { Telling the child that he or she is not allowed } \\
\text { certain snacks }\end{array}$ & $45(92 \%)$ & 4 & 0.50 & & & \\
\hline $\begin{array}{l}\text { Setting explicit rules about the number of } \\
\text { snacks the child is allowed to eat }\end{array}$ & $42(86 \%)$ & 4 & 1 & & & \\
\hline $\begin{array}{l}\text { Having the rule that the child is not allowed to } \\
\text { eat snacks at certain times }\end{array}$ & $41(77 \%)$ & 4 & 1 & & & \\
\hline $\begin{array}{l}\text { Telling the child that he or she is not allowed to } \\
\text { eat snacks shortly before a meal }\end{array}$ & $35(70 \%)$ & 4 & 1 & & & \\
\hline Forbidding the child to eat snacks & $42(88 \%)$ & 4 & 2 & $36(97 \%)$ & 4 & 1 \\
\hline $\begin{array}{l}\text { Telling the child that he or she cannot have } \\
\text { snacks }\end{array}$ & $34(68 \%)$ & 4 & 1 & $36(95 \%)$ & 4 & 0 \\
\hline $\begin{array}{l}\text { Articulating rules about when eating is } \\
\text { appropriate }\end{array}$ & $30(70 \%)$ & 4 & 2 & $34(92 \%)$ & 4 & 1 \\
\hline $\begin{array}{l}\text { Speaking out the rule that the child is not } \\
\text { allowed to take snacks by him or herself }\end{array}$ & $36(68 \%)$ & 4 & 1.75 & $36(92 \%)$ & 4 & 1 \\
\hline $\begin{array}{l}\text { Telling the child that he or she is allowed one } \\
\text { snack after school }\end{array}$ & $35(73 \%)$ & 4 & 2 & $34(92 \%)$ & 4 & 1 \\
\hline Allowing snacks only at a certain place & $21(44 \%)$ & 4 & 1 & $31(84 \%)$ & 4 & 0 \\
\hline Not allowing snacks shortly before dinner & $27(63 \%)$ & 4 & 1 & $31(84 \%)$ & 4 & 1 \\
\hline $\begin{array}{l}\text { Articulating rules about what type of food is } \\
\text { appropriate }\end{array}$ & $29(62 \%)$ & 4 & 1 & $28(76 \%)$ & 4 & 1 \\
\hline $\begin{array}{l}\text { Allowing snacks only at a certain time (e.g. in } \\
\text { the weekend) }\end{array}$ & $28(53 \%)$ & 4 & 1.75 & $29(74 \%)$ & 4 & 0 \\
\hline $\begin{array}{l}\text { Telling the child that he or she cannot have } \\
\text { snacks until a certain time }\end{array}$ & $26(61 \%)$ & 4 & 0.25 & $27(73 \%)$ & 4 & 1 \\
\hline \multicolumn{7}{|l|}{ STRUCTURE: } \\
\hline Giving snacks at fixed times & $34(72 \%)$ & 4 & 2 & $30(81 \%)$ & 4 & 0.25 \\
\hline \multicolumn{7}{|l|}{ VISIBILITY: } \\
\hline Having healthy foods easy to see & $24(56 \%)$ & 4 & 1 & $27(73 \%)$ & 4 & 1 \\
\hline
\end{tabular}




\section{Discussion}

Fundamental to the inconsistencies in measurements of food parenting is the lack of clarity about the scope of FPPs and about what is understood by different FPP concepts. This study sought to clarify FPP concepts with an application to snacking behavior.

An extensive set of FPPs, and related concepts, has been identified, establishing a wide range of distinct FPPs. Experts agreed on the concepts for a considerable number of FPPs by using 18 different concept names. Several of the concepts identified contained FPPs that extend beyond snacking, such as the concepts of meal routines and encouragement. Other concepts formulated are more general and pertain to both snacking and meal consumption. It is plausible that these general parenting constructs apply to meals in the same manner as to snacking. Many different FPP descriptions were indicated to fall within the concepts of rules and involving, which may imply multi-dimensionality of these concepts. Other concepts included less FPPs for which consensus was reached, indicating fewer dimensions or clearer ideas about the content of the concept. Some FPPs, particularly those falling within the scope of the concepts availability and rules, for example, have been widely studied. Other FPPs have hardly been studied, but may nevertheless be important, for example those falling within the scope of concepts such as discussing, educating, and permissiveness. Concepts that experts found hard to distinguish were rules, structure, and permissiveness, most likely because parents can create structure by having rules and parents without rules can be classified as being permissive (Blissett, 2011).

Conceptualizing the identified concepts may facilitate the next steps for research toward fully understanding FPPs, as relationships between concepts are then elucidated. To this end, higher order dimensions that have been identified in the literature may assist. The theoretical framework from Hughes et al. (2008) could guide this process. It builds upon the widely used dichotomy of parent-centered versus child-centered feeding, which is underpinned both by theory (Hughes et al., 2006) and evidence (Vereecken et al., 2010b). The three factor model adds structure as a third factor to control (parent-centered feeding) and responsiveness (child-centered feeding). Applied to food parenting, those factors are defined as follows (Davison et al., 2013): control stands for the use of directive, restrictive, and punitive parenting practices in order to force children to meet parental demands. Responsive parenting involves the use of warmth and autonomy support to foster selfassertion and individuality. Structure is provided by organizing children's social and physical 
environments to promote their competence. Control might involve the constructs of pressure to eat, emotional feeding, instrumental feeding, monitoring, rules, and permissiveness. Responsiveness might include involving, discussing, educating, encouragement, modeling, rewarding, and providing feedback. Finally, structure includes accessibility, availability, meal routines, structure, and visibility. A refinement of this three factor model could be helpful to indicate more subtle differences between the identified FPP concepts. For instance, the five factor parenting model (Sleddens et al., 2014) distinguishes two types of control, coercive control and behavioral control. Coercive control refers to parents who use pressure and domination, and could include pressure to eat, emotional feeding, and instrumental feeding (Sleddens et al., 2014). Behavioral control refers to parents who manage child's behavior with clear expectations without suppressing child's autonomy (Sleddens et al., 2014). Behavioral control might include accessibility, availability, monitoring, rules, and permissiveness. The fifth factor, overprotection, refers to high levels of nurturing and controlling practices, considering the age of the child (Sleddens et al., 2014).

The necessity of a conceptual modeling approach based on the results of our study is illustrated by two concept names that were often selected by a majority of the participants, without reaching consensus: instrumental feeding and rewarding. Both concept names have been used interchangeably in different studies (e.g. Monge-Rojas et al. (2010) vs. Kroller \& Warschburger (2009)). However, the results of the current study indicate that rewarding fits the nurturance dimension, while instrumental feeding is likely to fit the control dimension.

\section{Strengths and limitations}

Concerning the strengths of this study, it is probable that the experts who were invited properly represent the experts in this field. However, not every expert who was invited responded, and thus, the results may not be completely representative for the view of all experts. E-mails that were received from some experts indicated that it is likely that experts did not participate due to lack of time. Although the response rates in the first and second round can be considered quite low, other Delphi studies involving experts showed comparable response rates (Elfeddali et al., 2010; Schneider et al., 2012). In addition, few experts dropped out after round two, which is a prerequisite for sufficient quality of a Delphi study (Hsu \& Sandford, 2007). A limitation of the current study is that the data reduction 
after the input from round one involved a process of interpretation and there was no discussion between experts. Therefore, consensus reached in this Delphi study does not imply a definite solution to the lack of clarity about what is understood by different FPPs (Hasson et al., 2000). However, multiple researchers were involved in the data reduction process to avoid bias in interpretation and experts had the opportunity to elaborate on their answers in the questionnaire. Finally, the sample in this study may be weighted toward experts typically using the dominant and popular measures, which could be a second limitation.

\section{Implications for research}

Although FPP concepts seem to be overlapping or similar in their operationalization, such as the concepts of accessibility, availability, and visibility, this study shows that in essence they may be distinct and may impact child behavior by different mechanisms. Therefore, researchers investigating FPPs might consider including the concepts from this study. Furthermore, a comprehensive and diverse set of FPPs was obtained enabling researchers to carefully select appropriate FPPs from this set, depending on the goals of their research. The prevalence of the usage of FPPs among parents ought to be assessed in order to determine their relevance in specific populations.

The integration of the identified concepts into the three (Hughes et al., 2008) or five factor parenting model (Sleddens et al., 2014) may serve as tools during the process toward reaching consensus on FPP concepts.

\section{Conclusions}

This study was the first research which aimed to collect a full range of FPPs, which supports the essential process of consensus development with respect to food parenting practices concepts. The study led to increased clarity about what is understood by different FPP concepts. However, the study also indicates that there is still a lack of clarity about the exact meaning of, or difference between, some of the concept names. Nevertheless, the results of this study could guide the development of measurement instruments for studies concerning the impact of FPPs. In addition, the results provide a good starting point from which to progress toward reaching consensus. 


\section{Chapter 4}

Development of the Comprehensive Snack Parenting Questionnaire: test-retest reliability and discriminative value of constructs

This chapter has been submitted as: Gevers, D.W.M., Kremers, S.P.J., de Vries, N.K., van Assema, P. Development of the comprehensive snack parenting questionnaire: test-retest reliability and discriminative value of constructs. 


\section{Abstract}

Objective: The narrow focus of existing food parenting instruments led us to develop a brief food parenting practices instrument measuring the full range of Dutch parent's food practices constructs with a focus on snacking behavior. We tested its reliability and assessed the discriminative value of constructs.

Design: Instrument development study using cross-sectional data Setting/Participants: Main data source: a sample of 183 Dutch parents of children aged 4 to 12 years old.

Main outcome measures: test-retest reliability for and correlations of food parenting practices Analysis: Intra class correlation coefficients and percentage agreement were calculated to determine test-retest reliability. To assess the discriminative value of constructs, partial correlation coefficients between constructs were calculated. Results: The developed Comprehensive Snack Parenting Questionnaire (CSPQ) measures 21 constructs with 21 items. Test-retest reliability analysis revealed acceptable intra class correlation coefficients $(\geq 0.41)$ or agreement scores $(\geq 0.60)$. Pearson's correlations between constructs (all $\leq 0.63$ ) indicated the distinctiveness of the constructs.

Conclusions and Implications: The current comprehensive but brief instrument was found to have acceptable psychometric characteristics. The CSPQ opens up chances for new, highly relevant but unstudied research questions to understand and predict children's snack intake, for example with regard to clustering of and dynamics across food parenting practices. 


\section{Introduction}

Childhood overweight and obesity have become widespread and are a great burden to both the individual involved and society (Daniels, 2006; Lobstein et al., 2004). Evidence indicates that overweight children have an increased risk to become overweight in adulthood (Singh et al., 2008) and that dietary patterns settled in childhood track into adulthood (Craigie et al., 2011). Intervening during this stage of life is important to prevent children from becoming unhealthy adults. The social environment, especially parental behavior, seems to be important in this respect (Faith et al., 2012). Parental behaviors that may affect children's dietary pattern are called Food Parenting Practices (FPPs) (Darling \& Steinberg, 1993), and include for example restricting the child's access to foods or pressuring the child to eat certain types of food (Birch \& Davison, 2001). Many of them, particularly coercive or controlling types, occur between meals (Musher-Eizenman \& Kiefner, 2013). Intakes of energy-dense snack foods (EDSFs) between meals can highly contribute to a child's daily energy intake (Bell et al., 2005).

Several initiatives have been started to recommend parents about the use of parenting practices in order to promote healthy eating habits in children (e.g. Burrows et al., 2010; Ostbye et al., 2012). However, the effectiveness of intervention programs might be suppressed as evidence about the impact of many practices on children's actual intake is inconclusive (Gerards \& Kremers, 2015). Likely, two issues explain this inconclusiveness. First, existing instruments contain inconsistencies: similar constructs are given different labels and are operationalized inconsistently across instruments (Vaughn et al., 2013). Second, many existing instruments are operationalized in a very narrow fashion (e.g. only assessing controlling practices such as restriction or pressure to eat) (Hughes et al., 2013). Therefore, there is less evidence on the desirability of other practices, compared to controlling practices.

Although it is desirable to include all potentially relevant FPPs in a FPP measure, it may easily lead to lengthy questionnaires, which could trigger non-response. The number of questionnaire items is important, particularly because researchers increasingly recognize the importance of studying the larger environmental context (e.g. Kremers, 2010; Melbye et al., 2013a; Rollins et al., 2014; Vereecken et al., 2010b), implying lengthier questionnaires.

Hence, we aimed to systematically develop a comprehensive but brief instrument measuring the full range of FPP constructs. We emphasized parental behaviors related to 
snacking behavior and targeted parents of children aged 4-12 years old. This study aimed to examine the test-retest reliability and discriminant value of the constructs of the newly developed instrument.

Table 4.1: Descriptive statistics of participants in study

\begin{tabular}{lll}
\hline & $\begin{array}{l}\text { Reliability testing } \\
\text { (t2 data) }\end{array}$ & $\begin{array}{l}\text { Validity testing } \\
\text { (t1 data) }\end{array}$ \\
\hline $\mathbf{n}$ & 66 & 109 \\
Age, years (mean [sd]) & $39.7(\mathrm{SD}=5.7)$ & $39.5(\mathrm{SD}=5.3)$ \\
Gender (\%) & & \\
Male & 42.4 & 33.9 \\
Female & 57.6 & 66.1 \\
Educational level (\%) & & \\
Low & 9.1 & 13.9 \\
Intermediate & 30.3 & 29.6 \\
High & 60.6 & 56.5 \\
Ethnicity (\%) & & \\
Dutch & 81.8 & 80.7 \\
Non-Dutch & 18.2 & 19.3 \\
BMI & $23.9(\mathrm{SD}=3.0)$ & $24.3(\mathrm{SD}=4.0)$ \\
BMI category (\%) & & \\
Underweight & 3.2 & 1.9 \\
Normal weight & 64.5 & 64.4 \\
Overweight & 32.2 & 33.7 \\
SEP (mean [sd]) & $0.19(1.16)$ & $0.07(\mathrm{SD}=1.31)$ \\
Age of child (mean [sd]) & $7.4(\mathrm{SD}=2.3)$ & $7.5(\mathrm{SD}=2.3)$ \\
Gender of child (\%) & & \\
Male & 42.4 & 42.2 \\
Female & 57.6 & 57.8 \\
BMI child & & 18.6 \\
Underweight & 16.4 & 69.6 \\
Normal weight & 72.1 & 11.8 \\
Overweight & 11.5 & \\
\hline & &
\end{tabular}

\section{Methods}

The comprehensive snack parenting questionnaire (CSPQ) containing 21 items was developed through a systematic combination of methods for identification and conceptualization of constructs (i.e. expert consultation through a Delphi study), item development (i.e. a Delphi study, qualitative interviews with parents, and a pilot questionnaire survey), and refinement of the instrument (i.e. a pilot questionnaire survey, cognitive interviews with parents, and expert reviews). Subsequently, a group of parents was invited to fill out the final questionnaire twice, to assess the test-retest reliability of the instrument and to calculate correlations between constructs to indicate their discriminative 
value. Each of the steps in this systematic process is elaborated below. For this study, review by the IRB was not required as subjects were not subject to procedures or required to follow rules of behavior which infringed on their physical or psychological integrity.

\section{Conceptualization of Constructs}

The instrument was designed to measure FPPs among Dutch parents of children aged 4-12 years old. We defined FPPs as any behavior of parents that may affect the dietary intake of their child, including both behaviors employed by parents designed to alter child's dietary intake (Baranowski et al., 2013a; Darling \& Steinberg, 1993) for example setting food rules, and parental behavior that might affect the child's intake but was not undertaken with that intention, for example providing food when the child is upset. In order to establish the scope of FPPs constructs, a Delphi study was conducted among experts on this topic (Gevers et al., 2014a). Eighteen constructs and accompanying parental behaviors that represent FPPs were identified, extending on knowledge on constructs available from the literature (e.g. questionnaires): availability, accessibility, discussing, emotional feeding, avoiding unhealthy modeling, instrumental feeding, rules, structure, pressure to eat, providing feedback, permissiveness, encouragement, visibility, rewarding, healthy modeling, educating, involving, meal routines, and monitoring. The constructs of accessibility, availability, and modelling were each split into two constructs to cover healthy and unhealthy foods.

\section{Development and Refinement of the CSPQ}

As we intended to capture the full range of FPPs within one instrument, single-item measures were found to be advantageous as opposed to multi-item measures, particularly with regard to response burden.

An important requirement for single item measurements is that respondents should consider all aspects of the construct of interest (Youngblut \& Casper, 1993). Therefore, all items were accompanied by examples to increase understanding of the construct, particularly if it consisted of several aspects. Below the examples (e.g. "parents could have rules concerning eating sweets and snacks for their child. For example by having the rule that the child should ask first before taking sweets, the child is not allowed to have sweets just before a meal or to have certain sweets and snacks"), the actual question was asked 
(e.g. "I set rules for [child's name] about eating EDSFs") (see appendix 2). Answering options ranged from completely disagree (1) to completely agree (5) on a five-point scale.

To formulate the 21 questions and accompanying examples, three data sources were used. First, through the Delphi study, an initial list of 111 descriptions of FPPs was created. Second, an online questionnaire survey was used to investigate the occurrence of these 111 behaviors among Dutch parents ( $n=555)$ (unpublished data, 2013). Frequency distributions were used to drop items with low variability (i.e. highly skewed distributions) or extreme means. Third, twenty qualitative interviews (unpublished data, 2012) with parents from the target population were conducted about strategies they use regarding the energy-dense snack food intake of their children. The interviews gave us the opportunity to refine items and accompanying examples in line with parents" phrases. These salient aspects of parental food parenting behaviors, such as specific moments or situations described by parents, were likely to facilitate interpretation by the target population. Ultimately, the 21 items and accompanying examples were formulated by selecting those that best reflected the construct of interest, based on the degree of consensus (i.e. Delphi study) and inter-item statistics (i.e. questionnaire survey).

Subsequently, cognitive interviews among six parents from the target population were held to assess the final questionnaire on clarity of instructions, items, and answering options. In addition, scientists working in the field of Health Promotion and experienced in developing comparable questionnaires reviewed the final instrument to assess face validity and wording of items. Both methods led to adaptations in the phrasing of a few items. In addition, we decided to tailor each question to the child's name (e.g. "I have rules for [child's name] about eating EDSFs") because we noticed during the cognitive interviews that parents tend to answer questions on their child that ensues most struggles with regard to parent child interactions around eating.

\section{Design of the Reliability and Validity Study}

In order to investigate the quality of the CSPQ, we first identified item ambiguity to be a potential threat to its reliability. Consequently, respondents might be more likely to answer items differently on different occasions. Therefore, the questionnaire was assessed on its test- retest reliability (Dilorio, 2005). The discriminative validity of the CSPQ constructs was tested by examining correlations. At least 50 respondents were required at follow-up to 
adequately calculate reliability coefficients (Terwee et al., 2012). We estimated both response levels (i.e. $\mathrm{t} 1$ and $\mathrm{t} 2$ ) to be about $55 \%$, implying that we had to invite 185 parents.

Parents mastering Dutch language were recruited at public places in the south of the Netherlands. They were informed about the nature of the study and if interest was expressed, their email address and educational level were asked and gender was reported. A sample of 183 parents from the target population was invited to fill out the online questionnaire twice, with a two week interval. If parents had more than one child aged 4 to 12, they were asked to answer the questions about the child who is having his or her birthday first. This questionnaire also assessed demographic characteristics, including the respondent's and child's age and gender and variables to define the respondent's educational level (i.e. what is the highest level of education you completed?), BMI (i.e. what is your height; what is your weight?), ethnicity (i.e. were you, or (one) of your parents born abroad?) and socio-economic position (SEP; i.e. what is your postal code?), child's BMI-z (Fredriks et al., 2000) and BMI category (Barlow, 2007) (i.e. what is your child's height; what is your child's weight?).

Predictors of drop out between baseline (t1) and follow-up (t2) were examined using binary logistic regression analysis employing the enter method, with respondent's age, gender, SEP, ethnicity, BMI and educational level as independent variables. IBM SPSS Statistic 20 was used for all statistical procedures.

\section{Reliability testing}

Test-retest reliability was analyzed by computing intra class correlation coefficients (ICCs) using absolute-agreement and single rating reliability in two-way random models. In addition, the percentages agreement between scores on $\mathrm{t} 1$ and $\mathrm{t} 2$ were calculated for items with poor and fair ICC statistics, as ICC values in part depend on variability in scores (de Vet et al., 2006). ICCs were classified as poor ( $\leq .20)$, fair (0.21-0.40), moderate (.41 - .60), good (.61 - .80), and excellent ( $\geq .81)$ (Landis \& Koch, 1977). Agreement scores were classified as poor (<60\%), moderate (60\%-74\%), good (75\%-89\%), or excellent (>90\%) (Singh et al., 2011).

\section{Testing discriminative value of CSPQ constructs.}

Baseline data was used to calculate correlation coefficients between all FPP constructs while correcting for parental age, gender, and educational level. Correlations were classified in the 
following way: $<0.29$ small, 0.30 to 0.49 moderate, and $>0.50$ large (Cohen, 1988). These cut-off points were used to evaluate the discriminative value of constructs. In addition, we expected that correlations would not exceed 0.8 , thereby indicating their distinctiveness.

\section{Results}

The response on $t 1$ was $60 \%(n=109)$, of which $61 \%$ completed t2 $(n=66)$. On average, the interval between the two measures was 15.22 days $(S D=3.29)$. Female participants were less likely to complete $\mathrm{t} 2$ compared to male participants ( $\mathrm{OR}=2.78,95 \% \mathrm{Cl}$ 1.07-7.21, $\mathrm{P}=0.02$, Cox \& Snell $R^{2}=0.08$, Nagelkerke $R^{2}=0.11$ ). Most of the participants were female and highly educated, implying that they are overrepresented (table 4.1) (Statistics Netherlands, 2014). The sample was comparable to the Dutch population with regard to ethnicity and SEP (Statistics Netherlands, 2014; The Netherlands Institute for Social Research (SCP), 2014). Parents of overweight children were well represented, but the number of underweight children in the sample was higher than national numbers (Statistics Netherlands, 2014). Focal children were on average 7 years $(S D=2.3)$ of age and parents reported most often on their daughter. 
Table 4.2: Test-retest reliability characteristics of the CSPQ ( $n=109)$

\begin{tabular}{|c|c|c|c|c|c|}
\hline FPP construct & Item $^{\mathrm{a}}$ & $\begin{array}{l}\text { Mean } \\
\text { SD t1 }{ }^{\text {b }}\end{array}$ & $\begin{array}{l}\text { Mean } \\
\text { SD t2 }\end{array}$ & ICC & $\begin{array}{l}\% \\
\text { Agree }\end{array}$ \\
\hline $\begin{array}{l}\text { Availability of } \\
\text { unhealthy foods }\end{array}$ & $\begin{array}{l}\text { I limit the availability of EDSFs in the house } \\
\text { for [child's name] }\end{array}$ & $\begin{array}{l}3.81 \\
(1.01)\end{array}$ & $\begin{array}{l}3.76 \\
(0.95)\end{array}$ & 0.52 & \\
\hline $\begin{array}{l}\text { Accessibility of } \\
\text { unhealthy foods }\end{array}$ & $\begin{array}{l}\text { I make sure that [child's name] has easy } \\
\text { access to EDSFs. }\end{array}$ & $\begin{array}{l}2.61 \\
(1.11)\end{array}$ & $\begin{array}{l}3.38 \\
(1.04)\end{array}$ & 0.49 & \\
\hline Discussing & I talk to [child's name] about eating EDSFs. & $\begin{array}{l}3.83 \\
(1.01)\end{array}$ & $\begin{array}{l}3.91 \\
(0.97)\end{array}$ & 0.23 & 60 \\
\hline $\begin{array}{l}\text { Emotional } \\
\text { feeding }\end{array}$ & $\begin{array}{l}\text { I give [child's name] EDSFs to make [him/her] } \\
\text { feel better. }\end{array}$ & $\begin{array}{l}1.72 \\
(0.87)\end{array}$ & $\begin{array}{l}1.91 \\
(0.96)\end{array}$ & 0.65 & \\
\hline $\begin{array}{l}\text { Avoiding } \\
\text { unhealthy } \\
\text { modelling }\end{array}$ & $\begin{array}{l}\text { I consciously refrain from eating EDSFs when } \\
\text { [child's name] is around. }\end{array}$ & $\begin{array}{l}3.17 \\
(1.14)\end{array}$ & $\begin{array}{l}3.20 \\
(1.13)\end{array}$ & 0.61 & \\
\hline $\begin{array}{l}\text { Instrumental } \\
\text { feeding }\end{array}$ & $\begin{array}{l}\text { I give [child's name] EDSFs to reward him/her } \\
\text { for good behavior. }\end{array}$ & $\begin{array}{l}2.71 \\
(1.13)\end{array}$ & $\begin{array}{l}2.48 \\
(1.09)\end{array}$ & 0.50 & \\
\hline Rules & $\begin{array}{l}\text { I have rules for [child's name] about eating } \\
\text { EDSFs. }\end{array}$ & $\begin{array}{l}4.43 \\
(0.83)\end{array}$ & $\begin{array}{l}4.42 \\
(0.66)\end{array}$ & 0.36 & 70 \\
\hline Structure & I provide structure regarding EDSFs. & $\begin{array}{l}3.90 \\
(0.91)\end{array}$ & $\begin{array}{l}4.08 \\
(0.74)\end{array}$ & 0.51 & \\
\hline Pressure to eat & $\begin{array}{l}\text { I insist that [child's name] eats or finishes a } \\
\text { food item }\end{array}$ & $\begin{array}{l}3.23 \\
(1.23)\end{array}$ & $\begin{array}{l}3.22 \\
(1.08)\end{array}$ & 0.58 & \\
\hline $\begin{array}{l}\text { Providing } \\
\text { feedback }\end{array}$ & $\begin{array}{l}\text { I respond to [child's name]'s eating behavior } \\
\text { by providing him/her with feedback }\end{array}$ & $\begin{array}{l}4.04 \\
(0.74)\end{array}$ & $\begin{array}{l}4.09 \\
(0.72)\end{array}$ & 0.50 & \\
\hline Permissiveness & $\begin{array}{l}\text { I am flexible about [child's name]'s eating } \\
\text { behavior }\end{array}$ & $\begin{array}{l}2.11 \\
(0.89)\end{array}$ & $\begin{array}{l}2.25 \\
(1.09)\end{array}$ & 0.42 & \\
\hline $\begin{array}{l}\text { Availability } \\
\text { healthy foods }\end{array}$ & $\begin{array}{l}\text { I make sure healthy foods are available at } \\
\text { home for [child's name] }\end{array}$ & $\begin{array}{l}4.48 \\
(0.67)\end{array}$ & $\begin{array}{l}4.57 \\
(0.56)\end{array}$ & 0.33 & 67 \\
\hline $\begin{array}{l}\text { Accessibility } \\
\text { healthy foods }\end{array}$ & $\begin{array}{l}\text { I make sure [child's name] has easy access to } \\
\text { healthy foods }\end{array}$ & $\begin{array}{l}4.26 \\
(0.82)\end{array}$ & $\begin{array}{l}4.22 \\
(0.72)\end{array}$ & 0.48 & \\
\hline Encouragement & $\begin{array}{l}\text { I encourage [child's name] to eat healthy } \\
\text { food }\end{array}$ & $\begin{array}{l}4.40 \\
(0.70)\end{array}$ & $\begin{array}{l}4.42 \\
(0.63)\end{array}$ & 0.49 & \\
\hline Visibility & $\begin{array}{l}\text { I make sure healthy foods are visible for } \\
\text { [child's name] }\end{array}$ & $\begin{array}{l}4.15 \\
(0.89)\end{array}$ & $\begin{array}{l}4.20 \\
(0.77)\end{array}$ & 0.61 & \\
\hline Rewarding & $\begin{array}{l}\text { I reward [child's name]'s healthy eating with } \\
\text { something else than EDSFs }\end{array}$ & $\begin{array}{l}3.11 \\
(1.11)\end{array}$ & $\begin{array}{l}3.18 \\
(1.09)\end{array}$ & 0.41 & \\
\hline $\begin{array}{l}\text { Healthy } \\
\text { modelling }\end{array}$ & $\begin{array}{l}\text { I intentionally eat healthy foods in front of } \\
\text { [child's name] }\end{array}$ & $\begin{array}{l}3.67 \\
(0.91)\end{array}$ & $\begin{array}{l}3.65 \\
(1.04)\end{array}$ & 0.58 & \\
\hline Educating & I teach [child's name] things about food & $\begin{array}{l}4.29 \\
(0.74)\end{array}$ & $\begin{array}{l}4.28 \\
(0.70)\end{array}$ & 0.70 & \\
\hline Involving & $\begin{array}{l}\text { I involve [child's name] in food-related } \\
\text { activities }\end{array}$ & $\begin{array}{l}4.13 \\
(0.73)\end{array}$ & $\begin{array}{l}4.09 \\
(0.84)\end{array}$ & 0.67 & \\
\hline Meal routines & I ensure healthy mealtime habits & $\begin{array}{l}4.52 \\
(0.62)\end{array}$ & $\begin{array}{l}4.46 \\
(0.56)\end{array}$ & 0.52 & \\
\hline Monitoring & $\begin{array}{l}\text { I monitor what [child's name] is eating during } \\
\text { the day }\end{array}$ & $\begin{array}{l}3.63 \\
(1.06)\end{array}$ & $\begin{array}{l}3.34 \\
(1.09)\end{array}$ & 0.51 & \\
\hline
\end{tabular}

Note: ${ }^{a}$ this column shows the actual questions without the global description and examples, each question has been translated into English by an bilingual translator but have not been cross-culturally validated, ${ }^{\mathrm{b}}$ Range from 1 to 5 


\section{Test-retest Reliability Characteristics}

ICCs ranged from poor to good ( 0.23 to 0.70 ), with most being classified as moderate (table 4.2). Three ICCs were considered to be poor, but the corresponding percentages agreement were found to be acceptable, including discussing (agreement=60\%), rules (agreement=70\%), and availability of healthy foods (agreement=67\%). Five items, referring to the constructs emotional feeding, modeling, visibility, educating, and involving, were found to have good test-retest reliability statistics.

\section{Discriminative Value of CSPQ Constructs}

Partial correlations between constructs ranged from small to large, with the majority being classified as small. Twenty-seven (12.9\%) moderate and eight (3.8\%) large correlations were found, but none of them exceeded the threshold of 0.8 . The majority of the moderate to large correlations were found between constructs which likely represent similar types of food parenting practices. For example, responsive types of practices such as providing feedback, encouragement, educating, and involving were found to have relatively large correlations. Similarly, correlations between availability, accessibility, and visibility of foods were among the largest ones. 


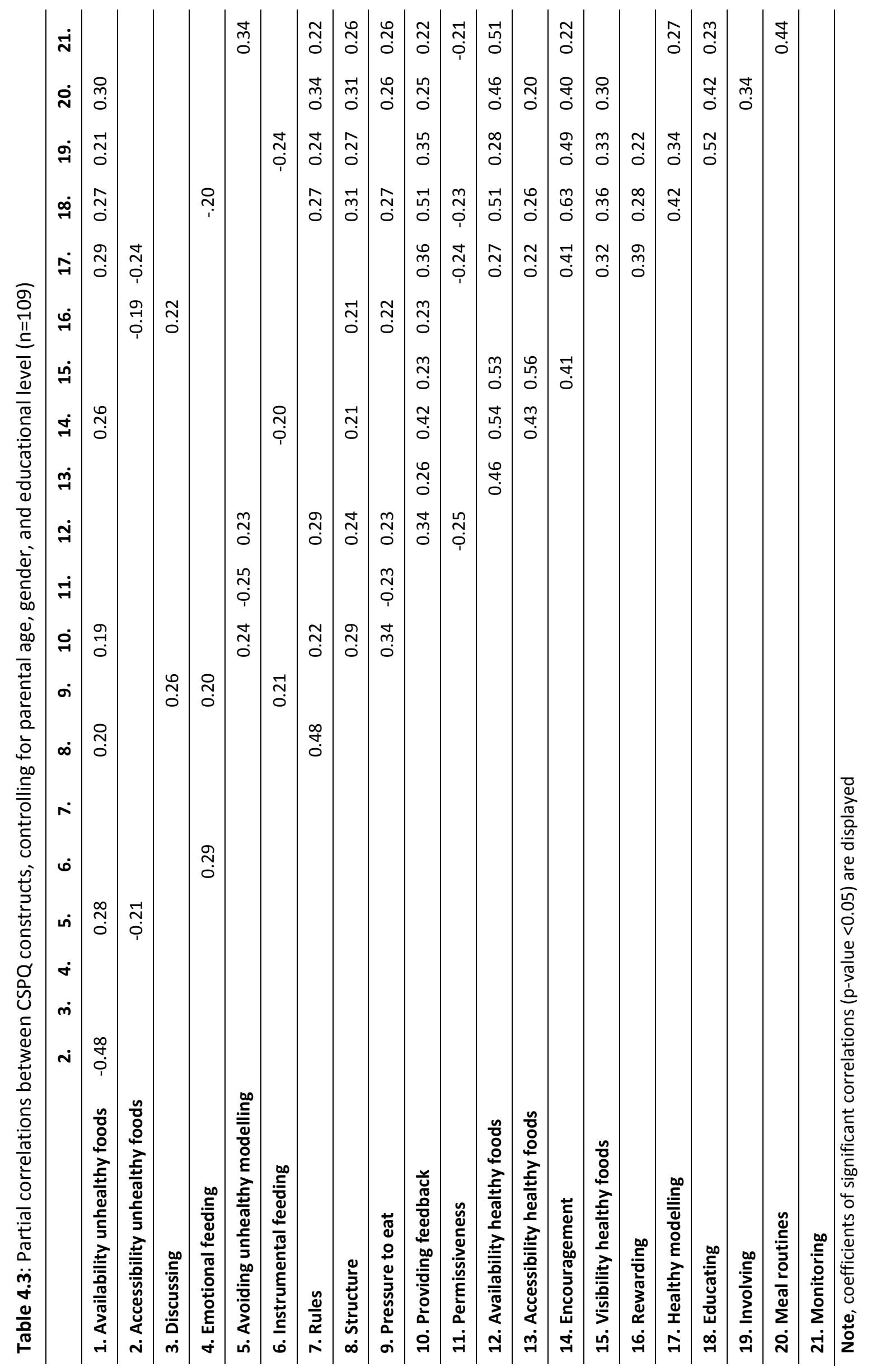




\section{Discussion}

We aimed to develop a food parenting practices instrument for parents with children aged 4 to 12 measuring the full range of food parenting practice (FPP) constructs and test its reliability and evaluate discriminant validity of constructs.

A questionnaire containing 21 constructs was developed through an extensive process for questionnaire construction and refinement, using a combination of methods. In terms of number of constructs, we think this instrument is the most comprehensive of all existing instruments (Vaughn et al., 2013), and likely covers all relevant parental behaviors in the context of child feeding in between meals (Gevers et al., 2014a).

We found that any item ambiguity had no detrimental impact on reliability as items showed moderate to good test-retest reliability, indicating its consistency over time. Discussing, rules, and healthy availability had relatively high mean scores, which likely explain their unfavorable reliability coefficients. Nevertheless, the percentages agreement for these constructs were acceptable. Particularly the item referring to availability of healthy foods might be prone to social desirability bias, which seems to be a common problem for this construct (e.g. Bryant et al., 2008; van Ansem et al., 2014; Vereecken et al., 2005).

Vaughn et al. (2013) found in their review that 27 of 71 identified validation studies included a test-retest assessment, with generally acceptable correlations. But in contrast with the current study, authors mostly reported Pearson's correlations (e.g. Kroller \& Warschburger, 2008), which are less adequate in test-retest designs compared to ICCS (Terwee et al., 2007). A paper published after that review reported on the one week testretest reliability of the „ENERGY-parent questionnaire on parenting practices". Similar to our study, most of their FPP constructs contained single items with several of them being very comparable. The authors found country specific ICC values which showed much more variation (e.g. range of ICC values in the Netherlands 0.00 to 0.82 ) compared to the current study (Singh et al., 2011) , implying that our instrument might be preferable in that respect.

The R-matrix confirmed the distinctiveness of the CSPQ constructs and potential discriminant value in explaining and predicting child intake behaviors. Additional indications for the instrument's validity were provided by the relatively large correlations between inter- related food parenting practices.

The CSPQ could support the investigation of relevant and innovative research questions. One of such research question relates to the co-occurrence of parental behaviors 
(e.g. O'Connor et al., 2010; Rodenburg et al., 2013). Studying FPP clusters is useful with regard to intervention development. For example, associations between clusters and children's food intake and parental factors could be investigated to increase knowledge on their combined impact and high risk groups could be identified. Given the instrument's brevity and high number of respondents completing the questionnaire, response burden is likely to be low. Therefore, a great move forward might be possible in mediation and moderation research as well, for example to study the moderating influence of general parenting (e.g. Taylor et al., 2011a) and child characteristics (e.g. de Bruijn et al., 2007) on the impact of FPPs. These types of studies involve multiple measures, which is why they would benefit from short measures. Asking too many questions might refrain respondents from completing the questionnaire and participating in follow-up measures, which is especially problematic in the case of selective drop-out.

A major strength of the current study is the use of multiple methods to develop the instrument. We determined shortcomings of existing questionnaires and proposed a new questionnaire to forward research in this field. Low educated parents were underrepresented and female participants were found to be less likely to complete the questionnaire on follow- up, most likely because of motivational aspects and not due to questionnaire weaknesses. Still, most respondents from our reliability sample were highly educated, resulting in an underrepresentation of low educated parents. This could be seen as a weakness of our study, as it reduces the representativeness of the sample. Against that, testing the reliability of the instrument in a more heterogeneous sample would probably lead to more variation in responses, and thereby to even more desirable reliability statistics (de Vet et al., 2006).

\section{Implications for research and practice}

In terms of number of constructs, we think the CSPQ is the most comprehensive instrument that currently exists and covers all relevant food practices related to children's snacking. The study demonstrated that the instrument is likely to be a feasible tool with acceptable reliability and discriminative validity characteristics to map parental food practices. The tool is easy to administer and has low response burden due to the small number of items, which is desirable in studies involving multiple measures (e.g. mediating and moderating processes in research on FPPs (e.g. Melbye et al., 2013a; Rollins et al., 2014; Vereecken et al., 2010b). 
The instrument opens up chances for new, highly relevant but presently unstudied, research questions for example with regard to clustering and dynamics across a broad range of food parenting practices.

The current study provides first indications for reliability and validity of the CSPQ. Further studies might be needed to confirm and extend current findings with regard to these measurement properties. 


\section{Chapter 5}

Patterns of food parenting practices and children's intake of energydense snack foods

This chapter has been published as: Gevers D.W.M., Kremers S.P.J., de Vries N.K., van Assema P. (2015). Patterns of Food Parenting Practices and Children's Intake of EnergyDense Snack Foods. Nutrients, 7, 4093-4106. 


\begin{abstract}
Most previous studies of parental influences on children's diets included just a single or a few types of food parenting practices, while parents actually employ multiple types of practices. Our objective was to investigate the clustering of parents regarding food parenting practices and to characterize the clusters in terms of background characteristics and children's intake of energy-dense snack foods. A sample of Dutch parents of children aged 412 was recruited by a research agency to fill out an online questionnaire. A hierarchical cluster analysis ( $\mathrm{n}=888$ ) was performed, followed by k-means clustering. ANOVAs, ANCOVAs and chi-square tests were used to investigate associations between cluster membership, parental and child background characteristics, as well as children's intake of energy-dense snack foods. Four distinct patterns were discovered: "high covert control and rewarding", "low covert control and non-rewarding", "high involvement and supportive" and "low involvement and indulgent". The "high involvement and supportive" cluster was found to be most favorable in terms of children's intake. Several background factors characterized cluster membership. This study expands the current knowledge about parental influences on children's diets. Interventions should focus on increasing parental involvement in food parenting.
\end{abstract}




\section{Introduction}

Childhood obesity has become a problem in many countries (Lobstein et al., 2004), including the Netherlands, where overweight prevalence rates have increased from about $5 \%$ of boys and $7 \%$ of girls in 1980 to about 13\% and 15\%, respectively, in 2009 (Schönbeck et al., 2011). These figures are alarming, as being overweight during childhood is associated with several health problems, including cardiovascular, metabolic and psychosocial problems (Daniels, 2009). Additionally, an increasing number of studies have indicated that being overweight in childhood persists during later life (Singh et al., 2008), so encouraging healthy energy balance-related behaviors in young children is important. One of the behavioral aims for interventions could be to reduce the consumption of energy-dense nutrient-poor foods, which include non-core foods, such as potato chips, chocolate and cookies. Although more research is needed to disentangle the association between the consumption of these foods and children's weight status, there is ample evidence indicating that intakes of such foods have increased substantially in U.S. children in recent decades, as well as some evidence that the frequency of snacking is positively related to total energy intake (Larson \& Story, 2013). The observed U.S. trends could also be indicative of other Western countries. In the national food consumption survey 2007-2010 in the Netherlands (NFCS), children were found to have an average of about three energy-dense snack food (EDSF) occasions a day, yielding more than $1500 \mathrm{~kJ}$ (Gevers et al., 2015a). Less than 10\% of the children researched met dietary guidelines regarding energy intake from non-core foods, illustrating the need for programs addressing this behavior.

Preventive actions might focus on home and family factors. Parents have been shown to be important environmental agents, as children are dependent on them with regard to food intake (Golan \& Crow, 2004). This dependency concerns a variety of food parenting practices (FPPs), such as bringing foods into the home and storing them, setting rules about food intake or modeling healthy food habits (Gevers et al., 2014a).

Traditionally, research has focused on relationships between individual FPPs and the child's diet (or aspects thereof). This approach implies that a few individual practices or constructs are treated as independent predictors, while exploring this relationship, for instance, by examining them by means of bivariate correlations or single regression models (e.g. Hendy et al., 2009; Kroller \& Warschburger, 2008; Melbye et al., 2013a; Melbye et al., 2013b; Van Lippevelde et al., 2013; Vereecken et al., 2004). The dynamics of parenting 
practices have scarcely been examined. We found two studies from the United States that examined the interrelatedness of parenting practices (Baranowski et al., 2013b; O'Connor et al., 2010). One of them investigated vegetable parenting practices, which clustered according to three theorized dimensions (i.e., responsiveness, structure and control) (Baranowski et al., 2013b), while the other (O'Connor et al., 2010) found three clusters of parents: one cluster of parents reporting low use of FPPs, one cluster of parents reporting high use of FPPs and the third a "non-directive" cluster (i.e., "enhanced availability and teachable moments and less firm discipline practices"). In a Dutch sample, evidence was found for interrelatedness between diet- and activity-related parenting practices (Rodenburg et al., 2013). These three studies all had different objectives (confirming vs. exploring the co-occurrence of parenting practices) and included different types of practices (vegetable, food and both physical activity and food), but all contribute to the evidence base on food parenting, thereby increasing the potential of future interventions. The present study was intended to extend this evidence base by examining the interrelatedness of a set of FPPs among a sample of Dutch parents.

Studying the co-occurrence of a wide range of FPPs has a great advantage over the traditional "isolated" approach. Parents do not employ single practices, but actually employ several of them, which might have synergistic (Rodenburg et al., 2013) or opposing effects. This might be revealed by examining patterns, which is not possible using isolated observations. Moreover, demographic characteristics might be used to profile clusters of parents, which would create opportunities to target parents belonging to particular clusters. For instance, parental educational level has emerged as an important correlate for all clusters discovered across the food and physical activity domain (Rodenburg et al., 2013). The clusters found by O'Connor et al. (2010) were associated with ethnicity, parental age and child age, all pointing toward potential target groups.

The aim of this study was to assess the co-occurrence of FPPs. We formulated three research questions. (1) Which clusters of parents can be distinguished, based on their food parenting practice pattern? (2) Which parental and child background factors characterize cluster membership? (3) Does the intake of EDSFs among children differ according to their parents' cluster membership? 


\section{Methods}

\section{Study Design and Participants}

This study used baseline data from an ongoing prospective study. Parents were recruited by are search agency (Flycatcher Internet Research), which meets quality standards for social science research and access panels, as indicated by the ISO20252 and ISO26362 standards (The International Organization for Standardization Standards, 2015). Their panel consists of about 16,000 Dutch people aged 12 years and older who receive credit points in exchange for their participation in online questionnaire research. On average, panel members are invited to participate in such research eight times a year. For the present study, panel members were invited if they had at least one child aged 4-12; this applied to 1985 persons. Data were retrieved from two questionnaires (together constituting the baseline measurement of the larger study) sent off in October and November 2014, respectively. Participants received 500 credit points for completion of both, which equals 5.56 Euros. If parents had more than one child aged $4-12$, they were asked in the first survey to answer all questions about the child whose birthday came first, counting from the moment of invitation, to limit potential confounding. To remind parents in the second survey of the child of interest, we used information from the first (i.e., children's age, gender and first name). Four to seven days after both invitations, non-responders received a reminder by email. This study was exempt from review by a research ethics committee, as it does not fall within the scope of the Dutch Medical Research Involving Human Subjects Act (Central Committee on Research Involving Human Subjects (CCMO), 2015).

\section{Measures}

\section{Parent and Child Background Information}

Respondents indicated their work status (i.e., employed versus unemployed) and reported their postal code, enabling us to calculate a factor score indicating their socio-economic position (SEP; -4 (low) to 4 (high). This score has been developed by the Netherlands Institute for Social Research and is based on income, educational level and occupation (SCP, 2015). Height and weight were self-reported, enabling us to calculate body mass index (BMI). The respondents' age, gender, educational level and ethnicity were known to the research agency. Children's age, gender, height and weight were reported by the 
respondents. Height and weight data were compared with a 1997 Dutch reference population (Fredriks et al., 2000) to calculate the child's BMI-z score.

\section{Food Parenting Practices}

FPPs were examined using the Comprehensive Snack Parenting Questionnaire (CSPQ) (Sleddens et al., 2014). This 21-item questionnaire was developed for the purpose of mapping 21 distinct food parenting behaviors related to snack food intake. Items showed acceptable test-retest reliability statistics (intra-class correlations ranging from 0.41-0.70; exact agreement scores ranging from $60 \%-70 \%$ for items with intra class correlations $\leq 0.40$ ) (Gevers et al., submitted). The CSPQ assesses practices categorized using a model of general parenting (Sleddens et al., 2014): Responsiveness, including encouragement, rewarding, discussing, providing feedback, involving, educating, healthy modeling and unhealthy modeling avoidance; structure, including the availability of healthy foods, accessibility of healthy foods, visibility of healthy foods, limited availability of unhealthy foods, limited accessibility of unhealthy foods, structure and meal routines; behavioral control, including permissiveness, rules and monitoring; and finally, psychological control, including instrumental feeding, emotional feeding and pressure to eat. For example, parents were asked to rate the following statements: "I give [child's first name] EDSFs to make [him/her] feel better"; "I teach [child's first name] things about food"; and "I consciously refrain from eating EDSFs when [child's first name] is around", with answer categories ranging from 1, strongly disagree, to 5 , strongly agree.

\section{Intake of Energy-Dense Snack Foods}

Thirteen questions assessed the child's number of energy-dense food occasions per week (with relevant examples of what constitutes energy-dense snack foods provided). Parents were asked to respond to the question: "Thinking about the last month, how many days a week did your child normally consume: (1) potato chips, (2) candy (e.g., wine gums, lollipops), (3) chocolates, (4) candy bars, (5) dried fruit biscuits, (6) small or medium sized cookies such as Dutch windmill cookies, (7) large cookies such as chocolate chip cookies, (8)

pie or pastry (e.g., pie, apple turnover), (9) savory snacks and peanuts (e.g., nuts, popcorn), and (10) gum throughout the day and (11) ice creams, (12) deep fried snacks or (13) gingerbread between meals." Answering categories ranged from never to 7 days a week. 
These scores were summed to create a variable indicating the number of energy-dense food occasions per week. The food items were taken from a validated Dutch food frequency questionnaire assessing children's energy intake (Brants et al., 2006; Dutman et al., 2011).

\section{Statistical Analysis}

A logistic regression analysis was performed to determine differences between responders and non-responders with regard to the parent's age, gender, educational level and ethnicity. Before running cluster analyses, we standardized food parenting practice scores, recoded univariate outliers (i.e., values $>3$ SD distance from the mean) and eliminated multivariate outliers (i.e., cases with large Mahalanobis distances (Tabachnick \& Fidell, 2001)). Additionally, data were checked for multicollinearity, applying a cut-off value of 0.80 ; patterns of FPPs were examined in a two-step procedure (Hair et al., 1998). The first step involved the use of a hierarchical cluster analysis using Ward's method and squared Euclidean distances. To determine the optimal number of clusters, we created a scree plot of the agglomeration coefficients and visually inspected the dendrogram. The second step of the procedure involved the performance of a non-hierarchical cluster analysis (i.e., k-means) with varying cluster solutions to discover which solution most meaningfully distinguished parents in terms of their FPPs. The stability of the final cluster solution was assessed using a cross-validation procedure (Breckenridge, 2000). To this end, data were randomly split into two subsamples (Samples A and B), and the full two-step cluster analysis was replicated in both. In addition, the resulting obtained cluster centers of Subsample A were saved and used to classify the participants from Sample B into a second set of clusters. By calculating Cohen's kappa, we assessed the similarity of the two Sample B solutions. We considered kappa $>0.6$ to be acceptable (Landis \& Koch, 1977). The final clusters were interpreted and labeled using the four factors (Sleddens et al., 2014) categorizing individual parenting practices: Responsiveness, structure, behavioral control and psychological control. ANOVAs (for continuous variables) and chi-square tests (for categorical variables) were used to investigate associations between cluster membership and parental and child background characteristics, including parental age, gender, BMI, ethnicity, SEP, working status and educational level, as well as the child's age, gender and BMI-z score. If the overall F-test or chi-square test resulted in a $p$-value $<0.05$, post hoc comparisons were performed using Tukey HSD (following F-tests) or Bonferroni (following chi-square tests). 
ANCOVAs followed by Bonferroni post hoc test were used to assess differences between clusters in terms of a child's energy-dense food intake, while correcting for background characteristics found to be significantly related to the clusters. IBM SPSS Statistics 20 was used for all analyses.

\section{Results}

\section{Sample}

In total, 939 parents (response 47.3\%) filled out both questionnaires completely, 888 of which were eligible (i.e., having a child aged 4-12 years old) and had complete responses of sufficient quality (i.e., no straight-lining responses as assessed by the research agency and no multivariate outliers) and were thus entered into the data analysis. Parents with low (OR = $1.85 ; 95 \% \mathrm{Cl}=1.39-2.46 ; \mathrm{p}$-value $<0.01)$ and intermediate $(\mathrm{OR}=1.40 ; 95 \% \mathrm{Cl}=1.2-1.7 ; \mathrm{p}$ value $<0.01)$ educational levels were less likely to fill out the questionnaire than parents with a high educational level. There were no differences between responders and nonresponders with regard to their age, gender and ethnicity.

Parents had a mean age of 40.6 (SD $=5.8$; range 25-64). More than half of the sample was female (65.2\%), and about one tenth of the sample had a low educational level. Parents with an intermediate educational (45.3\%) and high educational level (43.6\%) were equally represented. Most of the parents were of Dutch ethnicity (91.0\%) and were employed (79.3\%). The parents had an average BMI of 25.2 (SD $=4.2$ ), with $0.6 \%$ being classified as underweight (i.e., $<18.5 \mathrm{~kg} / \mathrm{m}^{2}$ ), $54.2 \%$ as normal weight (i.e., $18.5-24.9 \mathrm{~kg} / \mathrm{m}^{2}$ ) and $45.2 \%$ as overweight (i.e., $\geq 25 \mathrm{~kg} / \mathrm{m}^{2}$ ). The mean SEP score was 0.1 (SD = 1.2). Compared to the Dutch population, female parents and parents with medium and high educational levels (about $41 \%$ and $40 \%$, in the Dutch population, respectively) and being of Dutch origin (about $70 \%$ in the Dutch population) were overrepresented in the sample (Statistics Netherlands, 2015). With regard to BMI, the sample resembled self-reported national figures, but objectively measured height and weight indicate a slightly higher overweight rate in the Dutch population as a whole (Schokker et al., 2007). Children of participating parents (49.7\% female) had a mean age of 7.9 (SD = 2.6) and a mean BMI-z score of 0.19 (SD = 1.4). According to Barlow's cut-off points (Barlow, 2007), approximately $12 \%$ of the children were underweight, $73 \%$ had a healthy weight and $15 \%$ were overweight or obese. The number of overweight children corresponds to the national population (Schönbeck et 
al., 2011). On average, children had 12.4 (SD = 5.9) energy-dense snack food occasions per week.

\section{Identification of Clusters}

Before running cluster analyses, univariate outliers were replaced by the mean score plus three standard deviations (1.6\% of all responses on FPPs), and multivariate outliers (19 cases) were eliminated from the further analyses. No multicollinearity was observed between the included FPPs (all Pearson's correlations $\leq 0.63$ ). Ward's method indicated that a four-cluster solution gave the best fit, in view of the change in agglomeration coefficients. After considering this outcome and the dendrogram, we conducted k-means cluster analyses using 4-, 5-, 6- and 7-cluster solutions, from which a four-cluster solution was derived (Table 5.1; Figure 5.1). After replicating the full two-step clustering approach in two subsamples, we obtained a Cohen's kappa of 0.97 , indicating substantial stability of the cluster solution.

The first cluster ( $n=273 ; 30.7 \%$ ) was labeled "high covert control and rewarding" and was characterized by relatively high scores on avoidance of unhealthy modeling, high scores on limited availability and accessibility of unhealthy foods and high use of instrumental and emotional feeding. Cluster 2 ( $n=227 ; 25.6 \%$ ) consisted of parents with low scores on healthy modeling and avoidance of unhealthy modeling, low scores on limited availability and accessibility of unhealthy foods and low use of practices with a rewarding component (i.e., rewarding, instrumental and emotional feeding) and was called "low covert control and non-rewarding". The third cluster ( $\mathrm{n}=247 ; 27.8 \%$ ) was named "high involvement and supportive" because members of this cluster had high scores for the use of parenting practices from the responsiveness, structure and behavioral control categories, but low scores for permissiveness. Parents in Cluster 4 ("low involvement and indulgent"; $n=141$; 15.9\%) had relatively low scores on all types of FPPs, except for permissiveness.

\section{Characterizing Cluster Membership}

Membership Cluster membership was characterized by parental age, gender, BMI and SEP, as well as child's age and BMI-z score (Table 5.2). Parents from Cluster 1 (i.e., "high covert control and rewarding") appeared to be older than those from Cluster 4 (i.e., "low involvement and indulgent"). Cluster 2 (i.e., "low covert control and non-rewarding") included more woman than Cluster 4. Parents in Cluster 4 were found to have higher BMI 
scores than parents from Clusters 1 and 2 and tended to have a higher SEP than Cluster 2 parents. Children of parents from Clusters 2, 3 (i.e., "high involvement and supportive") and 4 were older than their peers from Cluster 1, while those from Clusters 2 and 4 were older than those from Cluster 3. Parents from Clusters 1 and 4 had children with higher BMI-z scores than parents from Cluster 2, and those from Cluster 4 had also higher BMI-z scores than those from Cluster 3. 
Table 5.1: Four-cluster solution: Mean z-scores for all food parenting practices $(n=888)$

\begin{tabular}{|c|c|c|c|c|}
\hline & $\begin{array}{c}\text { Cluster } 1 \\
\text { High Covert } \\
\text { Control and } \\
\text { Rewarding } \\
\\
n=273 \\
(30.7 \%)\end{array}$ & $\begin{array}{l}\text { Cluster } 2 \\
\text { Low Covert } \\
\text { Control } \\
\text { and Non- } \\
\text { rewarding } \\
n=227 \\
(25.6 \%)\end{array}$ & $\begin{array}{c}\text { Cluster } 3 \\
\text { High } \\
\text { Involvement } \\
\text { and } \\
\text { Supportive } \\
n=247 \\
(27.8 \%)\end{array}$ & $\begin{array}{c}\text { Cluster } 4 \\
\text { Low } \\
\text { Involvement } \\
\text { and } \\
\text { Indulgent } \\
n=141 \\
(15.9 \%)\end{array}$ \\
\hline \multicolumn{5}{|l|}{ Responsiveness } \\
\hline Encouragement & -0.32 & -0.08 & 0.95 & -0.92 \\
\hline Rewarding & 0.21 & -0.55 & 0.48 & -0.37 \\
\hline Discussing & -0.13 & 0.00 & 0.50 & -0.63 \\
\hline Providing feedback & -0.05 & -0.06 & 0.55 & -0.79 \\
\hline Involving & -0.21 & 0.08 & 0.60 & -0.78 \\
\hline Educating & -0.29 & 0.23 & 0.65 & -0.95 \\
\hline Healthy modelling & 0.02 & -0.39 & 0.79 & -0.80 \\
\hline Unhealthy modelling avoidance & 0.29 & -0.51 & 0.40 & -0.45 \\
\hline \multicolumn{5}{|l|}{ Structure } \\
\hline Availability of healthy foods & -0.34 & 0.11 & 0.85 & -1.00 \\
\hline Accessibility of healthy foods & -0.41 & -0.10 & 0.88 & -0.59 \\
\hline Visibility of healthy foods & -0.31 & -0.08 & 0.85 & -0.76 \\
\hline Limited availability of unhealthy foods & 0.25 & -0.54 & 0.54 & -0.56 \\
\hline Limited accessibility of unhealthy foods & 0.49 & -0.68 & 0.32 & -0.41 \\
\hline Structure & -0.11 & 0.09 & 0.56 & -0.92 \\
\hline Meal routines & -0.26 & 0.31 & 0.51 & -0.87 \\
\hline \multicolumn{5}{|l|}{ Behavioral Control } \\
\hline Rules & -0.11 & 0.13 & 0.62 & -1.09 \\
\hline Monitoring & 0.16 & -0.06 & 0.37 & -0.85 \\
\hline Permissiveness & -0.05 & 0.01 & -0.37 & 0.72 \\
\hline \multicolumn{5}{|l|}{ Psychological Control } \\
\hline Pressure to eat & 0.15 & -0.24 & 0.19 & -0.23 \\
\hline Emotional feeding & 0.36 & -0.54 & -0.14 & 0.43 \\
\hline Instrumental feeding & 0.41 & -0.44 & -0.13 & 0.14 \\
\hline
\end{tabular}

Note: Higher scores indicate more frequent use of the food parenting practice (FPP); Bold numbers indicate scores used to label the clusters; Higher scores indicate more frequent use of the FPP 

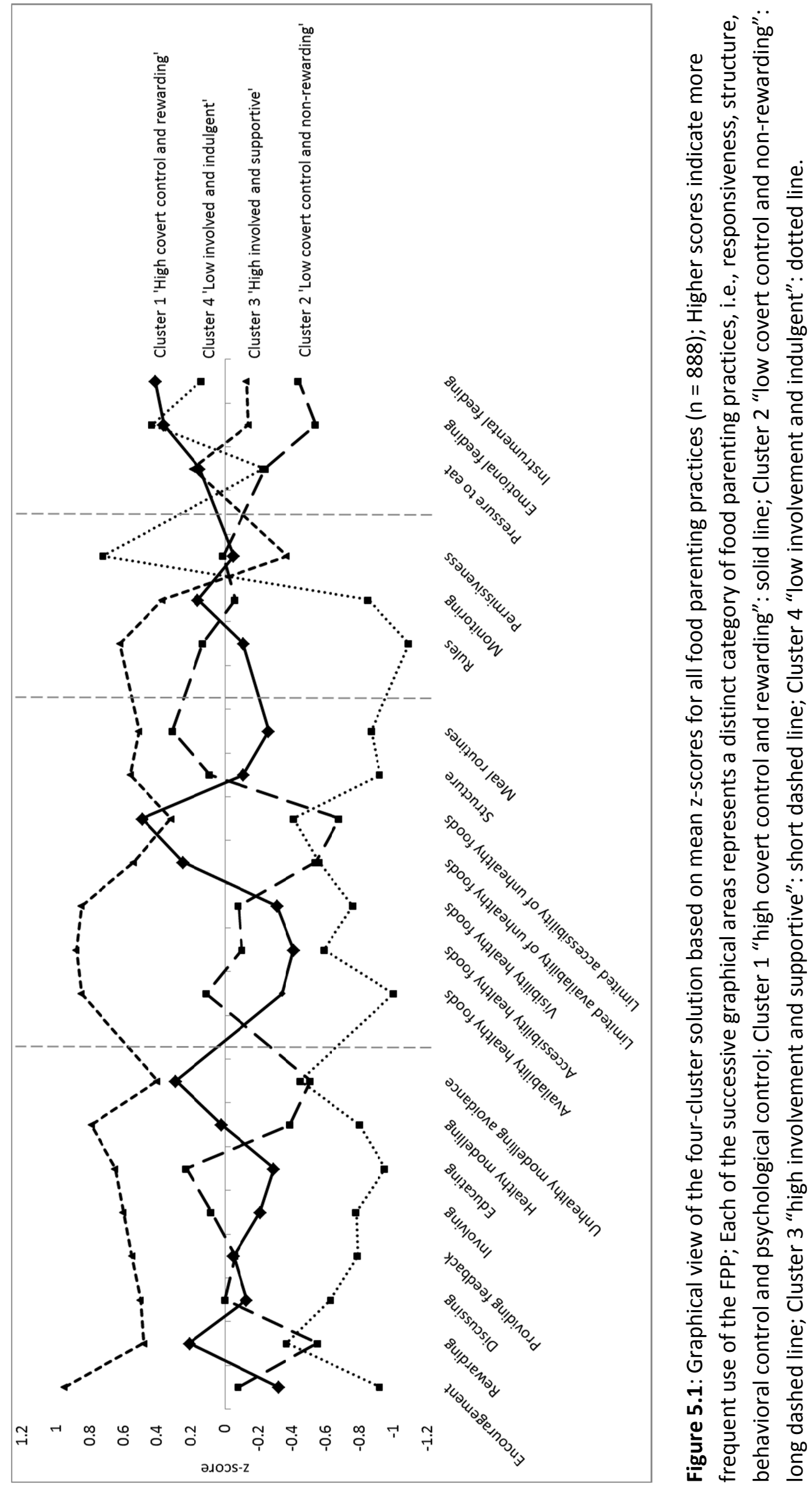


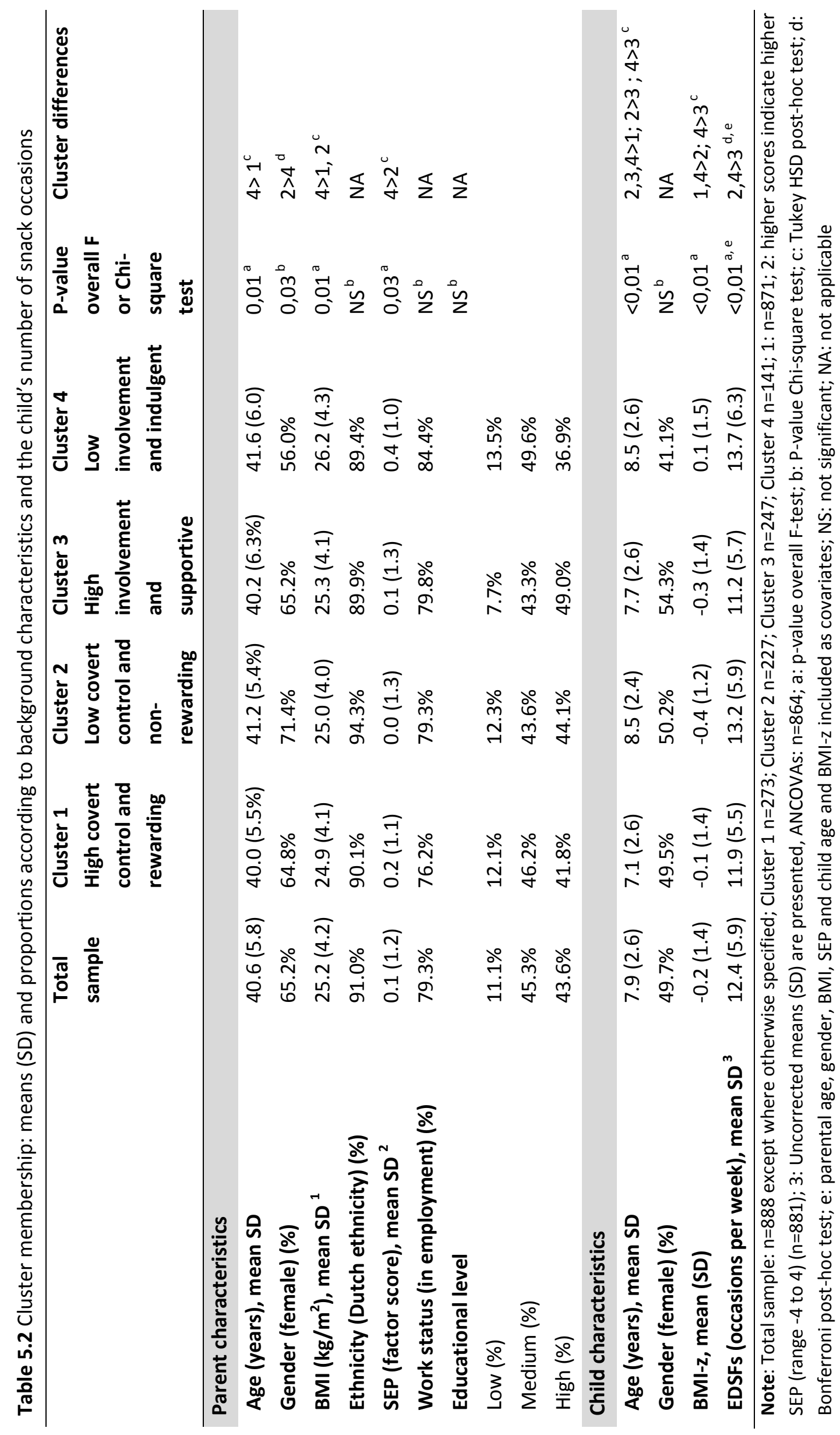


The number of EDSF occasions per week was the lowest among children from Cluster 3 (mean $=11.2, \mathrm{SD}=5.7$ ) and differed significantly from the intake among children from Clusters 2 (mean $=13.2, \mathrm{SD}=5.9$ ) and 4 (mean $=13.7, \mathrm{SD}=6.3$; Table 5.2, Figure 5.2). The mean number of EDSF occasions was $11.9(\mathrm{SD}=5.5)$ among children from Cluster 1 parents.

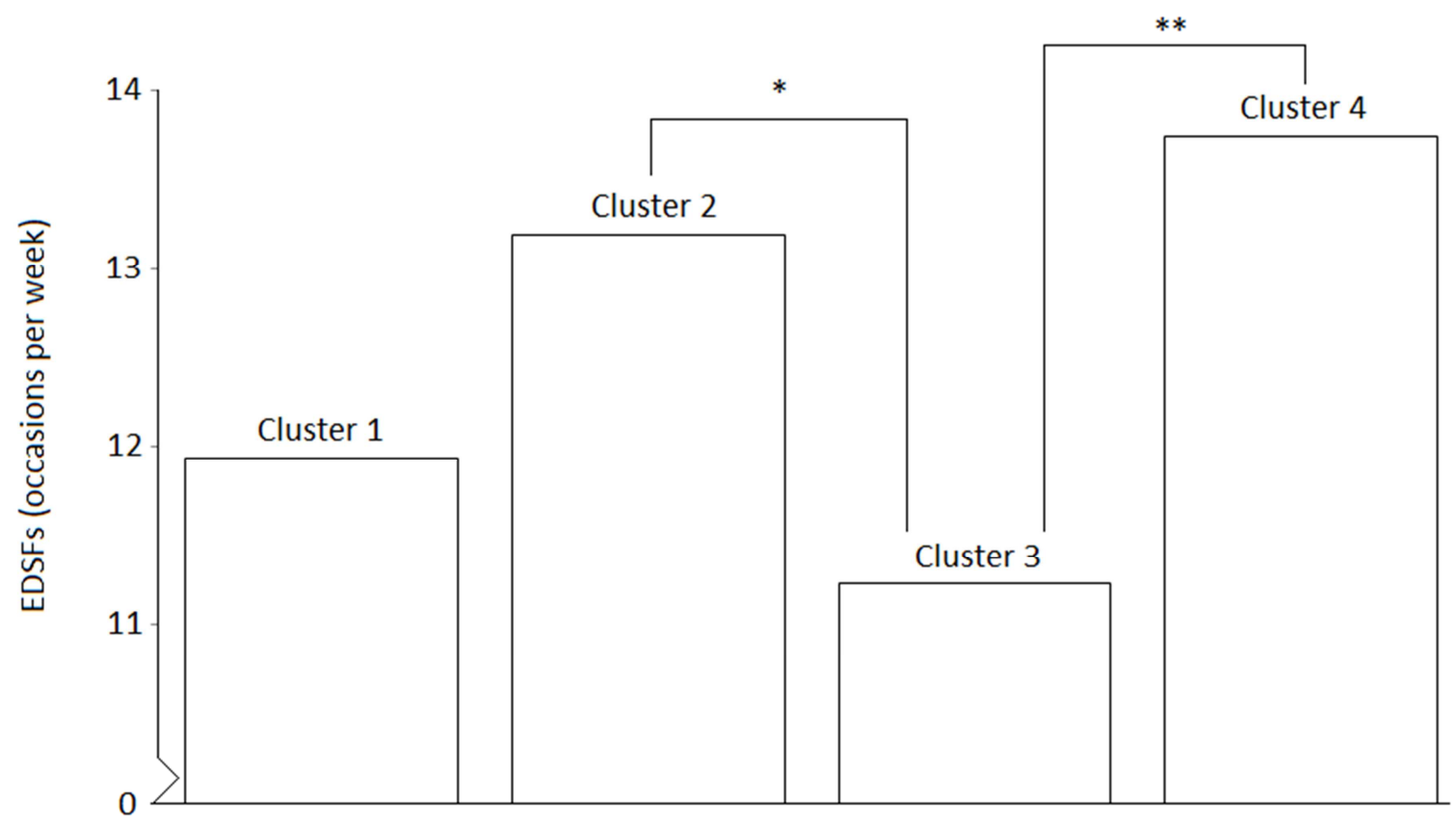

Figure 5.2 Mean energy-dense snack food (EDSF) occasions per week according to cluster membership; ${ }^{*} p<0.05,{ }^{* *} p<0.05$, uncorrected means (SD) are presented ( $\left.\mathrm{n}=888\right)$, ANCOVAs: $\mathrm{n}=$ 864, Cluster 1 = "high covert control and rewarding"; Cluster 2 = "low covert control and nonrewarding"; Cluster 3 = "high involvement and supportive"; Cluster $4=$ "low involvement and indulgent".

\section{Discussion}

Most previous studies of parental influences on children's diets applied a narrow and isolated focus on a single or a few types of food parenting practices (FPPs), while parents actually employ multiple types of practices. The combination of the practices likely influences child behavior, as opposed to independent influences of separate practices (Kremers et al., 2013). We therefore used a clustering approach to examine the interrelatedness of FPPs and investigated how these patterns relate to parental and child characteristics, including children's intake of energy-dense snack foods (EDSFs).

A two-step cluster analysis revealed four distinct patterns, of which the "high involvement and supportive cluster" was found to be the most favorable in terms of children's intake of EDSFs. Parents in this cluster tended to be involved in communicating 
about food, created a clear and supportive home food environment and are relatively strict regarding the application of snacking rules. Children of parents from the "low covert control and non-rewarding" and "low involvement and indulgent" clusters had significantly higher intakes, in spite of several relatively favorable scores on individual parenting practices (e.g., pressure to eat). About 40 percent of the parents we studied were characterized by these two patterns. The discovery of a low involvement food parenting pattern is in line with the results of O'Connor et al. (2010). Finally, a "high covert control and rewarding" pattern was identified in about $30 \%$ of the parents, consisting of parents that applied relatively many covert control practices with respect to unhealthy foods (e.g., keeping few snacks in the house), but tended to use snacks to reward or soothe their child. The label of this and the "low covert control and low rewarding" pattern were derived from

Ogden's work (Ogden et al., 2006), who defined covert control as "controlling a child's food intake in a way that cannot be detected by the child" and includes parental behaviors, such as avoiding bringing unhealthy foods into the house and trying not to eat unhealthy foods when their children are around (Ogden et al., 2006).

Previously established relationships between FPPs and children's snack food intake could be used to illustrate the dependence of FPPs on their wider context. For instance, availability and accessibility of snack foods have been found to be undesirable (Gerards \& Kremers, 2015), as well as instrumental and emotional feeding (Sleddens et al., 2010; Vereecken et al., 2004). The present study shows that low availability and accessibility of unhealthy foods in the home environment with instrumental and emotional feeding (i.e., Cluster 1 ) were more favorable than the opposite pattern (i.e., Cluster 2). Thus, FPPs from the psychological control category might be less detrimental in the context of high covert control (i.e., limiting unhealthy foods in the home and avoiding unhealthy modeling). In addition, previous studies on isolated FPPs may have produced spurious results. To illustrate, studies on restrictive rules among Dutch parents (de Bruijn et al., 2007; Gevers et al., 2015c; van der Horst et al., 2007) could have overstated its impact, as the measure of rules might have served simply as an indicator of a highly involved and supportive pattern, rather than as a measure of the effect of strict rules per se.

Our results regarding the four patterns and our attempt to profile them provide some directions for the design of interventions aimed at preventing childhood obesity. We found cluster differences based on parental age, gender, BMI and SEP and child's age and BMI. 
Developers of family interventions might consider tailoring to these factors to fit the needs and desires of potential users or targeting specific subgroups at high risk for low involvement in food parenting. We performed a sensitivity analysis by exploring FPP patterns in three different strata (based on child's age) and discovered that the low involvement pattern was more pronounced among parents of older children. Therefore, parents may need assistance in preventing a shift towards this pattern, and we suggest directly addressing parents who are not highly involved with food parenting. Further work is planned to predict the use of FPPs based on parental characteristics, such as behavior-specific cognitions (e.g., perceived behavioral control, attitude and intention), personality and demographics.

Although the cluster solution appeared to be stable within the sample, the technique has an explorative nature, so further research is needed to validate the findings and to demonstrate the value and potential impact of FPP clusters in longitudinal designs. Replication of the present study is possible, as we used a standardized measure of food parenting. It should be noted that few parents in our sample had a low educational level and few were immigrants, which reduces the representativeness of the sample. Future work using the same approach should pay particular attention to the representativeness of the sample to establish external validity. The self-report measures were probably biased towards socially-desirable scores, which is a well-known phenomenon in parenting research (Masse \& Watts, 2013). The children's EDSF intake scores may have been biased, in particular by recall bias, considering the low frequency of occasions compared to figures derived from 24hour recall data in the Dutch NFCS (Gevers et al., 2015a). It is unknown if the impact (i.e., size and direction) of this bias differed between the clusters.

\section{Conclusions}

By examining the co-occurrence of a set of FPPs, our study expands the knowledge base on parenting practices used to regulate children's food intake behaviors. Specifically, the study took account of the interdependence of practices. Parents were distinguished based on their FPP patterns, using four clusters. Differences between clusters were found in children's EDSF intake, with the "high involvement and supportive" cluster found to be the most favorable and the "low involvement" cluster the least favorable. Additional studies are needed to verify the existence of the patterns that we identified. 


\section{Chapter 6}

Associations between general parenting, restrictive snacking rules, and adolescent's snack intake. The roles of fathers and mothers and interparental congruence

This chapter has been published as: Gevers D.W.M., van Assema P., Sleddens E.F.C., de Vries N.K., Kremers S.P.J. (2015). Associations between general parenting, restrictive snacking rules, and adolescent's snack intake. The roles of fathers and mothers and interparental congruence. Appetite. 87, 184-191. 


\begin{abstract}
Introduction: Little research has been done on the role of fathers and parenting congruence between mothers and fathers. This study aimed to clarify the roles of general parenting and restrictive snacking rules set by fathers and mothers, and to explore parenting congruence in explaining adolescents' snack intake.

Methods: Adolescents aged 11 to 15 completed a questionnaire assessing their perception of general parenting constructs (i.e. nurturance, structure, behavioral control, coercive control, and overprotection), restrictive snacking rules set by their fathers and mothers, and their own energy-dense snack intakes between meals.

Results: Scores for mothers were significantly higher on all constructs than for fathers, except for coercive control. Generally, higher scores on general parenting constructs were associated with higher scores on restrictive snacking rules (most of the associations being significant). Most general parenting constructs were unrelated to the respondents' number of snacks consumed. The use of restrictive snacking rules by both fathers and mothers was significantly and negatively related to respondents' snack intake. Moderation analyses indicated that high levels of incongruence between parents attenuated the favorable impact of fathers' rules and nurturance on their children's snacking, but interactions of congruence with three other paternal scales and all maternal scales were absent.

Discussion: Our findings indicate that both paternal and maternal general parenting and restrictive snacking rules play important roles in adolescents' snacking, and that high parental incongruence regarding restrictive snacking rules and nurturance could be undesirable.
\end{abstract}




\section{Introduction}

Overweight adolescents are more likely to suffer from physical and mental health problems (Daniels, 2009) than normal weight adolescents, and are at risk of remaining overweight later in life (Singh et al., 2008). Overweight is the result of a positive energy balance, implying energy intake exceeding energy expenditure (Insel et al., 2011). At least in the United States, the contribution of energy-dense snack foods (e.g. potato chips, candy, and cookies) to the total daily energy intake among children increased from the seventies to recent years (Piernas \& Popkin, 2010). Although there is no conclusive evidence on its association with overweight (Johnson \& Anderson, 2010), the intake of particular energydense snack foods is related to other undesirable physical conditions, such as dental caries (Sheiham, 2001) and high blood pressure (He \& MacGregor, 2006). To develop effective intervention programs, we need to know how determinants relate to adolescents' energydense snack food intake.

Parents have crucial roles in their child's eating behavior and weight (Golan \& Crow, 2004). These roles are embodied in general parenting and in food parenting practices. General parenting refers to the emotional climate in which the child is raised (Baranowski et al., 2013a). Research into general parenting over the years has led to several approaches, including the identification of parenting factors or constructs (e.g. demandingness and responsiveness) and combinations of parenting factors constituting parenting styles (e.g. neglectful parenting: parents low in demandingness and responsiveness) (Power, 2013). Research into food specific parenting has quickly expanded from the year 2000 and in particular the Child Feeding Questionnaire (Birch et al., 2001) has been dominant. Food parenting practices (FPPs) are defined as behaviors or strategies employed by parents to alter their children's outcomes in the domain of nutrition (Darling \& Steinberg, 1993; Hughes et al., 2013) and include things such as making foods available, pressuring to eat, or setting rules about food (Gevers et al., 2014a).

General parenting and FPPs have been found to be related to children's eating behavior and body mass index (BMI) (Sleddens et al., 2011; Ventura \& Birch, 2008). An authoritative form of general parenting, implying responsive and nurturing parents that have clear expectations, regularly monitor their children, and set rules and boundaries which are consistently enforced, has been linked to healthier energy-balance related behaviors and lower BMI (Sleddens et al., 2011; Vollmer \& Mobley, 2013). Some FPPs (e.g. healthy 
modelling) have consistently been associated with favorable energy balance-related outcomes, while other FPPs (e.g. pressure to eat) have been associated with unfavorable outcomes. Studies toward other FPPs, such as restriction, have yielded more contradictory results (Ventura \& Birch, 2008). However, little research has been done to investigate paternal and maternal differences with regard to FPPs.

In their review, Sleddens et al. (2011) reported on the differential influences of fathers and mothers on weight-related child outcomes through their general parenting styles. Results with regard to the differential associations were inconclusive, although two studies similarly showed that children of authoritative mothers had more favorable scores on energy-balance related behavior while this relationship was absent for fathers (Lytle et al., 2003; Schmitz et al., 2002). Berge et al. (2010b) observed this same pattern in boys. Another study that separately analyzed fathers' and mothers' parenting style only found that fathers' responsiveness and possible permissiveness may be related to overweight in children (Taylor et al., 2011b).

The potential importance of fathers with regard to FPPs has just recently been recognized by Khandpur et al. (2014). They found considerable evidence of associations between fathers' FPPs and children's BMI. They also concluded that pressuring children to eat was employed more often by fathers than mothers, as did another two more recent studies (Lloyd et al., 2014; Pulley et al., 2014). Fathers are underrepresented in this field of research (Hughes et al., 2013) though, partly due to lower response rates among fathers compared to mothers (e.g. Hendy \&Williams, 2012) and researchers arguing that mothers are the primary caregivers, thereby neglecting the father's role (e.g. Hendricks et al., 2006). Although some studies did include both fathers' and mothers' general parenting or FPPs, most of them examined relationships between these factors and child outcomes in isolation (i.e. how fathers and mothers separately influence child outcomes such as eating disorders or dietary intake) (e.g. Berge et al., 2014; Haycraft \& Blissett, 2008; Lohaus et al., 2009; Loth et al., 2014). The interplay between paternal and maternal parenting may form an additional risk factor for the child's diet or BMI (Power, 2013). Some scales acknowledge these dynamics within families by addressing questionnaires separately to the two parents and aggregating the scores (e.g. Niermann et al., 2014). We are aware of only one study that examined the impact of parental interplay by studying the interaction of fathers' and mothers' parenting scores (Berge et al., 2010a). The authors of this study reported that 
families with authoritarian mothers and neglectful fathers had sons with a higher BMI. Additionally, inconsistency between paternal and maternal food parenting practices was found to be related to a higher BMI among daughters (Berge et al., 2010). Nevertheless, studies explicitly focusing on parenting congruence in explaining children's actual dietary intake are lacking.

To address the gaps with regard to the underrepresentation of fathers in the literature and the lack of research into parental interaction, we aimed to clarify the roles of the father, mother, and parenting congruence within parental dyads in explaining adolescents' snacking. Understanding these influences can aid intervention developers in constructing programs promoting healthy eating among adolescents. The current study examined five general parenting constructs and restrictive food rules, an FPP construct which has been associated with less soft-drink consumption by Dutch adolescents (de Bruijn et al., 2007; Ezendam et al., 2010; van der Horst et al., 2007) and less fat intake by Belgian boys (Haerens et al., 2008). We formulated the following research questions (Fig. 6.1): (i) Is there a difference between fathers and mothers in the general parenting they apply and the extent to which they use restrictive snacking rules? (ii) What are the associations between general parenting, restrictive snacking rules, and adolescents' snack intake? (pathways $A, B$, and $C$, separately for fathers and mothers) (iii) Does congruence between fathers and mothers on general parenting (pathway D) and restrictive snacking rules (pathway E) moderate the associations between the parenting constructs and adolescents' snacking? 


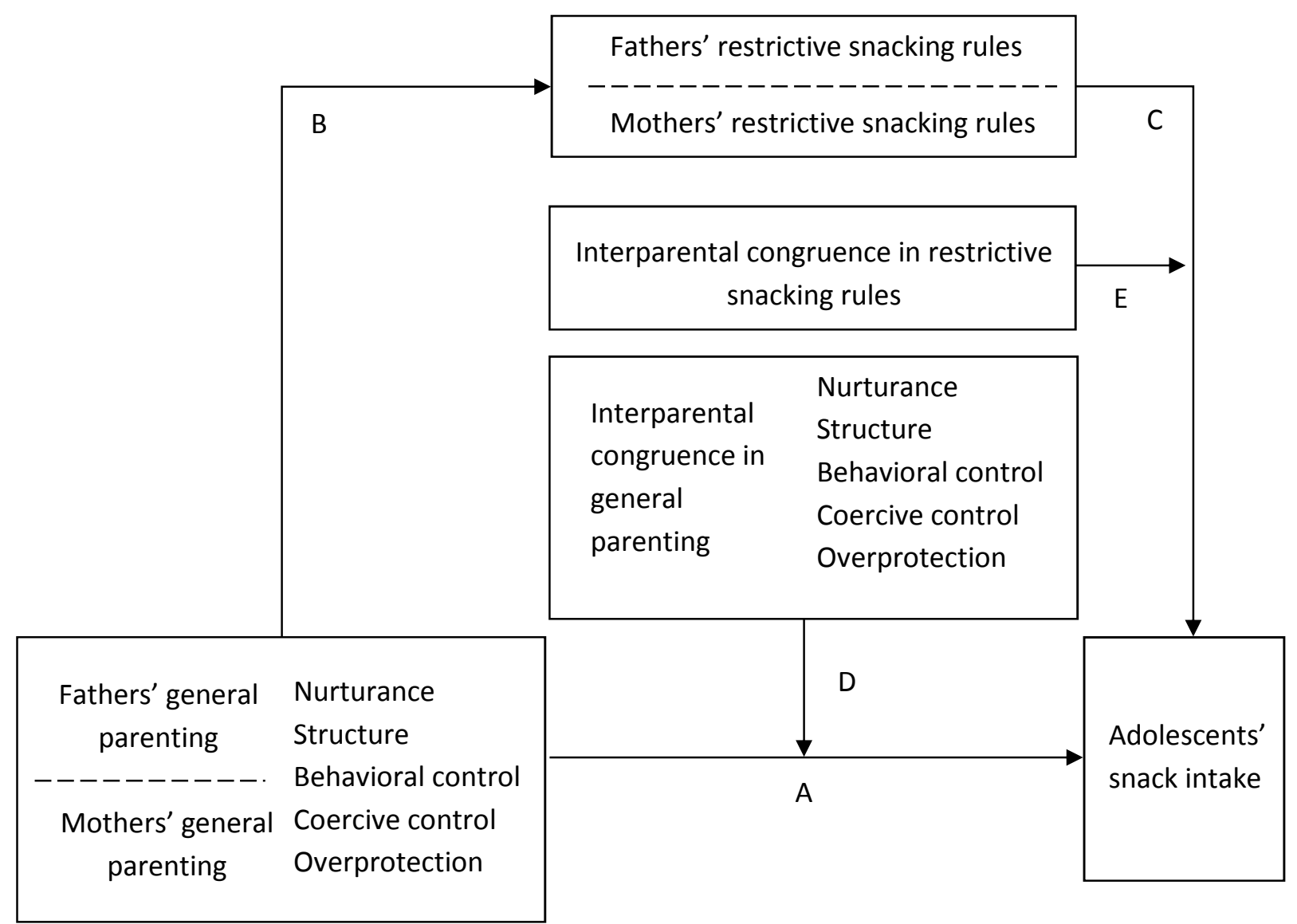

Figure 6.1: Model describing the relationships between general parenting, restrictive snacking rules, and parenting congruence

\section{Methods}

\section{Procedure and participants}

A convenience sample of six secondary schools in the southern part of the Netherlands was selected. These schools were invited to participate in this study to cover all educational levels (i.e. prevocational secondary education, senior general secondary education, and preuniversity education). Biology teachers were contacted by telephone and informed about the study. Additional information was sent by e-mail if teachers expressed an interest. All six schools agreed to participate but two were not able to arrange their participation. In total, four first-year classes and four second year classes of the four participating schools were visited by one researcher. The students were informed about the study, and asked to fill out a paper questionnaire immediately in the classroom in the presence of the researcher. Students were allowed to work on a school-related task if they did not want to participate. It 
took students between 15 and 45 minutes to complete the questionnaire, and none of them refused to participate. Participants did not receive any incentive for their participation and the study was exempt from ethical approval under Dutch law.

\section{Measures}

\section{General parenting}

General parenting was assessed using items of the validated Comprehensive General Parenting Questionnaire (CGPQ) (Sleddens et al., 2014). This questionnaire was developed for caregivers of 5- to 13-year-olds. A subsample of 51 items was selected from the original list of 85 items, based on the conceptual framework used to develop the original questionnaire and on their appropriateness for adolescents aged 12 to 14 years. The conceptual framework consisted of five general parenting constructs, with two to five subconstructs (17 sub-constructs in total). The shortened instrument was pretested among five adolescents from the target population by cognitive interviewing (Willis, 1999) which took place at the respondents' homes. The questionnaire was reviewed by two of the developers of the CGPQ (ES and SK) and the first author (DG) to assess its face validity and the wording of items. This led to adaptations in the instructions and adjustment of the phrasing of a few items. Five parenting constructs were assessed separately for father and mother: nurturance (e.g. 'My father/mother easily finds a way to make time for me'), structure (e.g. 'When my father/mother tells me that he/she will do something, he/she does it'), behavioral control (e.g. 'My father/mother expects me to follow our family rules'), coercive control (e.g. 'My father/mother does not allowme to question his/her decisions') and overprotection (e.g. 'My father/mother makes sure he/she knows exactly where I am at all times'). All items were assessed on a five-point scale ranging from completely disagree $(-2)$ to completely agree $(+2)$. The 17 sub-constructs were assessed with three items each. As a result of the weak psychometric properties of the general parenting constructs of structure and behavioral control in this study, two sub-constructs ('inconsistent discipline' and 'considering child input') were omitted from the analyses. The sub-construct of 'considering child input' was also omitted in another study among a Dutch sample of parents (Sleddens et al., 2014). Separate mean scores for fathers and mothers were calculated for each general parenting construct. The Cronbach's $\alpha$ values for each of the five parenting constructs in our sample ranged from 0.65 to 0.82 for fathers, and from 0.66 to 0.83 for mothers. Separate principal 
component analysis, forced to one factor, revealed mean factor loadings ranging from 0.42 to 0.62 for fathers and mean loadings ranging from 0.52 to 0.61 for mothers.

\section{Restrictive snacking rules}

Restrictive snacking rules were assessed by four items based on the parent-child control questionnaire by Cullen et al. (2001). This questionnaire had been adapted and used in earlier studies (de Bruijn et al., 2007; van der Horst et al., 2007) to assess rules about sugar sweetened beverages in Dutch samples. Four identical items for fathers and mothers assessed rules regarding snack consumption, i.e., 'As far as my father/mother is concerned, I can decide for myself when to consume snacks' (reversed coding), 'As far as my father/ mother is concerned, I can decide for myself how many snacks I am allowed to consume' (reversed coding), 'As far as my father/ mother is concerned, I am only allowed to consume snacks in the weekend', and 'My father/mother tells me which snacks I am allowed to consume'. All items were assessed on a five-point scale ranging from completely disagree $(-2)$ to completely agree $(+2)$. Restrictive food rule scores for fathers and mothers were created by calculating the mean score on the four items, with a higher score indicating more restrictive snacking rules. Cronbach's $\alpha$ values for this scale for fathers and mothers in our sample were 0.67 and 0.62 , respectively. Corrected item-total correlations (CITCs) for fathers and mothers were above 0.33 and 0.29 , respectively. Separate principal component analysis, forced to one factor, revealed factor loadings $>0.52$ for both the father's and mother's scale.

\section{Snack intake}

Two items to assess energy-dense snack food intake between meals were derived from a validated fat-intake questionnaire (Van Assema et al., 2001). Snacks products included all savory products, sweet products, cookies, cakes, ice creams, and fried snacks which are specifically intended to be consumed between meals. We first assessed on how many days a week snacks were usually consumed, with answering categories ranging from 0 to 7 days a week. We then assessed the number of energy-dense snacks by asking 'on a day that you eat snacks, how many snacks do you usually eat?', with answering categories ranging from one to eight or more. Examples of serving sizes that represent one snack were given. The average number of snacks per day was obtained by multiplying these two items and dividing the resulting number by seven. 


\section{Demographics and background variables}

The respondent's age, gender, and postal code were asked for. The postal code was recoded using a factor score for neighborhood socio-economic status (SES), ranging from -4 (high SES) to 4 (low SES) (SCP, 2006). The country of birth of each of the respondent's parents was asked for, and recoded into the variable 'ethnicity' in accordance with the definition of ethnicity used by Statistics Netherlands (i.e. immigrant status when having at least one parent born abroad) (Keij, 2002). Height and weight were asked for and BMI was calculated and transformed into a BMI z-score standardized for age and gender using a national reference population (Fredriks et al., 2000). These scores were categorized into underweight (i.e. <5th percentile BMI z < 1.64), normal weight (i.e. 5th-84th percentile BMI z = -1.641.04), and overweight (i.e. $\geq 85$ percentile $B M I ~ z>1.04$ ) (Barlow, 2007). Educational level was recorded for each class and split into low (i.e. pre-vocational secondary education) and high (i.e. senior general secondary education and pre-university education).

\section{Data analysis}

Respondents with invalid responses due to straight lining response patterns (i.e. selecting the same answer for a set of consecutive items), with more than one missing value on a general parenting sub-construct, or on a restrictive snacking rules construct, or who had filled out the questionnaire for one parent only were excluded from all analyses $(n=91)$.

A maximum of $5.2 \%$ of the respondents had one missing value on one of the general parenting sub-constructs, and no more than $0.9 \%$ had one missing value on one of the restrictive snacking rules constructs. These missing values were imputed by the scale mean at individual level. A multiple logistic regression analysis using the Enter method was conducted to determine whether included and excluded respondents differed in terms of gender, SES, educational level, ethnicity, BMI z-score, and snack intake. Differences between fathers and mothers regarding their general parenting and restrictive snacking rules were determined by conducting dependent-means t-tests.

Associations between the general parenting constructs, restrictive snacking rules, and respondents' snack intake were investigated by computing partial correlations separately for fathers and mothers. The partial correlations were adjusted for potential confounders, viz. the respondent's gender, BMI z-score, and educational level. 
Congruence scores were calculated by subtracting the father's score from the mother's score on the construct of interest and taking the absolute value of this difference. We calculated the distance from full congruence (congruence score $=0$ ) in standard deviation units for each construct, in order to indicate its relative congruence. The question whether congruence between fathers and mothers on the general parenting constructs or restrictive snacking rules moderated the associations between parenting constructs and respondents' snack intake was investigated using regression analyses with interaction terms between the parenting constructs (i.e. general parenting constructs or restrictive snacking rules) and the congruence score. The regression analyses included the respondents' snack intake as a dependent variable, while the independent variables included the respondent's gender, BMI z-score, educational level, the parenting construct of interest, the congruence score of the construct of interest and the corresponding interaction term (i.e. snack intake = $\beta 0+\beta 1$ gender $+\beta 2$ BMI-z score $+\beta 3$ educational level $+\beta 4$ parenting construct $i+\beta 5$ congruence score $i+\beta 6$ parenting construct $i \times$ congruence score $i+\varepsilon)$. If the interactions had p-values <0.10 (Rosnow \& Rosenthal, 1989), stratified analyses were conducted by creating four groups for each moderator (ranging from parent's showing full congruence [congruence score $=0$ ] to highly incongruent parents [highest tertile of parents not showing full congruence] on the congruence score for the parenting construct of interest).

All analyses were performed using IBM SPSS Statistics 20, and p-values $<0.05$ were considered to be significant, except for the interaction terms. 
Table 6.1: Sample characteristics ( $N=329)$

\begin{tabular}{lll}
\hline & $\mathbf{N}$ & Mean (SD) or \% \\
\hline Mean age, years (SD) & 329 & $13.21(0.8)$ \\
Age in years (\%) & 329 & \\
11 & 1 & 0.3 \\
12 & 52 & 15.8 \\
13 & 161 & 48.9 \\
14 & 106 & 32.2 \\
15 & 9 & 2.7 \\
Gender (\%) & 328 & \\
Male & 164 & 50.0 \\
Female & 164 & 50.0 \\
Education (\%) & & \\
Low & 212 & 64.4 \\
High & 117 & 35.6 \\
Ethnicity (\%) & 327 & \\
Native Dutch & 309 & 94.5 \\
Immigrant & 18 & 5.5 \\
Mean SES score (SD) (-4; 4) & 315 & $-0.1(0.5)$ \\
Mean BMI z-score (SD) & 298 & $-0.5(1.1)$ \\
BMI groups (\%) & & \\
Underweight & 39 & 13.1 \\
Normal weight & 236 & 79.2 \\
Overweight (including obese) & 23 & 7.7 \\
Mean snack intake per day (SD) & 323 & $1.71(1.32)$ \\
\hline
\end{tabular}

\section{Results}

In total, 329 students were eligible for analysis. There were no significant differences between the included and excluded respondents regarding SES, educational level, ethnicity, BMI z-score and snack intake, but more boys were excluded from analyses, compared to girls (OR $=0.50,95 \% \mathrm{Cl}=0.27-0.91, \mathrm{p}$-value $=0.02)$.

The mean age of the students was 13.2 (SD $=0.8$ ) years (Table 6.1). Boys and girls were equally represented and most students were attending a lower form of education (64.4\%). Native Dutch adolescents (94.5\%) were overrepresented and overweight adolescents were slightly underrepresented compared to the general Dutch population (Statistics Netherlands, 2014; Schönbeck et al., 2011). The mean SES score was close to the national mean (SCP, 2015). The mean snack intake was about $1.7(S D=1.3$ ) snacks a day. 
Differences between parents regarding general parenting and restrictive snacking rules, and interparental congruence

The scores for the mothers were significantly higher than the scores for the fathers on all constructs ( $p$-values < 0.01), except for coercive control (Table 6.2). The highest incongruence was found for

structure, while the highest congruence was found for coercive control. The mean parental congruence score for restrictive snacking rules was 0.24 (SD =0.35). The SD units distance from full congruence was highest for structure, indicating the highest relative incongruence between parents for this construct, compared to the congruence scores for all other constructs.

Table 6.2: Mean scores (SD) for study variables and results of the dependent-means t-tests ( $n=329$ )

\begin{tabular}{|c|c|c|c|c|c|}
\hline Parenting constructs & Mean (SD) & Mean (SD) & $P$-value & $\begin{array}{l}\text { Con- } \\
\text { gruence } \\
\text { score }^{a} \\
\text { Mean (SD) }\end{array}$ & $\begin{array}{l}\text { SD units } \\
\text { distance from } \\
\text { full congruence } \\
\text { SD }\end{array}$ \\
\hline \multicolumn{6}{|l|}{$\begin{array}{l}\text { General parenting } \\
\text { constructs: }\end{array}$} \\
\hline Nurturance & $0.79(0.62)$ & $0.94(0.60)$ & $<0.01$ & $0.28(0.36)$ & 0.77 \\
\hline Structure & $0.48(0.63)$ & $0.73(0.59)$ & $<0.01$ & $0.34(0.43)$ & 0.80 \\
\hline Behavioral control & $0.30(0.57)$ & $0.41(0.58)$ & $<0.01$ & $0.22(0.29)$ & 0.75 \\
\hline Coercive control & $-0.81(0.61)$ & $-0.84(0.58)$ & 0.19 & $0.19(0.31)$ & 0.64 \\
\hline Overprotection & $0.09(0.71)$ & $0.31(0.70)$ & $<0.01$ & $0.32(0.41)$ & 0.78 \\
\hline \multicolumn{6}{|l|}{ FPP construct: } \\
\hline $\begin{array}{l}\text { Restrictive } \\
\text { snacking rules }\end{array}$ & $-0.57(0.77)$ & $-0.44(0.74)$ & $<0.01$ & $0.24(0.35)$ & 0.67 \\
\hline
\end{tabular}

Note: a Lower scores reflect more parental congruence, with score 0 indicating full congruence.

\section{Associations between general parenting, restrictive snacking rules, and adolescent's snack intake}

For both fathers and mothers in general, all general parenting constructs were positively related to restrictive snacking rules ( $p$-values $<0.01$ ), although this relationship was not statistically significant for coercive control (Table 6.3). Additionally, the association of nurturance with restrictive snacking rules was not statistically significant for fathers. Structure was significantly and negatively related to the respondents' number of snacks consumed; this was true for both fathers ( $p$-value $<0.05$ ) and mothers ( $p$-value $<0.05$ ). 
Mothers' coercive control was significantly and positively related to the respondents' number of snacks consumed ( $p$-value $<0.05$ ), while this relation was not found for fathers. The use of restrictive snacking rules by both fathers ( $p$-values $<0.01)$ and mothers $(p$-values $<0.01)$ was significantly and negatively related to the respondents' number of snacks consumed.

Table 6.3: Partial correlations between father's and mother's general parenting constructs, restrictive snacking rules and adolescent's snack intake $(n=329)$

\begin{tabular}{|c|c|c|c|c|}
\hline \multirow[b]{2}{*}{ Parenting constructs } & \multicolumn{2}{|l|}{ Father } & \multicolumn{2}{|l|}{ Mother } \\
\hline & $\begin{array}{l}\text { Restrictive } \\
\text { snacking } \\
\text { rules }\end{array}$ & $\begin{array}{l}\text { Adolescents' } \\
\text { snack intake }\end{array}$ & $\begin{array}{l}\text { Restrictive } \\
\text { snacking rules }\end{array}$ & $\begin{array}{l}\text { Adolescents' } \\
\text { snack intake }\end{array}$ \\
\hline \multicolumn{5}{|c|}{ General parenting constructs: } \\
\hline Nurturance & 0.10 & -0.07 & $0.16^{* *}$ & - 0.10 \\
\hline Structure & $0.17 * *$ & $-0.12^{*}$ & $0.21 * *$ & $-0.14^{*}$ \\
\hline Behavioral control & $0.28 * *$ & -0.08 & $0.34 * *$ & - 0.09 \\
\hline Coercive control & 0.10 & 0.09 & 0.06 & $0.12 *$ \\
\hline Overprotection & $0.16 * *$ & -0.10 & $0.21 * *$ & - 0.10 \\
\hline \multicolumn{5}{|l|}{ FPP construct: } \\
\hline Restrictive snacking rules & & $-0.25^{* *}$ & & $-0.23 * *$ \\
\hline
\end{tabular}

\section{Moderating role of parenting congruence}

The interaction terms of the congruence score with fathers' nurturance ( $p$-value $=0.06$ ), overprotection $(p$-value $=0.04)$, and restrictive practices $(p$-value $=0.07)$ were significant. Stratified analyses were run with four groups in order to understand the nature of the interaction: (1) fully congruent, (2) nearly congruent, (3) somewhat incongruent, and (4) highly incongruent.

Stratified analyses revealed the strongest negative association between overprotection and snacking in children that were living in families with some incongruence ( $\beta=-0.17, p=0.17$ ), while the negative association was almost absent in fully congruent families $(\beta=-0.08 p=0.41)$. In addition, stratified analyses revealed no association between paternal nurturance and snacking in the most incongruent families $(\beta=0.00 p=0.99)$, while the strongest favorable association between paternal nurturance and snacking was found in the families with some incongruence $(\beta=-0.24, p=0.07)$. 
A similar pattern was found with respect to restrictive rules. The association of the fathers' restrictive snacking rules was least favorable among families with parents that were most incongruent with respect to these rules $(\beta=-0.09, p=0.60)$, while the negative association between restriction and snacking was strongest among children of parents that were somewhat incongruent $(\beta=-0.45, p=0.01)$.

\section{Discussion}

The present study used a questionnaire survey among adolescents to investigate differences between fathers and mothers regarding perceived general parenting and restrictive snacking rules, as well as the associations for fathers and mothers between general parenting, restrictive snacking rules, and adolescents' snack intake, and the role of interparental congruence regarding parenting.

Scores for mothers were higher on four out of five general parenting constructs and restrictive snacking rules than scores for fathers. This finding might indicate that adolescents perceive their mother's role to be more prominent than their father's role. Blissett and Haycraft (2008) tested differences in general parenting between fathers and mothers and found that mothers were slightly more authoritative than fathers, which is in line with our findings. Our finding that fathers employed less restrictive snacking rules than mothers is consistent with the observation by Hendy et al. (2009) that fathers were less likely to report setting snack limits. Other studies did not observe differences in restriction or limit setting between mothers and fathers, or even found that mothers employ less restriction or limit setting (Blissett et al., 2006; Brann \& Skinner, 2005; Haycraft \& Blissett, 2008; Lloyd et al., 2014; Loth et al., 2013; Tschann et al., 2013). These inconsistencies between findings might originate from differences in the FPP constructs being measured (Vaughn et al., 2013) or differences in the persons being questioned (i.e. parent report or child report) (Taylor et al., 2011a; van Assema et al., 2007).

All associations between the general parenting constructs, restrictive snacking rules, and adolescents' snack intake were in the same direction for fathers and mothers, except for the association between overprotection and adolescents' snacking. A study which included the CGPQ also reported positive associations between all five general parenting constructs and the parental control over food (Sleddens et al., 2014). As regards associations between general parenting and adolescents' snack intake, Sleddens et al. (2011) concluded in their 
review that snacking was not correlated to most general parenting factors. In the current study, negative associations were found between snacking and the scores on the structure construct for both fathers and mothers, and a positive association between maternal coercive control and snacking. The strengths of these associations were small, but the directions were in accordance with theory (Sleddens et al., 2014). Restrictive snacking rules were negatively associated with snack intake among adolescents, which is consistent with previous research assessing an analogous construct (de Bruijn et al., 2007; Ezendam et al., 2010; Haerens et al., 2008; van der Horst et al., 2007). The associations we found between general parenting and adolescents' snacking were smaller than associations between restrictive snacking rules and adolescents' snacking, which parallels theories assuming that FPPs are more proximal to child's outcomes than general parenting (Kremers et al., 2013).

Incongruence between parents was not very large in the current sample. This low level of incongruence may be explained by the method of measurement, as questions for fathers and mothers were to be filled out in separate columns next to each other. Adolescents might have become less conscientious, thereby ticking the same boxes for both parents. As a result, the strength of incongruence could be underestimated. Additionally, congruence between parents in traditional families might be stronger than in non-traditional families (e.g. families with grandparents living in the same house, stepparents, divorced parents) and the interaction between these caregivers may be pronounced more clearly (Patrick et al., 2013). Our study only included respondents who completed the questionnaire for their biological parents but we had no information on the marital status or living situation of parents. With regard to congruence, we expect the living situation of both parents to be more influential than marital status, but there are no figures available about the family situation in the current population.

Still, we found that large incongruence regarding restrictive snacking rules unfavorably affected the negative association between the use of these rules by fathers and adolescents' snacking. Thus, restrictive rules may help to prevent snacking behavior in children, but only when both parents apply rules with similar levels of restrictiveness. Paternal scores on restrictive snacking rules showed greater variation than maternal scores regarding this construct, probably explaining the absence of an interaction between mothers' restrictive snacking rules and the congruence score. It is likely that the weak associations between general parenting constructs and snacking made it difficult to clearly 
establish the interaction between congruence and general parenting. We did find, however, that large incongruence regarding nurturance unfavorably affected the association between father's nurturance and snacking. Nurturance may thus only be a protective factor for a child when both parents are nurturing. The biggest differences were not discovered between the fully congruent and highly incongruent groups, which might relate to the method of measurement quoted previously: part of the children in the fully congruent groups could be the ones that underreport their snack intake. Nevertheless, subgroup differences were in the expected direction. The findings concerning incongruence about overprotection are less clear to interpret. Especially since the main effect of overprotection on snack intake was counterintuitive, we feel hesitant in inferring strong conclusions regarding the moderating role of incongruence with respect to this factor. A great number of explanations for this finding are possible and we opt for more research on this factor.

If replicated, our findings indicate that it would be useful for health promotion practitioners to consider enhancing congruence regarding parenting. Additional research could establish which families are at high risk for incongruence. Parents act in a system (Kremers et al., 2013), as also our study points out. Therefore, it is not possible to disentangle the isolated effects of fathers and mothers. Still, program developers should also take into account the comparable strengths of the associations for fathers and mothers between parenting constructs and adolescents' snacking, which suggest that fathers are of equal importance in influencing adolescent snack intake as mothers. Therefore, both fathers and mothers need to be included in programs aimed at promoting healthy eating among children.

A strong point of the current study is its attempt to capture parental congruence. In more general terms, the current study contributes to the small number of studies incorporating tests of moderation between environmental influences in the examination of their impact on child dietary intake (see debate paper of Gubbels et al.,, 2014). It used an innovative approach to explain adolescent's diet by exploring congruence between fathers and mothers. Because we omitted respondents with straight lining response patterns, invalid responses were disregarded and we likely drew more credible conclusions than we would have obtained from the total sample. Compared to other studies, social desirability might be less of a concern to the current study, because child measures are less likely to trigger social desirable answers on parenting measures (Taylor et al., 2011a; van Assema et al., 2007). 
Researchers need to be aware that study results could be different if parents are proxy respondents.

Some limitations need to be considered when interpreting the results of this study. The validity of the CGPQ and the restrictive snacking rules scale were not extensively tested in our research design, but we found satisfactory reliability coefficients (i.e. Cronbach's alpha coefficients, (Portney \& Watkins, 2000) and CITCs (Nunnally \& Bernstein, 1994)) and acceptable factor loadings (Comrey \& Lee, 1992). Furthermore, two previous studies in adolescent samples in the Netherlands indicated the restrictive items to be reliable as well (de Bruijn et al., 2007; van der Horst et al., 2007). With regard to the weight data, underreporting was probably present in the current study as the number of overweight children was lower than national figures, which were derived from objective measures. This underestimation of overweight in self-reported data is confirmed in a review of other studies (Sherry et al., 2007) and should be considered when interpreting the results. Additionally, data were cross-sectional, which hinders the possibility to make causal inferences. Another limitation was the inclusion of a single FPP construct. Including a broader range of FPP constructs (Gevers et al., 2014a) would have generated a better understanding of the roles played by the father, the mother, and the parenting congruence in their children's snack intake. Generalizability is limited by the lack of information about the living situation and the low number of immigrants, particularly because parenting is likely to differ among ethnic groups (Kocken et al., 2012), and the higher number of boys excluded from our analyses. Finally, our sample size made it difficult to properly examine higher-order moderation (i.e. general parenting altering the impact of FPPs). Researchers might explore the moderating role of congruence within the conceptual model that assumes an interaction between general parenting and FPPs (i.e. explore a three-way interaction) (Kremers et al., 2013). Previous research has found, for example, that the favorable impact of restrictive rules on child's soft drink intake was the strongest in families high in nurturance (van der Horst et al., 2007). We could hypothesize that this model is accurate only among parents who are congruent on either one (i.e. nurturance or restrictive rules) or both factors (i.e. nurturance and restrictive rules). Considering this higher order moderation and our finding with regard to the absence of interactions in mothers, more research is needed to determine the significance of interparental congruence. Studies using longitudinal or experimental designs would be particularly helpful to adequately acquire high levels of scientific evidence. Finally, 
research on factors underlying fathers' FPPs is scarce (e.g. Haycraft \& Blissett, 2012; Mallan et al., 2014), but essential with respect to the development of interventions.

\section{Conclusion}

The current study indicates that general parenting and restrictive snacking rules help to explain adolescents' snacking behavior. Mothers generally had higher scores than fathers on parenting constructs, but incongruence between parental dyads was not very large. Nevertheless, we found that high levels of incongruence between parents attenuated the favorable impact of fathers' rules and nurturance on their children's snacking. Our results, if replicated across cultures and countries, may indicate that program developers should consider involving fathers and enhancing parenting congruence when developing interventions. 


\section{Chapter 7}

Explaining food parenting practices: the importance of predisposing factors and parental cognitions

This chapter has been submitted as: Gevers, D.W.M., van Assema, P., de Vries N.K., Kremers, S.P.J. Explaining food parenting practices: the importance of predisposing factors and parental cognitions. 


\section{Abstract}

Background: The high caloric intake from energy-dense foods among children in developed countries is undesirable. Improving food parenting practices has the potential to lower snack intakes among children. To inform the development of interventions, we aimed to predict food parenting practice patterns around snacking (i.e. "high covert control and rewarding", "low covert control and non-rewarding", "high involvement and supportive", and "low involvement and indulgent").

Methods: A sample of Dutch parents of children aged 4-12 was recruited to fill out a questionnaire. To predict the patterns of food parenting practices, multinomial logistic regression analyses were run $(n=888)$. Predictors included predisposing factors (i.e. demographics, personality, general parenting, and parenting practices used by own parents) and parental cognitions (i.e. perceived behavior of other parents, subjective norms, attitudes, self-efficacy, and outcome expectations).

Results: After backward elimination, nineteen factors had a statistically significant contribution to the model (Nagelkerke $R^{2}=0.63$ ). Overall, self-efficacy and outcome expectations were among the strongest explanatory factors. With regard to the predisposing factors only, the general parenting factor nurturance most strongly predicted the food parenting clusters. Nurturance particularly distinguished highly involved parents from parents employing a pattern of low involvement.

Conclusions: Parental cognitions and nurturance are important factors to explain food parenting practices around snacking. The results suggest that intervention developers should attempt to increase self-efficacy and educate parents about what constitute effective and ineffective parenting practices, while promoting nurturance might be a prerequisite to improve parenting practices. 


\section{Background}

The high caloric intake from energy-dense foods among children in developed countries (e.g. Bell et al., 2005; Gevers et al., 2015a; Piernas \& Popkin, 2010) is undesirable as such foods tend to be of little nutritional value and are superfluous to a healthy diet (WHO, 2003). Several studies suggest that snacking has increased the last few decades, thereby contributing to excessive energy intakes (Adair \& Popkin, 2005; Duffey et al., 2014; Larson \& Story, 2013; Wang et al., 2012). It is important to invert this trend and establish healthy dietary patterns in childhood. There is evidence to indicate that their dietary behaviors (Craigie et al., 2011) and overweight (Singh et al., 2008) track into adulthood. Parents can have a significant impact on their children's food consumption through their food specific parenting practices (Gerards \& Kremers, 2015) (i.e. behaviors used to shape a child's diet, such as restricting children's access to snack foods or modeling healthy food intake (Gevers et al., 2014a)). Recently, we demonstrated that, based on a cluster analytic approach, four categories of Dutch parents could be distinguished when it comes to food parenting practices (FPPs) around snacking (Gevers et al., 2015b) (see box 7.1). Children of high involved and supportive parents had lower energy-dense snack food (EDSF) intakes compared to children of parents employing any of the other three patterns. Therefore, parental involvement in children's diets and supportive parenting practices should be promoted.

From an intervention mapping perspective (Bartholomew et al., 2011), intervention developers aiming at improving parenting practices should know the determinants of behavior and, subsequently, fit theoretical methods and practical strategies in order to evoke maximal behavioral change. Therefore, research on the precursors of parenting practices is essential. So far, research has mainly linked demographic factors with FPPs. Another potential precursor includes the general parenting style of parents: several researchers have tested the hypothesis that parenting practices, although they are domain specific (e.g. food or physical activity), find their origin in general parenting (Collins et al., 2014). Personality serves as a guiding principle of a person's behavior (Ajzen, 2005; Flay \& Petraitis, 1994). Consequently, personality might be reflected in general parenting (Belsky, 1984) and also relate to parenting practices. Probably, the use of parenting practices also traces back to childhood experiences, and is linked with practices used by one's own parents (i.e. the practices imposed during the parent's own childhood). This hypothesis is supported 
by qualitative research (Mena et al., 2015) and parallels Belsky's theory on determinants of general parenting (Belsky, 1984). Besides the more distal factors such as general parenting and personality, other potential, more proximal, precursors of parenting practices include the ones as specified by socio-cognitive theories of health behavior. For instance, the Social Cognitive Theory (SCT) (Bandura, 1986) stresses the importance of outcome expectations as well as modelling in shaping behavior. For instance, parents might favor certain practices by considering their expected effectiveness (i.e. outcome expectations) or by considering practices used by other parents (i.e. vicarious learning or modeling). Self-efficacy is another core concept of the SCT and should be considered here as well, in view of evidence indicating that parents of obese children had less confidence in managing children's energybalance related behaviors (Morawska \& West, 2013). In addition to modeling, another form of social influence, subjective norms (Fishbein \& Ajzen, 1975) might be important too. It reflects the degree to which parents find that most people, who are important to them, think they should employ particular parenting practices. Finally, parents' attitude towards child's snacking more in general is expected to determine the type of practices used. Two sets of determinants formed our research framework: predisposing factors and parental cognitions (figure 7.1). The present manuscript reports on the relative importance of both sets of determinants in explaining a parent's pattern of FPPs and describes the contribution of each single factor to the exploratory model.

Box 7.1: Four patterns of food parenting practices around snacking (outcome variable)

\begin{tabular}{|ll|}
\hline Pattern: & $\begin{array}{l}\text { Food Parenting Practices that particularly characterize } \\
\text { the pattern: }\end{array}$ \\
"high covert control and rewarding" & $\begin{array}{l}\text { Low availability and accessibility of snack foods, } \\
\text { avoidance of unhealthy modeling, high use of } \\
\text { instrumental-and emotional feeding } \\
\text { "low covert control and non-rewarding" } \\
\text { High availability and accessibility of snack foods, low } \\
\text { avoidance of unhealthy modeling, low use of } \\
\text { instrumental-and emotional feeding } \\
\text { "high involvement and supportive" } \\
\text { encouragement and involving, being a healthy role } \\
\text { model, providing an healthy food environment, setting } \\
\text { rules, low use of instrumental-and emotional feeding } \\
\text { Low use of responsive parenting practices such as } \\
\text { encouragement and involving, not being a healthy role } \\
\text { model, having an unhealthy food environment, } \\
\text { permissive, low use of instrumental- and emotional } \\
\text { feeding }\end{array}$ \\
\hline
\end{tabular}




\section{Methods}

\section{Study design, setting, and participants}

The full study design has been described elsewhere (Gevers et al., 2015b). In sum, 1985 parents of 4 to 12 year old children were recruited by a research agency (i.e. Flycatcher Internet Research) and invited to fill out an online questionnaire. Participants received credit points for participation which could be exchanged for gifts: completion of the current study yielded approximately 5.56 Euros. Considering the "Dutch Medical Research Involving Human Subjects Act" (CCMO, 2015), the study was exempt from ethical review.

Predisposing factors

- Demographics and BMI

- Personality

- General Parenting

- Food parenting practices used by own parents

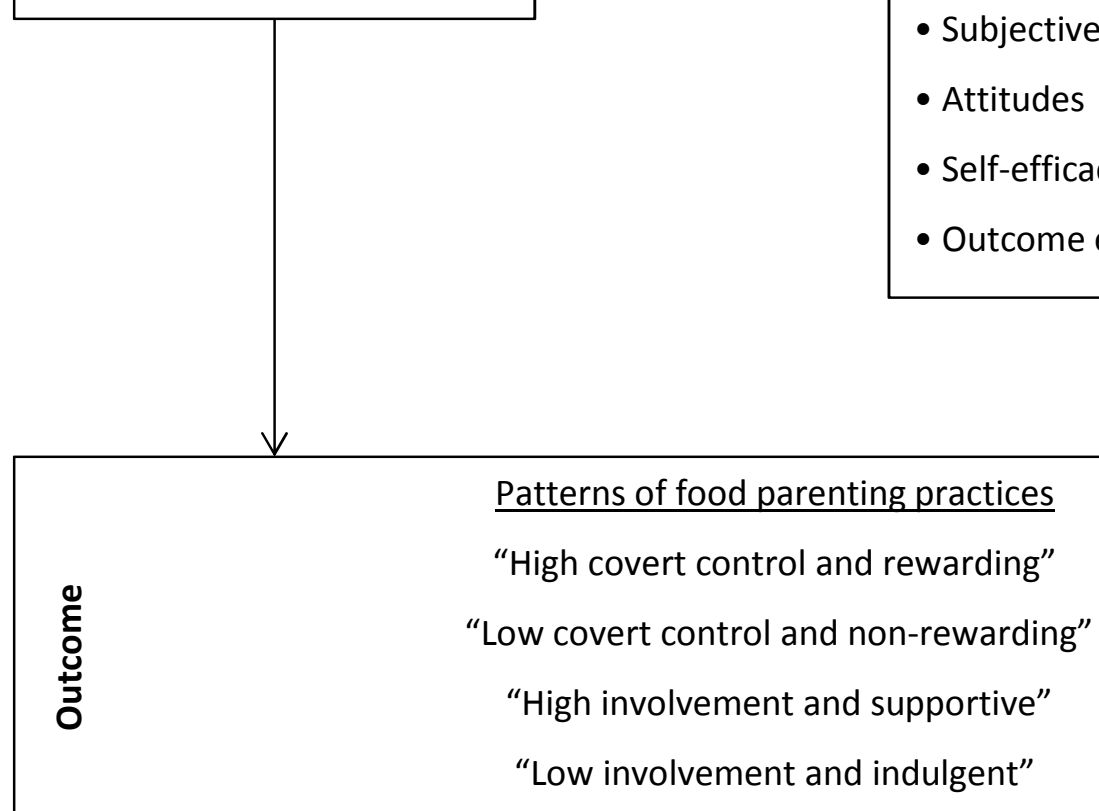

$\underline{\text { Parental cognitions }}$

- Perceived behavior of other parents

- Subjective norms

- Attitudes

Self-efficacy

Outcome expectations

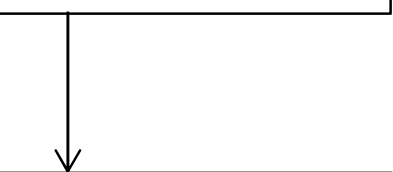

Figure 7.1: Theoretical framework used to predict patterns of food parenting practices around snacking

\section{Outcome variable}

The outcome variable was the type of FPP pattern. These patterns were derived from a cluster analysis on 21 FPPs around snacking (Gevers et al., 2015b), including the following 
constructs: encouragement, rewarding, discussing, providing feedback, involving, educating, healthy modeling, unhealthy modeling avoidance, availability of healthy foods, accessibility of healthy foods, visibility of healthy foods, limited availability of unhealthy foods, limited accessibility of unhealthy foods, structure, meal routines, permissiveness, rules, monitoring, instrumental feeding, emotional feeding, and pressure to eat. Four distinct patterns were derived (see box 7.1), which were stable according to a cross-validation procedure (i.e. Cohen's kappa of 0.97) and characterized as indicated in box 7.1 (Gevers et al., 2015b).

\section{Measures}

\section{Predisposing factors}

Respondents were asked to report their own age, gender, work status, postal code (to calculate a factor score for their socio-economic position (SEP; -4=low; 4=high (SCP, 2015), body height and weight (to calculate parental body mass index; BMI), and their child's age, gender, and body height and weight (to calculate BMI-z using a reference population (Fredriks et al., 2000)). The respondents' educational level and ethnicity were known to the research agency. For measuring the personality dimensions of extraversion, conscientiousness, agreeableness, emotional stability, and openness to experience, the Dutch 30-item "Quick Big Five" (QBF) questionnaire (Gerris et al., 1998) was used. Parents were asked to rate personality traits on a seven-point Likert scale. Cronbach's alphas of the five personality dimension within the current sample were all above 0.84 . General parenting was assessed using 32 items from the validated Comprehensive Parenting General Parenting Questionnaire (CGPQ) (Sleddens et al., 2014) on a five-point Likert scale, ranging from 1 (strongly disagree) to 5 (strongly agree). Five general parenting constructs were measured, including nurturance, structure, behavioral control, coercive control, and overprotection. Each of these five general parenting constructs consisted of two to four sub constructs, of which "physical punishment" (a sub construct of coercive control) was not included in the current study. One item within structure (i.e. "I teach my child to keep his/her bedroom clean and orderly") and two items within behavioral control (i.e. "I make sure I give my child lots of freedom to make mistakes and learn from them" and "I give my child a lot of freedom to make up his/her own mind") were dropped as a result of low corrected item total correlations (CITCS). The Cronbach's alphas of the five general parenting factors ranged from 0.59 to 0.76 . As an indicator of "practices used by own parents", participants were asked to 
indicate to what extent their own parents used to employ the 21 FPPs which were used to cluster parents into the four groups. The items were formulated as follows: "My own parents (caregivers) used to... when I was a child" and had to be answered on a five-point Likert scale ranging from 1 (strongly disagree) to 5 (strongly agree) and a possibility answer "I don't know". Exploratory factor analyses (i.e. Principal Component Analysis; PCA) using oblique rotation were performed to derive factors and create scales using mean scores from the items because they were expected to be multi-dimensional. "I don't know" answers were recoded to the middle value $(=3)$. Eigenvalues $>1.0$ was used as a criterion to retain factors. Items were dropped for PCA if factor loadings were $<0.40$ or showed cross-loadings. PCA resulted in five factors referring to parenting practices used by own parents, with moderate to good Cronbach's alphas expect for one (i.e. the scale "pressure to eat and rewarding"). Example items, reliability statistics, and factors loadings of the scales used to predict parenting practices are presented in table 7.1. 


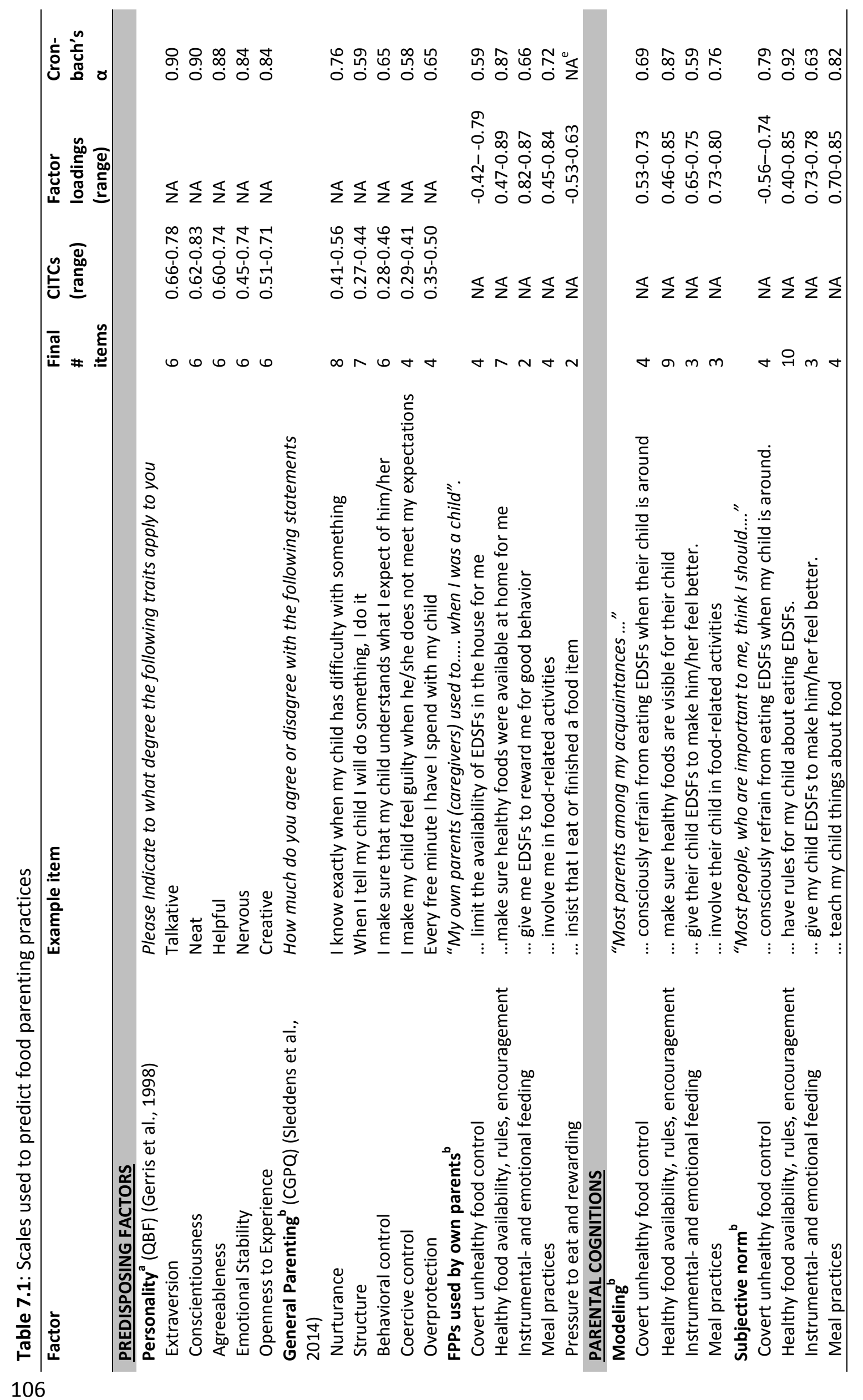




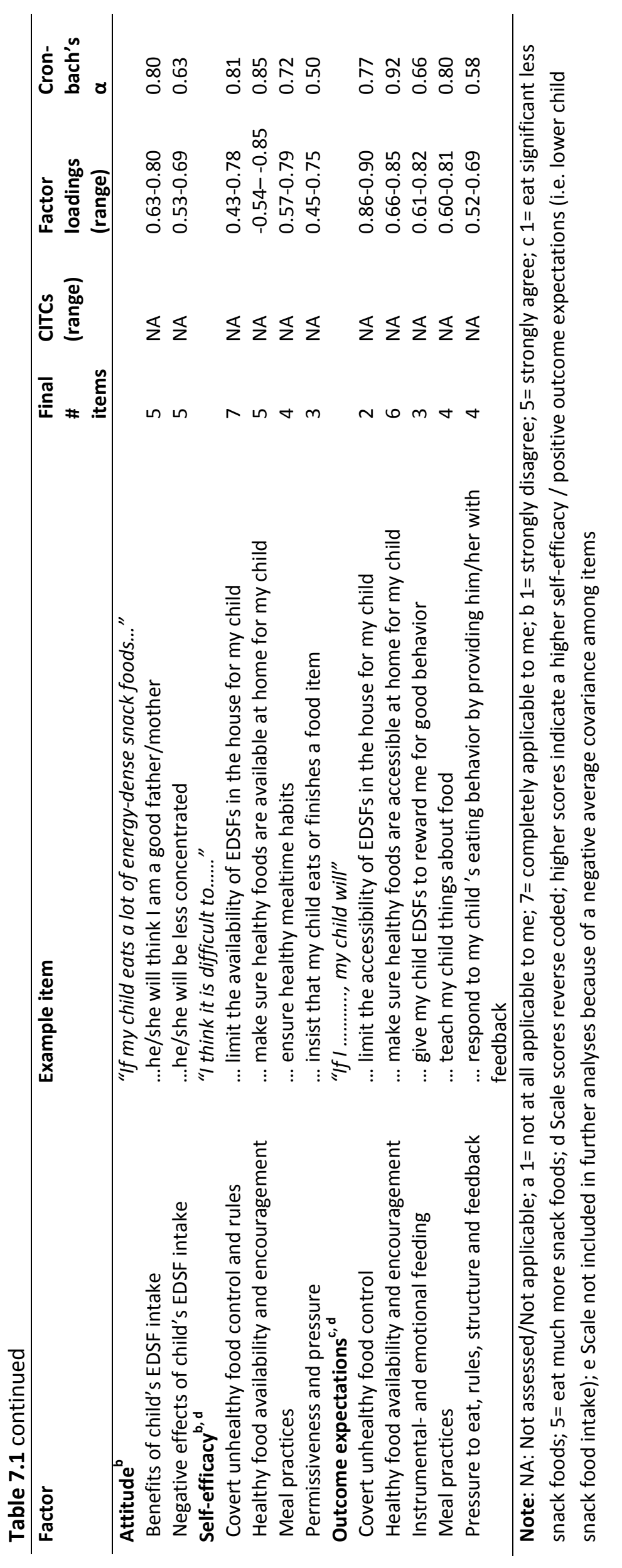




\section{Parental cognitions}

Items used to measure social influences (i.e. perceived behavior of other parents, subjective norm) also referred to the 21 individual FPPs around snacking and entered a PCA in a similar fashion. "Perceived behavior of other parents" was assessed using the question: "Most parents......" followed by the 21 individual FPPs. "Subjective norms" were assessed using items starting with: "Most people, who are important to me, think I should......". All questions were accompanied with a five-point Likert scale ranging from 1 (strongly disagree) to 5 (strongly agree) and a possibility to answer "I don't know".

Qualitative interviews with fifteen parents from the target population informed the development of the attitude items. Two sets of five items were formulated to assess parents' attitude towards benefits (Cronbach's $\alpha=0.80$ ) and negative effects (Cronbach's $\alpha=0.63$ ) of a high snack intake by their child. Attitude items were rated on a five-point Likertscale ranging from strongly disagree to strongly agree and loaded on two factors, thereby confirming the attitude dichotomy. In line with items used to measures social influences (i.e. perceived behavior of other parents, subjective norm), self-efficacy and outcome expectations items referred to the 21 FPPs and entered the PCA. Self-efficacy items started with the following phrase: "I think it is difficult to......" and was also rated on a five-point Likert scale ranging from strongly disagree to strongly agree. Because self-efficacy tends to be of minor importance with regard to instrumental- and emotional feeding, we decided not to measure self-efficacy for both constructs. Outcome expectations were assessed using the statement "If I ......, my child will" and a five-point scale ranging from 1 (eat far less snack foods) to 5 (eat a lot more snack foods). Four self-efficacy factors (Cronbach's alphas ranging from 0.50-0.81) and five outcome expectation factors (Cronbach's alphas ranging from 0.580.71) were derived. Self-efficacy and outcome expectations were reverse recoded so that higher scores indicate a higher self-efficacy and positive outcome expectations (i.e. lower child snack food intake), respectively.

\section{Statistical analysis}

To diagnose multicollinearity, correlations between predictor variables were explored and variance inflation factors (VIFs) were calculated through a linear regression analysis with all predictors as independent variables. A cut-off value of $>0.8$ for correlations (Field, 2013) and $>10$ for VIFs (Myers, 1990) was applied for multicollinearity. To predict the patterns of FPPs, 
multinomial logistic regression analyses were run using the "high involvement and supportive" pattern as the reference category. Each predictor was tested individually and in a total model by using backward elimination. Subsequently, significant predictors in the final model were entered into two separate multinomial logistic regressions (i.e. one including predisposing factors and one including parental cognitions) to investigate the importance of both sets of predictors. All analyses were conducted using IBM statistics SPSS 20. P-values $<0.05$ were considered to be statistically significant.

\section{Results}

\section{Sample}

The sample consisted of 888 parents with a mean age of $40.6(S D=5.8)$. Of the sample, $65.2 \%$ were female and about $45.3 \%$ had an intermediate and $43.6 \%$ had a high educational level. Most parents were of Dutch ethnicity (91.0\%) and were employed (79.3\%). The mean BMI was $25.2(S D=4.2)$ and the mean SEP score was $0.1(S D=1.2)$. With regard to $B M I, 54.2 \%$ had a healthy weight (i.e., $18.5-24.9 \mathrm{~kg} / \mathrm{m}^{2}$ ) and $45.2 \%$ were overweight (i.e., $\geq 25.0 \mathrm{~kg} / \mathrm{m}^{2}$ ). The mean age of the children was $7.9(S D=2.6)$ years with half of them being female $(49.7 \%)$. The mean BMI-z score was 0.19 (SD=1.4), with $73.2 \%$ being healthy weight and $14.6 \%$ were overweight according to Barlow's (2007) cut-off points. 
Table 7.2: Predictors of food parenting practices patterns around snacking: Odds Ratios and p-values from the univariate and backward multinomial logistic regression

\begin{tabular}{|c|c|c|c|c|c|c|}
\hline $\begin{array}{l}\text { Reference category= } \\
\text { high involvement and supportive }\end{array}$ & 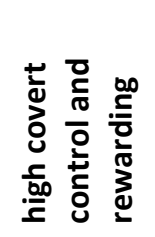 & 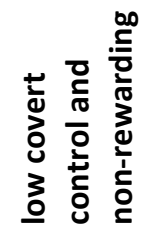 & 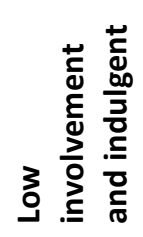 & 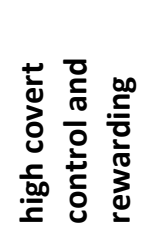 & 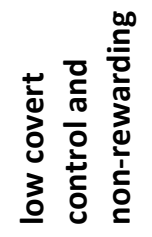 & 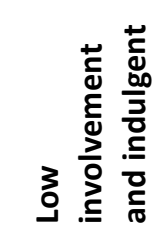 \\
\hline & \multicolumn{3}{|c|}{ Univariate ( $n=871$ to 888 ) } & \multicolumn{3}{|c|}{ Backward procedure $(n=864)$} \\
\hline Nagelkerke $\mathrm{R}^{2}$ & NA & & & 0.63 & & \\
\hline \multicolumn{7}{|l|}{ PREDISPOSING FACTORS } \\
\hline \multicolumn{7}{|l|}{ Background variables } \\
\hline Parent age & 0.99 & 1.03 & $1.04^{*}$ & & & \\
\hline Parent gender ${ }^{a}$ & 1.02 & 0.75 & 1.47 & & & \\
\hline Parent BMI & 0.98 & 0.99 & $1.05^{*}$ & & & \\
\hline Parent ethnicity ${ }^{\mathrm{b}}$ & 1.03 & 1.85 & 0.95 & & & \\
\hline Parent SEP & 1.07 & 0.96 & $1.26^{*}$ & 1.01 & 0.97 & $1.34^{*}$ \\
\hline Parent educational level low ${ }^{c}$ & 1.84 & 1.78 & $2.33^{*}$ & & & \\
\hline Parent educational level intermediate ${ }^{c}$ & 1.25 & 1.12 & 1.25 & & & \\
\hline Parent work status ${ }^{d}$ & 0.81 & 0.97 & 1.37 & & & \\
\hline Child gender $^{a}$ & 0.82 & 0.85 & $0.59 *$ & & & \\
\hline Child age & $0.91^{*}$ & $1.13^{*}$ & $1.13^{*}$ & $0.86 * * *$ & 1.04 & $1.07^{*}$ \\
\hline Child BMI-Z & 1.13 & 0.95 & $1.23^{*}$ & & & \\
\hline \multicolumn{7}{|l|}{ Parent's personality } \\
\hline Extraversion & $0.95 * * *$ & 0.98 & $0.93 * * *$ & & & \\
\hline Conscientiousness & $0.97^{*}$ & 0.97 & $0.91 * * *$ & & & \\
\hline Agreeableness & $0.86 * * *$ & $0.90 * * *$ & $0.77^{* * *}$ & & & \\
\hline Emotional Stability & $0.96 *$ & 0.99 & $0.94 * * *$ & & & \\
\hline Openness to Experience & $0.94 * * *$ & $0.93 * * *$ & $0.90 * * *$ & 0.97 & 0.95 & 0.95 \\
\hline \multicolumn{7}{|l|}{ General Parenting } \\
\hline Nurturance & $0.17 * * *$ & $0.35 * * *$ & $0.04 * * *$ & $0.51^{*}$ & 0.69 & $0.22 * * *$ \\
\hline Structure & $0.29 * * *$ & 0.95 & $0.12 * * *$ & & & \\
\hline Behavioral control & $0.61^{*}$ & $0.57^{* *}$ & $0.20 * * *$ & & & \\
\hline Overprotection & 1.04 & $0.74^{*}$ & $0.70^{*}$ & & & \\
\hline Coercive control & $1.50 * *$ & 0.87 & $1.53^{* *}$ & & & \\
\hline \multicolumn{7}{|l|}{ FPPs used by own parents } \\
\hline Covert unhealthy food control & 0.93 & $0.34 * * *$ & $0.51 * * *$ & 1.37 & $0.54 * * *$ & 0.73 \\
\hline $\begin{array}{l}\text { Healthy food availability, rules, } \\
\text { encouragement }\end{array}$ & $0.47 * * *$ & $0.42 * * *$ & $0.26 * * *$ & $0.58^{*}$ & 0.72 & $0.57^{*}$ \\
\hline Instrumental- and emotional feeding & $1.43 * * *$ & $0.58 * * *$ & 1.12 & 1.08 & $0.65 * *$ & 0.71 \\
\hline Meal practices & $0.57 * * *$ & $0.50 * * *$ & $0.30 * * *$ & 1.20 & 0.77 & 0.69 \\
\hline \multicolumn{7}{|l|}{ PARENTAL COGNITIONS } \\
\hline \multicolumn{7}{|l|}{$\overline{\text { Modeling other parents }}$} \\
\hline Covert unhealthy food control & 1.33 & $0.53 * * *$ & 0.73 & & & \\
\hline $\begin{array}{l}\text { Healthy food availability, rules, } \\
\text { Encouragement }\end{array}$ & 0.81 & $0.52 * * *$ & $0.38 * * *$ & & & \\
\hline Instrumental- and emotional feeding & 1.17 & $0.64 * *$ & 0.75 & & & \\
\hline Meal practices & 0.78 & $0.66^{*}$ & $0.43^{* * *}$ & & & \\
\hline \multicolumn{7}{|l|}{ Subjective norm } \\
\hline Covert unhealthy food control & 0.96 & $0.33^{* * *}$ & $0.54 * * *$ & & & \\
\hline $\begin{array}{l}\text { Healthy food availability, rules, } \\
\text { encouragement }\end{array}$ & $0.58 * * *$ & $0.33^{* * *}$ & $0.32 * * *$ & & & \\
\hline Instrumental- and emotional feeding & $1.52 * *$ & $0.43 * * *$ & 1.10 & 0.81 & $0.45 * * *$ & 0.76 \\
\hline Meal practices & $0.52 * * *$ & $0.36 * * *$ & $0.39 * * *$ & $0.47 * * *$ & $0.67^{*}$ & $0.46 * *$ \\
\hline
\end{tabular}


Table 7.2 continued

\begin{tabular}{|c|c|c|c|c|c|c|}
\hline $\begin{array}{l}\text { Reference category= } \\
\text { high involvement and supportive }\end{array}$ & 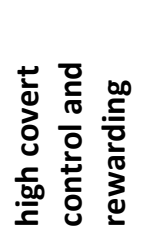 & 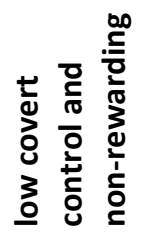 & 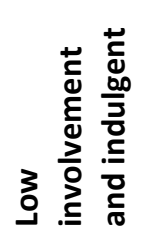 & 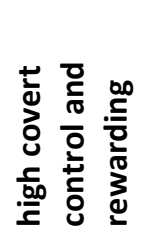 & 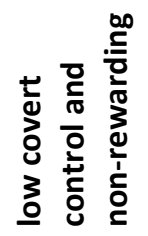 & 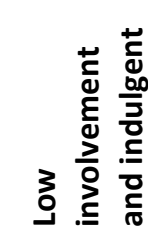 \\
\hline \multicolumn{7}{|l|}{ Attitude } \\
\hline Benefits of child's EDSF intake & $3.23 * * *$ & 1.20 & $4.52 * * *$ & $1.98^{* * *}$ & $1.13^{*}$ & $2.29 * *$ \\
\hline Negative effects of child's EDSF intake & $0.52 * * *$ & $0.37^{* * *}$ & $0.20 * * *$ & 0.94 & 0.75 & $0.34 * * *$ \\
\hline \multicolumn{7}{|l|}{ Self-efficacy } \\
\hline Covert unhealthy food control and rules & $0.22 * * *$ & $0.64^{*}$ & $0.11 * * *$ & 0.65 & 0.88 & $0.29 * * *$ \\
\hline $\begin{array}{l}\text { Healthy food availability and } \\
\text { encouragement }\end{array}$ & $0.15^{* * *}$ & $0.36^{* * *}$ & $0.09 * * *$ & $0.23 * * *$ & $0.31 * * *$ & $0.15^{* * *}$ \\
\hline Meal practices & $0.31^{* * *}$ & $0.67^{*}$ & $0.16^{* * *}$ & $0.61^{*}$ & 0.80 & $0.32 * * *$ \\
\hline Permissiveness and pressure & $0.53 * * *$ & 0.91 & $0.54 * * *$ & 1.34 & 1.16 & $2.62 * * *$ \\
\hline \multicolumn{7}{|l|}{ Outcome expectations } \\
\hline Covert unhealthy food control & $0.73^{*}$ & $0.18^{* * *}$ & $0.40 * * *$ & 0.93 & $0.31 * * *$ & 0.69 \\
\hline $\begin{array}{l}\text { Healthy food availability and } \\
\text { encouragement }\end{array}$ & $0.35^{* * *}$ & $0.14^{* * *}$ & $0.09 * * *$ & $0.39 * * *$ & $0.27 * * *$ & $0.14 * * *$ \\
\hline Instrumental- and emotional feeding & $1.84 * * *$ & 1.28 & $3.40 * * *$ & 1.32 & $0.63^{*}$ & 1.68 \\
\hline Meal practices & $0.28 * * *$ & $0.14^{* * *}$ & $0.07^{* * *}$ & & & \\
\hline $\begin{array}{l}\text { Pressure to eat, rules, structure and } \\
\text { feedback }\end{array}$ & $0.44 * * *$ & $0.28 * * *$ & $0.20 * * *$ & & & \\
\hline
\end{tabular}

Note: ${ }^{*} p<0.05 ;{ }^{* *} p<0.01 ;{ }^{* * *} p<0.001 ;$ NA: Not assessed/Not applicable a: $1=$ male; $2=$ female. b: $1=$ Dutch $2=$ non-Dutch. c: $1=$ low. $2=$ intermediate. $3=$ high. $\mathrm{d}$ : $1=$ employed. $2=$ non-employed

\section{Predictors of patterns of food parenting practices}

Multicollinearities between the scales were not found. Results from the multinomial logistic regression analysis showed that after backward elimination, nineteen factors had a statistically significant contribution to the final model (Nagelkerke $R^{2}=0.63$; table 7.2).

All parental cognitions remained in the model, except for the factors measuring perceived behavior of other parents, one out of four factors measuring subjective norms, and two out of five factors measuring outcome expectations. Overall, self-efficacy and outcome expectations were among the strongest predictors: parents were more likely to be highly involved and supportive in food parenting, rather than employing any other pattern, if they had a high self-efficacy and more positive outcome expectations regarding the "availability of healthy food and encouragement" and more positive outcome expectations regarding "meal practices".

With regard to the predisposing factors in particular, nurturance most strongly predicted food parenting clusters. Parents scoring high on nurturance were less likely to have the "low involvement and indulgent" and the "high covert control and rewarding" pattern, rather than having the "high involvement and supportive" pattern. From the 
background variables, child age and SEP remained significant explanatory factors of cluster membership in the final model: higher SEP parents were more likely to have the "low involvement and indulgent" pattern, rather than the opposite one (i.e. "high involvement and supportive"). Parents of younger children were more likely to covertly control unhealthy foods and reward, rather than being highly involved and supportive and parents of older children were more likely to have the "low involvement and indulgent" pattern, rather than being highly involved and supportive. Parent's current use of FPPs also appeared to be related to the ones used by their own parents. From those factors, the strongest predictor was the former use of covert unhealthy food control: if their own parents highly used covert unhealthy food control, parents were more likely to be high involved and supportive, rather than being member of the low covert control and non-rewarding cluster. The models including predisposing factors and parental cognitions had a Nagelkerke $R^{2}$ of 0.37 and Nagelkerke $R^{2}$ of 0.55 , respectively.

\section{Discussion}

In a previous study, we identified four different categories of Dutch parents with patterns of food parenting practices (Gevers et al., 2015b) The current study aimed at explaining membership of these patterns and found that parental cognitions where generally stronger predictors than predisposing factors, which included, among others, personality and general parenting. The greatest effect sizes were found among comparisons between the high involvement and supportive cluster and its opposite; the low involvement and indulgent cluster. Self-efficacy and outcome expectations regarding "healthy food availability and encouragement" were the two factors that discriminated best between high involved and supportive parents from all three other types of parents. Parents were more likely to be high involved and supportive if they had a high self-efficacy and more positive outcome expectations regarding making healthy foods available, accessible, and visible and regarding encouraging and modeling healthy food intake. These results contribute to the expanding research focus on the role of self-efficacy in parent's energy-balance related parenting practices (e.g. Bohman et al., 2014; Ek et al., 2015; Gerards et al., 2013; Hnatiuk et al., 2015; Jago et al., 2015). Consequently, the increased attention of interventions to address selfefficacy seems to be justified (e.g. Nyberg et al., 2015; Ruiter et al., 2015). In addition, the results demonstrate that parents might decide not to use some parenting practices because 
they believe they are not effective in lowering children's EDSF intake. In contrast to subjective norms, perceived behavior of other parents was not predictive for parent's use of parenting practices, probably because of the moderate sized inter-correlations between these factors. It has previously been highlighted that parents misperceive other parent's acceptance of child's frequent snacking (Lally et al., 2012), suggesting that parent's subjective norms regarding the use of parenting practices around snacking might be a misperception of the actual norm too. This hypothesis might be addressed in future research. Only a few studies have used theories of health behavior to predict the use of FPPs. For instance, Theory of Planned Behavior (TPB) constructs (i.e. attitudes, social norms, perceived behavioral control, and intention) and outcome expectations were significant predictors in one study, which specifically focused on parents' tracking behavior of snack food intake (Andrews et al., 2010). Another line of research focused on predicting the use of vegetable parenting practices using a model that includes among others TPB and Self Determination Theory constructs (Baranowski et al., 2013c). Habits most strongly predicted effective and ineffective parenting practices related to vegetable intake (Baranowski et al., 2015; Diep et al., 2015). Since the target populations and type of FPPs were different across these studies and the current research, the results cannot easily be merged to indicate the most important predictors.

Besides parental cognitions, the general parenting factor nurturance was found to be a significant and strong predictor: parents were more likely to be high involved and supportive if they demonstrated high levels of nurturance. It was also the only general parenting factor that was a significant predictor in the full model and had a very large effect size in the univariate model. Nurturance mainly represents the extent to which parents are responsive to their children's needs, are involved and spend time with their child, and is also referred to as "responsiveness" or "involvement" (Gerards \& Kremers, 2015; Sleddens et al., 2014). As such, nurturance may transfer from general parenting to involvement and supportiveness in food parenting.

The finding that parents of older children were less likely to covertly control and reward than those of younger children is consistent with earlier studies reporting on negative associations between child's age and instrumental- and emotional feeding (Hendy \& Williams, 2012; Raaijmakers et al., 2014) but different from a study finding no link between age and covert snack control (Brown et al., 2008). We found older parents to be 
more likely employing the "low involvement and indulgent" pattern, which is reasonable given that parental involvement and monitoring tend to decline from childhood to adolescence (Melbye et al., 2013b). Lower SEP parents were more likely to be highly involved and supportive, rather than being in the low involvement and indulgent cluster, which is promising. With regard to the remaining predisposing factors, personality was of minor importance in predicting FPPs, but part of the practices used by own parents did have a link with the food parenting patterns. More research is necessary to establish the significance of how parents were parented themselves in determining current parenting practices around energy-balance related behaviors.

\section{Implications for research and practice}

Based on this study, planners of health promotion programs aiming to reduce children's snack intake should focus on parental cognitions towards food parenting. Most importantly, self-efficacy and outcome expectations should be targeted. Although parental cognitions tend to be proximal to food parenting, interventions might be targeted at more fundamental and distal factors such as nurturance as well. Although we cannot draw conclusions on the mediation of general parenting via cognitions to parenting practices, Jago and colleagues (20150 recently found evidence for such a pathway. Consequently, more sustainable change in parenting practices might be expected if change is achieved in general parenting (Kitzmann \& Beech, 2006). Non-modifiable predictors including the child's age, parent's age and practices used by parents' own parents should be taken into account when developing interventions.

\section{Strengths and limitations}

A strength of the current study included the use of a broad set of potentially important factors. To the best of our knowledge, this is the first study using a combination of contextual and intrapersonal factors in the prediction of food related parenting practices. It should be noted that the study included self-report measures, which might have biased the results. There was one predictor that showed a different relationship in the univariate (i.e. $\mathrm{OR}<1$ ) compared to the backward procedure (i.e. $O R>1$ ). Possibly, the low internal consistency of the scale concerned (i.e. "self-efficacy towards permissiveness and pressure") caused this inconsistent result. Finally, the study was cross-sectional, implying that no causal 
inferences could be drawn. More specifically, parental cognitions such as self-efficacy or outcome expectations might have been constructed ad hoc because none existed, or were aligned with (current) behavior by parents, resulting in overestimated associations between cognitions and parenting practices (Armitage \& Conner, 1999). In addition, we cannot draw conclusions on the causal direction between general parenting and FPPs.

\section{Conclusion}

This study showed that parental cognitions are important factors in explaining the use of FPPs around snacking. It also found that the general parenting factor nurturance is a strong predictor variable to particularly distinguish highly involved parents from parents employing a pattern of low involvement. These results suggest that intervention developers might take measures aimed at increasing self-efficacy and educating parents about what constitute effective and ineffective parenting practices. Potentially, focusing on general parenting factors such as nurturance is necessary. 


\section{Chapter 8}

General discussion 
The objective of the research reported in this dissertation was to stimulate research and the development of theory around parental influences on children's diets, with a particular focus on food parenting practices (FPPs) in the context of snacking. This final chapter provides the main results of the studies and presents findings from secondary data analyses that were performed to support conclusions drawn in chapters 2 and 5. Subsequently, methodological considerations are discussed so that accurate implications for research and theory could be derived. Since the ultimate goal of the studies was to produce starting points for intervention developers, implications for practice are described. The chapter ends with an overall conclusion.

\section{Main findings}

The first aim of this dissertation was to assess the intake of energy-dense snack foods (EDSFs) and drinks (EDDs) among children in the Netherlands. EDSFs included non-core foods meant for consumption between main meals, while EDDs included soft drinks and squash. Based on the National Food Consumption Survey, the sample's mean number of EDSF events was found to be 3.3 ( $S D=1.6)$ per day, yielding 1569.7 (SD=928.7) kJ. The sample's average EDD consumption was $594.2(S D=342.3) \mathrm{ml} / \mathrm{d}$, yielding 737.2 (SD=495.9) $\mathrm{kJ}$. The mean total energy intake from EDSF and EDD was 2306.8 (SD 1113.8) kJ/d (about $550 \mathrm{kcal} / \mathrm{day}$ ) with over $90 \%$ over the sample not complying with the national recommendation regarding the consumption of non-core foods. Several subgroup differences with regard to children's intakes were found. Most importantly, higher intakes among older children and children with lower educated mothers were detected. About half of the EDSF events took place in the afternoon and nearly 60\% took place at home. Cookies (about 30\%) and sweets (about 20\%) were consumed most often. EDDs were most frequently (almost one-third) consumed in the afternoon. The majority of the drinks were consumed at home and soft drinks were more popular than squash. The results indicated that the consumption of energy-dense snack foods and drinks is highly prevalent and call for action.

The second aim was to bring consensus regarding the conceptualization of constructs within the domain of FPPs. A three round Delphi study among an international group of experts resulted in a list of descriptions of FPPs and 21 constructs of FPPs around snacking matched with these descriptions. A conceptual framework was proposed to classify the constructs identified using four factors derived from the general parenting literature, 
including nurturance, structure, behavioral control, and coercive control. The results of this study could serve as a starting point for the development of instruments and impulse the process of consensus development concerning terminology around FPPs.

The third aim of the research was to develop a questionnaire that can be used to measure a wide range of parenting practices around snacking. The results from the Delphi study served as a starting point for the instrument. The study found acceptable test-retest reliabilities and evidence for the discriminative value of constructs. The instrument is comprehensive but brief and therefore offers the opportunity to study dynamics across FPPs, for example by using a clustering approach.

As a demonstration, the fourth aim was to assess the co-occurrence of FPPs parents and to assess the relationships with the snack intake of children from those parents. Four clusters of parents emerged in the sample. The clusters of parents were based on the individual FPPs derived in the Delphi study and operationalized in chapter 4. They included "high covert control and rewarding", "low covert control and non-rewarding", "high involvement and supportive" and "low involvement and indulgent" parents. Several background factors were related to membership of the clusters, including parent's age, gender and children's age and snack intake. Most importantly, parents in the "high involvement and supportive" cluster were found to have children with the lowest snack intakes. Parents with any other pattern of parenting around snacking should be addressed and the use FPPs from the high involvement and supportive patterns should be encouraged.

The fifth aim was to assess the impact of parental congruence concerning general parenting and restrictive snacking rules on the intake of EDSFs in adolescents. The most salient finding from this study was that high levels of incongruence between parents regarding restrictive snacking rules attenuated the negative association between father's rules and children's snacking. Therefore, it may be pivotal to consider parenting incongruence between fathers and mothers within one family in research and practice.

The sixth and final aim was to predict parent's patterns of FPPs found in the study of chapter 5 using predisposing factors (e.g. personality and general parenting) and parental cognitions (e.g. attitudes, self-efficacy, outcome expectations) regarding these practices. Parental self-efficacy and outcome expectations were found to be among the strongest predictors overall. Considering the predisposing factors only, the general parenting factor nurturance (i.e. stimulate individuality by being supportive and responsive to the child, 
among others) most strongly predicted cluster membership: parents scoring high on general nurturance were more likely to have the "high covert control and rewarding" pattern with respect to child snacking. Intervention developers should select appropriate methods to address parent's self-efficacy and outcome expectations. Increasing the level of nurturance in parents might be a prerequisite for sustained use of high involvement FPPs.

\section{Findings secondary data-analyses}

In chapter 2, the consumption of EDSFs and EDDs was reported using means and standard deviations. However, compared to the mean, the median is relatively unaffected by extreme scores. In addition, it might be more straightforward to report medians and percentiles for policy makers, because the percentage of children under or above a certain intake value can be inferred. Therefore, with the objective to provide additional information that may support optimal reflection on the data presented in this dissertation, a table presenting medians and the 10th and 90th percentile for the total sample and subgroups (e.g. age, BMI, ethnicity) is presented (see table A3.1 in appendix 3). The median intakes (amount and energy) of EDSFs and EDDs were generally lower than the average intakes. For instance, the median number of snack events per day for the total sample was 3.00, compared to 3.30 on average. However, the conclusion that the consumption of these foods and drinks is prevalent and excessive in many children is still legitimate. Further research that specifically focuses on predictors of snack consumption in the small group of children with the highest intakes (e.g. $>90^{\text {th }}$ percentile) might be warranted.

In chapter 5, two examples were used to illustrate the value of the clustering approach. Firstly, we suggested that instrumental- and emotional feeding might be less detrimental in a context of high covert control. Secondly, we reported that the construct of rules might be a meaningful indicator of the "high involvement and supportive pattern". Both illustrations might be supported by additional data analyses. Hence, we calculated correlations between instrumental- and emotional feeding and children's snack intake and found that both are weakly, but positively associated with children's snack intake (Pearson's correlations 0.15 and 0.06 , respectively). The two isolated correlations pointed out that also in the current sample these parenting practices are related to higher snack intakes, underlining the importance of the contextual approach that was applied in chapter 5 . Subsequently, a multinomial logistic regression was performed to predict membership of the 
four clusters of FPPs using the construct of rules as the only predictor. The results indicated that rules significantly differentiated between parents in the high involvement and supportive cluster (i.e. reference category) and parents in the low involvement and indulgent cluster $(\mathrm{OR}=0.096, \mathrm{p}$-value $<0.001)$, with parents in the high covert control and rewarding cluster $(\mathrm{OR}=0.246$, $\mathrm{p}$-value<0.001), and the low covert control and non-rewarding cluster $(\mathrm{OR}=0.353, \mathrm{p}$-value $<0.001)$. Thus, the hypothesis that rules can serve as an indicator of the high involvement and supportive pattern was supported by this additional analysis. As a consequence, the negative association between employing restrictive rules and children's unhealthy food intake reported in several Dutch studies (de Bruijn et al., 2007; Van der Horst et al., 2007) and chapter 6 might be driven by the co-occurrence of multiple practices (i.e. the practices from the high involvement and supportive pattern), rather than the rules per se.

\section{Methodological considerations}

In the following paragraphs, several characteristics of the studies will be discussed, including the cross-sectional study designs, study samples, measurement instruments, and statistical analyses. The issues discussed need to be kept in mind when interpreting findings and deriving implications from the studies.

\section{Cross-sectional study designs}

The three studies that assessed the central pathways as outlined in the general research framework (see figure 1.1) all had a cross-sectional design (i.e. chapters 5, 6, 7), implying that causality cannot be inferred. For example, in chapter 5 and 6 the relationships between (patterns of) FPPs and children's intake of snack foods were examined. Although it is reasonable to suppose that parenting practices influenced children's intake and BMI-z, the opposite direction would have been possible as well: children's dietary behavior or BMI-z may have evoked certain parenting practices. This opposite pathway and a bi-directional pathway have been suggested and tested by several researchers (e.g. (Jansen et al., 2013; Rhee et al., 2009; Webber et al., 2010)). As such, care should be taken when interpreting the findings presented. But despite the cross-sectional nature of chapters 5 through 7, some directions of relationships can still be assumed. For instance, several variables of the study presented in chapter 7 are more likely to predict FPPs, rather than vice versa. These 
variables include the way parents were parented (i.e. chronologically preceding parenting practices currently used), and personality and general parenting (i.e. relatively distal and stable factors).

\section{Study samples}

The study presented in chapter 2 used data from the Dutch National Food Consumption Survey. These data were derived from a sample that was conscientiously recruited, based on several characteristics of the Dutch population (e.g. age, educational level). If differences existed between the study sample and the Dutch population regarding socio-demographic factors, weighing factors were used with the aim to produce results that are representative for the Dutch population. Although the participants in the NFCS are well represented in socio-demographic terms, they may have had a particular interest in food or healthy eating and, as a result, have been highly motivated to participate. As such, these participants (or their parents) may have had healthier dietary patterns and the intakes found could be lower than the actual intakes among Dutch children. Therefore, the study in chapter 2 may be subject to selection bias, meaning that the actual study participants differ from the target population. Similarly, the study in chapter 4 might be prone to selection bias because participants could be more interested in the study topic than non-participants. Two other studies (chapters 5 and 6) used a sample that was derived from a research agency's panel. Although this panel complies with requirements set by ISO-standards (e.g. with regard to the frequency of participation of panel members in studies and the quality of their responses), panel members may be primarily motivated by the fact that they would be financially rewarded for their participation. This may have led to less accurate answers. In addition, highly educated participants were overrepresented in the research sample derived from this panel. Thus, although high SEP parents were found to be more likely employing the low involvement and indulgent pattern, the prevalence of the patterns that were identified is not generalizable to the Dutch population. Finally, the adolescents in the study of chapter 7 were asked to fill out the survey in the classrooms of secondary schools agreeing to participate. Since all approached schools agreed to participate and all adolescents completed the questionnaire, there is little chance of selection bias. However, the generalizability of the results of this study is limited, since a relatively homogenous set of young adolescents were questioned (e.g. adolescents with a Dutch ethnicity from a small part of the Netherlands). 
With regard to the studies assessing parenting behaviors (chapters 4 to 7), data were collected on both fathers and mothers, which is a strength. The majority of previous studies included mothers only, while fathers are argued to be influential as well (Hughes et al., 2013). A recent review of the available evidence on father's FPPs supports this hypothesis and highlights some future directions in this respect (Khandpur et al., 2014).

\section{Measurement instruments}

The studies from chapters 4 through 7 all used data derived from questionnaires and these may be prone to the bias of social desirability. In particular, the actual scores on general parenting, food parenting practices and children's intakes of snack foods in these chapters might be less desirable than reported.

All data were parent reported, excluding data used in chapter 7 , which was child reported. The literature on parenting around food has heavily relied on parent reports (Musher-Eizenman \& Kiefner, 2013; Patrick et al., 2013). Therefore, children's perceptions of parenting practices are largely unclear. Children's perceptions of FPPs might differ from parent's perceptions and both may uniquely predict children's nutrition behavior (Patrick et al., 2013). Few studies collected both parent and child data, but those that did consistently found relatively low agreement on food parenting practices (Rebholz et al., 2014; van Assema et al., 2007). In the study of chapter 7 (i.e. child reported), a high number of adolescents scored their fathers and mothers as being identical on many individual items. This might partly be explained by the questionnaire lay-out (i.e. two columns for scoring fathers and mothers next to each other). As a consequence, parents may be less congruent than currently found.

In two studies (i.e. chapters 5 and 6), the intake of energy-dense snack foods among children was measured using items taken from an existing food frequency questionnaire. Most likely, the intakes obtained from these items are an underestimation of the actual intake because of social desirability and/or recall bias (Willet, 1998). To illustrate, the number of snack food events among the primary school children in chapter 5 was found to be about 12.4 per week on average. Adolescents in chapter 6 had 1.7 snack events a day on average. Both are significantly lower than the number of snack occasions obtained in chapter 2, which used 24 hour recall data from the NFCS (i.e. 3.3 per day on average). In addition, the assessments were limited to the number of snack foods and unadjusted for 
portion size. The energy intake from these foods might have had different relations to the (patterns of) FPPs than the number of snack foods consumed.

Since there was no questionnaire available that could be used to adequately measure the full spectrum of FPPs, one of the aims of the current dissertation was to develop such a questionnaire. In order to enable researchers studying the co-occurrence of multiple FPPs and additional contextual influences without placing high burden on respondents, the decision was made to use single items to measure constructs. To increase the quality of the instrument, global items were carefully developed as indicators of each construct, instead of picking items from existing multi-item measures (Youngblut \& Casper, 1993). The majority of the other latent constructs in this dissertation (e.g. general parenting and personality) were measured by validated questionnaires or items borrowed from such questionnaires.

\section{Statistical analysis}

Sometimes, several methods are available for comparable analytic approaches, for instance to perform a cluster analysis (chapter 5 ). Therefore, the procedure on which consensus exists was applied and the cluster solution was cross-validated (Breckenridge, 2000). A second example may refer to the regression analysis conducted to assess correlates of FPPs (chapter 7). Structural equation modeling (SEM) could have been performed as an alternative to this method. By using SEM, the entire theoretical model, including hypothesized mediated pathways, could have been tested at once. Nevertheless, regression analysis was regarded as an appropriate method for this exploratory research. The statistical methods in this dissertation have all been selected in view of recent insights as well as the study aims.

\section{Implications for research, theory, and practice}

The main findings and methodological considerations presented hold various recommendations for research, theory and practice, which will be discussed below.

\section{Implications for research and theory}

The overall purpose of this dissertation was to advance research and theory development around food parenting practices. The following paragraphs outline the most important implications and recommendations in this regard. 


\section{Terminology and conceptualization of food parenting practices}

First of all, the Delphi study (chapter 3 ) can be used as a basis to agree on terminology and conceptualization of food parenting practices and to develop measurement instruments. The Delphi study proved to be a first step, which was followed by several comparable initiatives that have been taken since the publication of this article. For instance, Davison et al. (2015) identified core constructs and developed a model of parenting practices in the context of snacking by using theory and data from qualitative interviews with caregivers. They reported that most parenting practices identified and described by caregivers were consistent with the perspectives of the experts from chapter 3 (Davison et al., 2015). In this way, it supports the validity of our Delphi study results. In addition, partly building upon the Delphi study, they developed a conceptual model of the FPPs identified that included coercive control, structure, permissiveness, and autonomy support. Recently, another group of scholars working in the field of FPPs also identified, defined, and conceptualized constructs of food parenting practices (Vaughn et al., 2015). They proposed three factors providing the potential dimensional structure around FPPs: coercive control, parental structure, and autonomy support. These papers indicate that, fully in line with the objectives of the study in chapter 3 , investigators have started to reconsider terminology and conceptualization of FPPs to advance the field. The studies also proposed comparable conceptual models to categorize FPP constructs. Future studies could focus on empirically testing the suggested models. For instance, a study of Baranowksi et al. (2013b) is one of the few that validated a factor structure of parenting practices using the factors of responsiveness (closely related to autonomy support), structure, and control. Particular attention should be paid to the factor of permissiveness, which was included in the model of Davision et al. (2015), but absent in our and most other existing conceptual models around FPPs. We see permissiveness merely as the absence of rules and monitoring, rather than a separate factor.

In addition to establishing the dimensional structure of FPPs, the proximity of practices to children's outcomes (e.g. diet or BMI) should be determined in future research. In particular, the FPPs included in our studies are probably not of equal distance to children's intake of snack foods, i.e. certain FPPs could act as mediators of other FPPs. In line with this view, Larson et al. (2015) presented a theoretical framework proposing that influences of FPPs such as rules, monitoring, and structure, are largely mediated by changes in the child's home food environment (i.e. food availability and modeling). Such studies are very useful to 
understand the mechanisms that underlie the parental impact on children's dietary behaviors.

The Delphi study was the first of several steps that were taken to create novel research opportunities around FPPs. That was one of the reasons to concentrate on parenting practices around specific foods (i.e. energy-dense snack foods). Vaughn et al. (2015) state that it is still unclear to what extent it is beneficial to differentiate parenting practices based on the types of foods (e.g. vegetables, snacks, fruit). Nevertheless, the instrument (chapter 4) that emanated from the expert consultation is not restricted to snack food only. It roughly distinguishes FPPs about healthy foods from unhealthy foods, which is precisely what was suggested recently (Vaughn et al., 2015). Researchers might even inspect the possibility to transfer the constructs or conceptual model to other lifestyle domains, for example to describe or conceptualize physical activity parenting practices.

Finally, earlier (e.g. chapter 6) we defined FPPs according to the widely used definition of Darling (1993) as goal-directed parental behaviors directed at influencing children's dietary behaviors. However, this definition does not necessarily apply to all practices that are employed by parents. For instance, unhealthy food modeling has not the specific aim of influencing the child's diet. FPPs may be defined by neglecting the term goaldirected or specifying the type of parental behaviors that are referred to.

\section{The co-occurrence of food parenting practices}

Up to now, researchers have approached FPPs in an isolated fashion. For example, in the current literature, parenting practices have been investigated independently from each other. Cluster analysis is a useful method to examine their co-occurrence. Besides the study of O'Connor et al. (2010), the study in chapter 5 is the only study available applying this method. Replication of such studies is necessary to improve our understanding of how parenting practices coexist and to determine their combined influences. Replication studies can also show if FPPs cluster into similar patterns of use in other populations. The present dominant instruments, such as the Child Feeding Questionnaire (CFQ) (Birch et al., 2001), are not appealing to perform cluster analysis because they mostly include only a limited set of (highly controlling) parenting practices. Conversely, the newly developed questionnaire (chapter 4) is a very useful tool in this regard. 
Besides taking into account the influence of multiple parenting practices used together by one parent, the co-occurrence of father's and mothers' practices needs to be considered. To date, parenting practices of fathers and the interplay between parents have been studied infrequently (Khandpur et al., 2014). Chapter 6 showed that one of the ways to investigate caregivers' level of congruence between parents is to calculate difference scores. In these analyses, the father's or mother's single score on the parenting construct of interest, the difference score, and an interaction term of those two were entered in one model. However, high interrelations across fathers and mothers parenting scales (i.e. all Pearson's correlations between father and mother parenting scales $>0.71$ ) impede constructing a robust regression model that includes both parents' FPPs. Other methods might be possible: recently, Berge et al. (2015) conducted a comparable study and they defined parental congruence with two categories of congruence (i.e. both parents endorsing a child's health behavior and neither parent endorsing this behavior) and an incongruent category (i.e. disagreement between parents). This congruence variable was used as an indicator variable in regression models with the child's behavior as the outcome variable. Likely, the method of Berge is a more refined approach to study incongruence than the method used in chapter 6 . Their method takes into consideration both caregivers' scores and can be extended with interactions between parent gender and parenting congruence and child gender and parenting congruence. Researchers should consider appropriate methods for measuring both father's and mother's parenting practices, in case of child-report. In addition to including fathers and assessing the interplay between parental dyads, research might include other caregivers such as grandparents (e.g. Farrow, 2014), step parents and childcare staff (e.g. Gubbels et al., 2015), as they are involved in the care of many children.

\section{Bi-directionality and (in)stability of parent-child interactions around snacking}

Besides the co-occurrence of parenting practices, the direction of relationships between FPPs and children's eating behaviors deserves attention. Longitudinal designs are needed in order to draw sound conclusions on causality and bi-directionality between FPPs and children's snacking behaviors and weight. Related to this point, longitudinal designs are able to capture changes in parenting behaviors over time. Scaffolding is the term used to describe the process of providing just enough assistance relative to the capacities of the child (Wood et al., 1976). It is worth to assess if potential changes in parenting practices employed by 
parents are a response to the child's age and fit the changes children undergo (e.g. increasing independence). More specifically, it would be interesting to study if the FPP patterns found in chapter 5 are stable or adapt in response to changes in children. The next steps would be to assess the (in)stability of FPP patterns over time, to predict potential (in)stability and infer causality between patterns and children's dietary behavior.

\section{Evidence base regarding food parenting practices}

Altogether, considering the work on FPPs specific to child snacking presented in the current dissertation and the progress in the field in a more general sense, researchers may have to reconsider the current state of the evidence. This evidence base heavily relies on studies using the CFQ (Birch et al., 2001). To indicate, the original article had 830 citations according to Google Scholar (9 February, 2016). In addition, I would like to encourage scholars to be critical of prevailing research approaches, for example in choosing research instruments to assess FPPs, and to be receptive for novel research directions proposed in the literature such as the ones proposed in this dissertation.

\section{Implications for practice}

The overall purpose of the research in this dissertation was to stimulate research around food parenting practices, rather than directly contributing to the evidence base in this area. Nevertheless, the findings from chapter 2 and our exploratory studies (chapters 5 through 7) may guide intervention developers as described below.

\section{Interventions to reduce child snacking}

The study on the intake of energy-dense snack foods and drinks clearly established the need for intervention programs in the Netherlands. It opened new avenues for attempting to change children's snack consumption by the assessment of subgroup differences and by reporting popular types of foods and drinks (e.g. cookies, sweets) as well as places (e.g. at home) and occasions (e.g. in the afternoon) to consume them. It is advised to pay particular attention to children of low educated parents and after school snacking. A large difference in snacking behavior was found between children aged 8 and 9 , suggesting that actions before the age of 9 are pivotal to suppress this increase. 


\section{Interventions targeting food parenting practices}

Since research in this dissertation confirmed that FPPs are factors of importance with regard to child snacking and BMI, targeting these parental behaviors is recommended. It is worth considering the clusters of parents employing similar FPP patterns (chapter 5). In that way, interventions can be targeted on groups of parents at high risk of having a pattern that promotes child snacking. The most critical cluster of parents to address would be the one that is called low involvement and indulgent. This pattern is a constellation of low use of responsive practices (e.g. involving, educating) and low use of structure practices (e.g. availability of healthy foods, meal routines). Prevention programs may try to encourage parents of overweight or obese children to employ these desirable parenting practices. Chapter 7 provides an overview of the factors that could be addressed: subjective norms, self-efficacy, and outcome expectations towards the practices seem to be the most important ones. In this view, Lifestyle Triple $\mathrm{P}$ is a promising program, since it aims to enhance self-efficacy regarding the management of children's energy-balance related behaviors (Gerards et al., 2012; West et al., 2010). Moreover, the program acknowledges the critical role of a positive general parenting climate, in line with findings from chapter 7. Although relatively distal, a positive parenting climate impacts children's dietary intake through its interaction with FPPs (Sleddens et al., 2011) and may be a prerequisite for the employment of healthy parenting practices on the long term. Several other intervention programs addressing parenting practices to prevent childhood obesity or promote healthy energy-balance related behaviors have been developed (e.g. Burrows et al., 2010; Epstein et al., 2008). Yet, the developers of these programs poorly describe which precursors of parenting practices are addressed, indicating that there is a lot of work to be done to inform the development of evidence-based programs.

Although we just found preliminary evidence for the importance of father's parenting practices and adverse effects of parental incongruence, it could be considered in future programs as well. One of the few programs targeting fathers showed promosing results (Morgan et al., 2011). It is aimed at fathers only and might be extended to include mothers and with a component focusing on the interplay between fathers and mothers. Healthcare professionals treating overweight or obese children may spend time on inspecting both caregivers' parenting practices, instead of relying on a single parent's influence. 


\section{Conclusion}

The objective of the project reported in this dissertation was to advance research around food parenting practices. The international Delphi study was a first step in the process of defining, conceptualizing, and operationalizing pertinent constructs of FPPs around child snacking. Several comparable initiatives of other researchers succeeded to this study, indicating that it is part of the necessary process towards establishing clear terminology and conceptualization. In addition to this fundamental work, research was conducted to address the scarcity of studies on the co-occurrence of FPPs and on the precursors of these parental behaviors (see the general research framework on page 11). Four clusters of parents were distinguished, based on FPPs that are used together: "high covert control and rewarding", "low covert control and non-rewarding", "high involvement and supportive" and "low involvement and indulgent". In addition, high incongruence in restrictive snacking rules is undesirable, suggesting that the co-occurrence of FPPs between parents also needs to be considered in research and practice. Finally, the socio-cognitive variables parental selfefficacy and outcome expectations appeared to be strong predictors, as well as the more distal general parenting construct of nurturance. The newly developed questionnaire creates the opportunity to investigate more of such unexplored key issues in food parenting to continue advancing research is this relevant area. 


\section{Valorization addendum}


The main purpose of this dissertation was to gain knowledge and stimulate research, and thus, researchers were the direct target group and scientific value the main outcome. Although most studies were relatively explorative and fundamental in nature, they can also inform other professionals such as interventions developers and policy makers. This chapter discusses the value of the dissertation in a societal context and how its findings can reach the ultimate target group: parents and their children.

\section{Relevance}

High intakes of energy-dense snack foods promote weight gain and obesity, according to the WHO (WHO, 2003). Obesity in childhood, in turn, is related to a variety of physical (e.g. cardiovascular diseases) and psychosocial conditions and diseases (e.g. depression) (Daniels, 2006). In addition, being obese as a child is a risk factor for being obese during adulthood (Singh et al., 2008). As a result, children's diets, including snack consumption, and overweight are topics of importance in current society: overweight has been one of the spearheads of Dutch policy for years (Rijksoverheid, 2013). However, there is a lack of empirical evidence around Dutch children's snack consumption (e.g. how much is consumed, what is consumed). Therefore, intervention programs lack clear a foundation when it comes to this health behavior.

Among the critical factors influencing children's consumption of snack foods are the behaviors of their parents, which can be classified into general parenting and parenting practices. Studies indicate that these parental behaviors are important in influencing children's dietary behavior (Sleddens et al., 2011; Gerards \& Kremers, 2015). This is also recognized by the Dutch national government, since one of the three main domains in the 2014 prevention program refers to 'parenting and education' (Rijksoverheid, 2013). However, the current evidence base around food parenting practices (FPPs) has several shortcomings as indicated by the scientific conference called 'Parenting measurement: current status and consensus reports', which was held in 2013 to boost this research area (Baranowski et al., 2013). A special issue of Childhood Obesity was devoted to this conference and provided several key suggestions for future research, including enhanced conceptualization of constructs and studying fathers (Baranowski et al., 2013; Hughes et al., 2013). Studies in this dissertation fully comply with these recommendations and lead to 
improved understanding of parental influences around child snacking, thereby increasing the efficacy of parent-focused interventions to prevent childhood obesity.

\section{Target groups, products, and innovation}

Clearly, the fundamental work carried out in this dissertation is directly relevant for researchers. For instance, the newly developed questionnaire can be used in future studies with a variety of study designs and settings. However, several findings are of importance not only to researchers, but also to policy makers, intervention developers, health care professionals, parents, and children. First of all, chapter 2 showed that the intake of energydense snack foods and drinks is beyond the recommendations for the vast majority of Dutch primary school aged children. This main finding is a clear signal and provides a strong basis for policy makers to draw on resources to address this dietary behavior.

Findings from the empirical studies can be translated into interventions, by which they are of importance to intervention developers and health care professionals treating overweight children. Interventions addressing children's snack intake might be improved by considering when, where and which types of foods and drinks are consumed, for instance. Chapters 5, 6, and 7 provide starting points for parent-focused interventions. These three studies were pre-eminently innovative. Rather than building on existing research paradigms, shortcomings of the current literature in the field were identified and addressed. In particular, the co-occurrence of FPPs (i.e. within and between parents) was studied while previous research applied a more isolated approach. To the best of our knowledge, only one study (O'Connor et al. 2010) has applied a cluster analysis before and few studies are available studying the interplay of FPPs between parents (e.g. Berge et al., 2010a; Berge et al., 2015). In addition, the shortage of research on (socio-cognitive) determinants of FPPs was addressed. The studies from this dissertation are thus likely to assist in improving interventions. For instance, besides mothers, fathers should be targeted in intervention programs. Dissimilarities between both parents need to be taken into account, which is relatively uncommon at present. The knowledge on factors related to the use of FPPs can be used to develop interventions according to the Intervention Mapping protocol (Bartholomew et al., 2011) by creating change objectives and specifying methods towards change. For instance, modelling and skill training might be suitable methods for increasing 
parent's self-efficacy regarding FPPs. Ultimately, parents and their children are expected to benefit from those interventions and public health will improve.

\section{Dissemination of study findings}

Several studies from this dissertation have been published in peer reviewed journals and presented at (inter)national conferences. In this way, researchers are able to advance this research area. For instance, in line with our suggestions, researchers used findings from the Delphi study to continue enhancing the conceptualization of FPPs (Davison et al., 2015). Two of the peer reviewed articles were also distributed through media targeting non-academics. The Delphi study was published in VoedingNu, a Dutch journal addressing the relation between food, nutrition and health (Gevers et al., 2014). Findings from the article on parenting congruence were published at an online community called Yellowbrick.me (http://yellowbrick.me/question/being-in-sync-with-your-partner-improves-your-childsdietary-health/). This portal aims to transfer scientific knowledge on parenting to parents and exchange experiences between researchers and parents. As such, it's an excellent outlet for parenting research and a very convenient way to disseminate such knowledge to parents. The newly developed FPPs questionnaire was spread through a Dutch working group on parenting and children's energy balance related behaviors so that knowledge around FPPs can expand and, ultimately, children's health could improve. 
References 
Adair, L. S., \& Popkin, B. M. (2005). Are child eating patterns being transformed globally? Obesity Research, 13, 1281-1299.

Adler, M., \& Ziglio, E. (1996). Gazing into the oracle: The Delphi method and its application to social policy and public health. London: Jessica Kingsley Publishers.

Ajzen, I. (2005). Attitudes, personality, and behavior. Maidenhead: McGraw-Hill Education.

Andrews, K. R., Silk, K. S., \& Eneli, I. U. (2010). Parents as health promoters: A theory of planned behavior perspective on the prevention of childhood obesity. Journal of Health Communication, 15, 95-107.

Armitage, C. J., \& Conner, M. (1999). The theory of planned behaviour: Assessment of predictive validity and'perceived control. British Journal of Social Psychology, 38, 3554.

Ayala, G. X., Baquero, B., Arredondo, E. M., Campbell, N., Larios, S., \& Elder, J. P. (2007). Association between family variables and Mexican American children's dietary behaviors. Journal of Nutrition Education and Behavior, 39, 62-69.

Bandura, A. (1986). Social foundations of thought and action: A social cognitive theory. Englewood Cliffs, NJ: Prentice-Hall.

Baranowski, T., O'Connor, T., Hughes, S., Sleddens, E.F.C., Beltran, A., Frankel, L., . . . Baranowski, J.C. (2013a). Houston... We have a problem! Measurement of parenting. Childhood Obesity, 9, S1-S4.

Baranowski, T., Chen, T. A., O'Connor, T., Hughes, S., Beltran, A., Frankel, L., . . Baranowski, J. C. (2013b). Dimensions of vegetable parenting practices among preschoolers. Appetite, 69, 89-93.

Baranowski, T., Beltran, A., Chen, T.A., Thompson, D., O'Connor, T., Hughes, S., . . . Baranowski, J.C. (2013c). Psychometric assessment of scales for a Model of Goal Directed Vegetable Parenting Practices (MGDVPP). International Journal of Behavioral Nutrition and Physical Activity, 10, 110.

Baranowski, T., Beltran, A., Chen, T.A., Thompson, D., O'Connor, T., Hughes, S., . . . Baranowski, J. C. (2015). Predicting use of ineffective vegetable parenting practices with the Model of Goal Directed Behavior. Public Health Nutrition, 18, 1028-1035.

Barlow, S. E. (2007). Expert committee recommendations regarding the prevention, assessment, and treatment of child and adolescent overweight and obesity: Summary report. Pediatrics, 120, S164-S192. 
Bartholomew, L. K. B., Parcel, G. S., Kok, G., \& Gottlieb, N. H. (2011). Planning health promotion programs: an intervention mapping approach. San Fransisco: John Wiley \& Sons.

Bell, A. C., Kremer, P. J., Magarey, A. M., \& Swinburn, B. A. (2005). Contribution of 'noncore' foods and beverages to the energy intake and weight status of Australian children. European Journal of Clinical Nutrition, 59, 639-645.

Belsky, J. (1984). The determinants of parenting: A process model. Child development, 83-96.

Berge, J. M., MacLehose, R. F., Meyer, C., Didericksen, K., Loth, K. A., \& Neumark-Sztainer, D. (2015). He Said, She Said: Examining Parental Concordance on Home Environment Factors and Adolescent Health Behaviors and Weight Status. Journal of the Academy of Nutrition and Dietetics, 116, 46-60.

Berge, J. M., Wall, M., Bauer, K. W., \& Neumark-Sztainer, D. (2010a). Parenting characteristics in the home environment and adolescent overweight. A latent class analysis. Obesity, 18, 818-825.

Berge, J. M., Wall, M., Neumark-Sztainer, D., Larson, N., \& Story, M. (2010b). Parenting Style and Family Meals: Cross-Sectional and 5-Year Longitudinal Associations. Journal of the American Dietetic Association, 110, 1036-1042.

Berge, J. M., Wall, M., Larson, N., Eisenberg, M. E., Loth, K. A., \& Neumark-Sztainer, D. (2014). The unique and additive associations of family functioning and parenting practices with disordered eating behaviors in diverse adolescents. Journal of Behavioral Medicine, 37(2), 205-217. doi:10.1007/s10865-012-9478-1.

Birch, L. L., \& Davison, K. K. (2001). Family environmental factors influencing the developing behavioral controls of food intake and childhood overweight. Pediatric Clinics of North America, 48, 893-907.

Birch, L. L., Fisher, J. O., Grimm-Thomas, K., Markey, C. N., Sawyer, R., \& Johnson, S. L. (2001). Confirmatory factor analysis of the Child Feeding Questionnaire: a measure of parental attitudes, beliefs and practices about child feeding and obesity proneness. Appetite, 36, 201-210.

Bjelland, M., Lien, N., Grydeland, M., Bergh, I. H., Anderssen, S. A., Ommundsen, Y., . . . Andersen, L. F. (2011). Intakes and perceived home availability of sugar-sweetened beverages, fruit and vegetables as reported by mothers, fathers and adolescents in the HEIA (HEalth In Adolescents) study. Public Health Nutrition, 14, 2156-2165. 
Blissett, J. (2011). Relationships between parenting style, feeding style and feeding practices and fruit and vegetable consumption in early childhood. Appetite, 57, 826-831.

Blissett, J., Meyer, C., \& Haycraft, E. (2006). Maternal and paternal controlling feeding practices with male and female children. Appetite, 47, 212-219.

Blissett, J., \& Haycraft, E. (2008). Are parenting style and controlling feeding practices related? Appetite, 50, 477-485.

Bohman, B., Nyberg, G., Sundblom, E., \& Elinder, L. S. (2014). Validity and reliability of a parental self-efficacy instrument in the healthy school start prevention trial of childhood obesity. Health Education \& Behavior, 41, 392-396.

Brann, L. S., \& Skinner, J. D. (2005). More controlling child-feeding practices are found among parents of boys with an average body mass index compared with parents of boys with a high body mass index. Journal of the American Dietetic Association, 105, 1411-1416.

Brants, H., Stafleu, A., ter Doest, D., Hulshof, K., \& Thijs, C. (2006). Ontwikkeling van een voedselfrequentievragenlijst: energie-inneming van kinderen van 2 tot en met 12 jaar (Development of a food frequency questionnaire: energy-intake of children 2-12 years of age). Voeding $\mathrm{Nu}, 2,25-28$.

Breckenridge, J. N. (2000). Validating cluster analysis: Consistent replication and symmetry. Multivariate Behavioral Research, 35, 261-285.

Briefel, R. R., Wilson, A., \& Gleason, P. M. (2009). Consumption of low-nutrient, energydense foods and beverages at school, home, and other locations among school lunch participants and nonparticipants. Journal of the American Dietetic Association, 109, S79-S90.

Brown, K. A., Ogden, J., Vögele, C., \& Gibson, E. L. (2008). The role of parental control practices in explaining children's diet and BMI. Appetite, 50, 252-259.

Brown, R., \& Ogden, J. (2004). Children's eating attitudes and behaviour: a study of the modelling and control theories of parental influence. Health Education Research, 19, 261-271.

Brug, J., van Stralen, M. M., Chinapaw, M. J. M., De Bourdeaudhuij, I., Lien, N., Bere, E., ... te Velde, S. J. (2012a). Differences in weight status and energy-balance related behaviours according to ethnic background among adolescents in seven countries in Europe: the ENERGY-project. Pediatric Obesity, 7, 399-411. 
Brug, J., van Stralen, M. M., te Velde, S. J., Chinapaw, M. J. M., De Bourdeaudhuij, I., Lien, N., .. Manios, Y. (2012b). Differences in weight status and energy-balance related behaviors among schoolchildren across Europe: the ENERGY-project. PLoS One, 7, e34742.

Bryant, M. J., Ward, D. S., Hales, D., Vaughn, A., Tabak, R. G., \& Stevens, J. (2008). Reliability and validity of the Healthy Home Survey: A tool to measure factors within homes hypothesized to relate to overweight in children. International Journal of Behavioral Nutrition and Physical Activity, 5, 23.

Burrows, T., Warren, J., \& Collins, C. (2010a). The impact of a child obesity treatment intervention on parent child-feeding practices. International Journal of Pediatric Obesity, 5, 43-50.

Buurma-Rethans, E., Fransen, H., \& van Rossum, C. (2012). Consumptie van dranken met toegevoegd suiker door kinderen van de basisschoolleeftijd. (consumption of beverages with added sugars among primary school children). Bilthoven: RIVM

Central Committee on Research Involving Human Subjects (CCMO) (2015). Your research: does it fall under the WMO. Retrieved 22 May, 2015, from http://www.ccmo.nl/en/your-research-does-it-fall-under-the-wmo.

Clark, H. R., Goyder, E., Bissell, P., Blank, L., \& Peters, J. (2007). How do parents' child-feeding behaviours influence child weight? Implications for childhood obesity policy. Journal of Public Health, 29, 132-141.

Cohen, J. (1988). Statistical Power Analysis for the Behavioral Sciences. Hillsdale: Lawrence Erlbaum Associates.

Collins, C., Duncanson, K., \& Burrows, T. (2014). A systematic review investigating associations between parenting style and child feeding behaviours. Journal of Human Nutrition and Dietetics, 27, 557-568.

Comrey, A. L., \& Lee, H. B. (1992). A first course in factor analysis. Hillsdale, NJ: Lawrence Erlbaum.

Corsini, N., Danthiir, V., Kettler, L., \& Wilson, C. (2008). Factor structure and psychometric properties of the Child Feeding Questionnaire in Australian preschool children. Appetite, 51, 474-481. 
Craig, L. C. A., McNeill, G., Macdiarmid, J. I., Masson, L. F., \& Holmes, B. A. (2010). Dietary patterns of school-age children in Scotland: association with socio-economic indicators, physical activity and obesity. British Journal of Nutrition, 103, 319-334.

Craigie, A. M., Lake, A. A., Kelly, S. A., Adamson, A. J., \& Mathers, J. C. (2011). Tracking of obesity-related behaviours from childhood to adulthood: A systematic review. Maturitas, 70, 266-284.

Cullen, K. W., Baranowski, T., Rittenberry, L., Cosart, C., Hebert, D., \& de Moor, C. (2001). Child-reported family and peer influences on fruit, juice and vegetable consumption. Reliability and validity of measures. Health Education Research, 16, 187-200.

Daniels, S. R. (2006). The consequences of childhood overweight and obesity. The Future of Children, 16, 47-67.

Daniels, S. R. (2009). Complications of obesity in children and adolescents. International Journal of Obesity, 33, S60-S65.

Darling, N., \& Steinberg, L. (1993). Parenting style as a context: an integrative model. Psychological Bulletin, 113, 487-496.

Datar, A., Nicosia, N., \& Shier, V. (2014). Maternal work and children's diet, activity, and obesity. Social Science \& Medicine, 107, 196-204.

Davison, K. K., Blake, C. E., Blaine, R. E., Younginer, N. A., Orloski, A., Hamtil, H. A., . . Fisher, J. O. (2015). Parenting around child snacking: development of a theoretically-guided, empirically informed conceptual model. International Journal of Behavioral Nutrition and Physical Activity, 12, 109.

Davison, K. K., Masse, L. C., Timperio, A., Frenn, M. D., Saunders, J., Mendoza, J. A., . . Trost, S. G. (2013). Physical activity parenting measurement and research: challenges, explanations, and solutions. Childhood Obesity, 9, S103-S109.

De Bruijn, G. J., Kremers, S. P. J., de Vries, H., van Mechelen, W., \& Brug, J. (2007). Associations of social-environmental and individual-level factors with adolescent soft drink consumption: results from the SMILE study. Health Education Research, 22, 227-237.

De Coen, V., Vansteelandt, S., Maes, L., Huybrechts, I., De Bourdeaudhuij, I., \& Vereecken, C. (2012). Parental socioeconomic status and soft drink consumption of the child. The mediating proportion of parenting practices. Appetite, 59, 76-80. 
De Vet, H. C. W., Terwee, C. B., Knol, D. L., \& Bouter, L. M. (2006). When to use agreement versus reliability measures. Journal of Clinical Epidemiology, 59, 1033-1039.

Diep, C. S., Beltran, A., Chen, T.A., Thompson, D., O’Connor, T., Hughes, S., . . Baranowski, T. (2015). Predicting use of effective vegetable parenting practices with the Model of Goal Directed Behavior. Public Health Nutrition, 18, 1389-1396.

Dilorio, C. K. (2005). Measurement in health behavior: Methods for research and evaluation. San Fransisco: Jossey-Bass.

Duffey, K. J., Rivera, J. A., \& Popkin, B. M. (2014). Snacking Is Prevalent in Mexico. Journal of Nutrition, 144, 1843-1849.

Dutman, A. E., Stafleu, A., Kruizinga, A., Brants, H. A. M., Westerterp, K. R., Kistemaker, C., . . . Goldbohm, R. A. (2011). Validation of an FFQ and options for data processing using the doubly labelled water method in children. Public Health Nutrition, 14, 410-417.

Ek, A., Sorjonen, K., Nyman, J., Marcus, C., \& Nowicka, P. (2015). Child behaviors associated with childhood obesity and parents' self-efficacy to handle them: Confirmatory factor analysis of the Lifestyle Behavior Checklist. International Journal of Behavioral Nutrition and Physical Activity, 12, 36.

Elfeddali, I., Bolman, C., Mesters, I., Wiers, R. W., \& de Vries, H. (2010). Factors underlying smoking relapse prevention: results of an international Delphi study. Health Education Research, 25, 1008-1020.

Epstein, L. H., Paluch, R. A., Beecher, M. D., \& Roemmich, J. N. (2008). Increasing healthy eating vs. reducing high energy-dense foods to treat pediatric obesity. Obesity, 16, 318-326.

Ezendam, N. P., Evans, A. E., Stigler, M. H., Brug, J., \& Oenema, A. (2010). Cognitive and home environmental predictors of change in sugar-sweetened beverage consumption among adolescents. British Journal of Nutrition, 103, 768-774.

Faith, M. S., Scanlon, K. S., Birch, L. L., Francis, L. A., \& Sherry, B. (2004). Parent-child feeding strategies and their relationships to child eating and weight status. Obesity Research, $12,1711-1722$. 
Faith, M. S., Van Horn, L., Appel, L. J., Burke, L. E., Carson, J. A., Franch, H. A., . . WylieRosett, J. (2012). Evaluating parents and adult caregivers as "agents of change" for treating obese children: evidence for parent behavior change strategies and research gaps: a scientific statement from the American Heart Association. Circulation, 125, 1186-1207.

Farrow, C. (2014). A comparison between the feeding practices of parents and grandparents. Eating Behaviors, 15, 339-342.

Field, A. (2013). Discovering statistics using IBM SPSS statistics. London: Sage.

Fishbein, M., \& Ajzen, I. (1975). Belief, Attitude, Intention, and Behavior: An Introduction to Theory and Research. Reading, MA: Addison-Wesley.

Fisher, J. O., Johnson, R. K., Lindquist, C., Birch, L. L., \& Goran, M. I. (2000). Influence of body composition on the accuracy of reported energy intake in children. Obesity Research, 8, 597-603.

Flay, B. R., \& Petraitis, J. (1994). The theory of triadic influence: A new theory of health behavior with implications for preventive interventions. Advances in Medical Sociology, 4, 19-44.

Fredriks, A. M., van Buuren, S., Wit, J. M., \& Verloove-Vanhorick, S. P. (2000). Body index measurements in 1996-7 compared with 1980. Archives of Disease in Childhood, 82, 107-112.

Gattshall, M. L., Shoup, J. A., Marshall, J. A., Crane, L. A., \& Estabrooks, P. A. (2008). Validation of a survey instrument to assess home environments for physical activity and healthy eating in overweight children. International Journal of Behavioral Nutrition and Physical Activity, 5, 3.

Gerards, S. M. P. L., Hummel, K., Dagnelie, P. C., de Vries, N. K., \& Kremers, S. P. J. (2013). Parental self-efficacy in childhood overweight: validation of the Lifestyle Behavior Checklist in the Netherlands. International Journal of Behavioral Nutrition and Physical Activity, 10, 7.

Gerards, S. M.P.L., Dagnelie, P. C., Jansen, M. W. J., van der Goot, L. O. H. M., de Vries, N. K., Sanders, M. R., \& Kremers, S. P. J. (2012). Lifestyle Triple P: a parenting intervention for childhood obesity. BMC Public Health, 12, 267 
Gerards, S. M. P. L., \& Kremers, S. P. J. (2015). The Role of Food Parenting Skills and the Home Food Environment in Children's Weight Gain and Obesity. Current Obesity Reports, 4, 30-36.

Gerris, J. R. M., Houtmans, M. J. M., Kwaaitaal-Roosen, E. M. G., De Schipper, J. C., Vermulst, A. A., \& Janssens, J. M. A. M. (1998). Parents, adolescents and young adults in Dutch families: a longitudinal study. Nijmegen: Institute of Family Studies, University of Nijmegen.

Gevers, D. W. M., Kremers, S. P. J., de Vries, N. K., \& van Assema, P. (2014a). Clarifying concepts of food parenting practices. A Delphi study with an application to snacking behavior. Appetite, 79, 51-57.

Gevers, D. W. M., Kremers, S. P. J., de Vries, N. K., van Assema, P. (2014b).

Voedingsspecifieke opvoedingspraktijken meetbaar maken. VoedingNu, 16, 29.

Gevers, D. W. M., Kremers, S. P. J., de Vries, N. K., \& van Assema, P. (2015a). Intake of energy-dense snack foods and drinks among Dutch children aged 7-12 years: how many, how much, when, where and which? Public Health Nutrition, 1-10.

Gevers, D. W. M., Kremers, S. P. J., de Vries, N. K., \& van Assema, P. (2015b). Patterns of Food Parenting Practices and Children's Intake of Energy-Dense Snack Foods. Nutrients, 7, 4093-4106.

Gevers, D. W. M., van Assema, P., Sleddens, E. F. C., de Vries, N. K., \& Kremers, S. P. J. (2015c). Associations between general parenting, restrictive snacking rules, and adolescent's snack intake. The roles of fathers and mothers and interparental congruence. Appetite, 87, 184-191.

Gilbert, J. A., Miller, D., Olson, S., \& St-Pierre, S. (2012). After-school snack intake among Canadian children and adolescents. Canadian Journal of Public Health, 103, e448e452.

Golan, M., \& Crow, S. (2004). Parents are key players in the prevention and treatment of weight-related problems. Nutrition Reviews, 62, 39-50.

Gregori, D., Foltran, F., Ghidina, M., \& Berchialla, P. (2011). Understanding the influence of the snack definition on the association between snacking and obesity: a review. International Journal of Food Sciences and Nutrition, 62, 270-275.

Gregori, D., \& Maffeis, C. (2007). Snacking and obesity: urgency of a definition to explore such a relationship. Journal of the American Dietetic Association, 107, 562-563. 
Gubbels, J. S., Gerards, S. M. P. L., \& Kremers, S. P. J. (2015). Use of food practices by childcare staff and the association with dietary intake of children at childcare. Nutrients, 7, 2161-2175.

Gubbels, J. S., van Kann, D. H., de Vries, N. K., Thijs, C., \& Kremers, S. P. (2014). The next step in health behavior research. The need for ecological moderation analyses - an application to diet and physical activity at childcare. International Journal of Behavioral Nutrition and Physical Activity, 11, 52.

Guenther, P. M., Dodd, K. W., Reedy, J., \& Krebs-Smith, S. M. (2006). Most Americans eat much less than recommended amounts of fruits and vegetables. Journal of the American Dietetic Association, 106, 1371-1379.

Haerens, L., Craeynest, M., Deforche, B., Maes, L., Cardon, G., \& de Bourdeaudhuij, I. (2008). The contribution of psychosocial and home environmental factors in explaining eating behaviours in adolescents. European Journal of Clinical Nutrition, 62, 51-59.

Hair, J. R., Anderson, R. E., Tatham, R. L., \& Black, W. C. (1998). Multivariate data analysis. Upper Saddle River, NJ: Prentice-Hall.

Hart, C. N., Raynor, H. A., Osterholt, K. M., Jelalian, E., \& Wing, R. R. (2011). Eating and activity habits of overweight children on weekdays and weekends. International Journal of Pediatric Obesity, 6, 467-472.

Hasson, F., Keeney, S., \& McKenna, H. (2000). Research guidelines for the Delphi survey technique. Journal of advanced nursing, 32, 1008-1015.

Haycraft, E., \& Blissett, J. (2012). Predictors of paternal and maternal controlling feeding practices with 2- to 5-year-old children. Journal of Nutrition Education and Behavior, 44, 390-397.

Haycraft, E. L., \& Blissett, J. M. (2008). Maternal and paternal controlling feeding practices. Reliability and relationships with BMI. Obesity, 16, 1552-1558.

He, F. J., \& MacGregor, G. A. (2006). Importance of salt in determining blood pressure in children: meta-analysis of controlled trials. Hypertension, 48, 861-869.

Hendricks, K., Briefel, R., Novak, T., \& Ziegler, P. (2006). Maternal and child characteristics associated with infant and toddler feeding practices. Journal of the American Dietetic Association, 106, S135-S148.

Hendy, H. M., \& Williams, K. E. (2012). Mother's feeding practices for children 3-10 years of age and their associations with child demographics. Appetite, 58, 710-716. 
Hendy, H. M., Williams, K. E., Camise, T. S., Eckman, N., \& Hedemann, A. (2009). The Parent Mealtime Action Scale (PMAS). Development and association with children's diet and weight. Appetite, 52, 328-339.

Hill, A. J., \& Pallin, V. (1998). Dieting awareness and low self-worth: related issues in 8-yearold girls. International Journal of Eating Disorders, 24, 405-413.

Hirasing, R. A., Fredriks, A. M., van Buuren, S., Verloove-Vanhorick, S. P., \& Wit, J. M. (2001). Toegenomen prevalentie van overgewicht en obesitas bij Nederlandse kinderen en signalering daarvan aan de hand van internationale normen en nieuwe referentiediagrammen. (Increased prevalence of overweight and obesity in Dutch children, and the detection of overweight and obesity using international criteria and new reference diagrams). Nederlands Tijdschrift voor Geneeskunde, 145, 1303-1308.

Hnatiuk, J. A., Salmon, J., Campbell, K. J., Ridgers, N. D., \& Hesketh, K. D. (2015). Tracking of maternal self-efficacy for limiting young children's television viewing and associations with children's television viewing time: a longitudinal analysis over 15-months. BMC Public Health, 15, 517.

Hsu, C. C., \& Sandford, B. A. (2007). Minimizing non-response in the Delphi process: How to respond to non-response. Practical Assessment, Research \& Evaluation, 12, 62-78.

Hughes, S. O., O'Connor, T. M., \& Power, T. G. (2008). Parenting and children's eating patterns: examining control in a broader context. International Journal of Child and Adolescent Health, 1, 323-330.

Hughes, S. O., Anderson, C. B., Power, T. G., Micheli, N., Jaramillo, S., \& Nicklas, T. A. (2006). Measuring feeding in low-income African-American and Hispanic parents. Appetite, $46,215-223$.

Hughes, S. O., Frankel, L. A., Beltran, A., Hodges, E., Hoerr, S., Lumeng, J., . . Kremers, S. P. J. (2013). Food parenting measurement issues: working group consensus report. Childhood Obesity, 9, S95-S102.

Insel, P., Ross, D., McMahon, K., \& Bernstein, M. (2011). Nutrition. Sudbury: Jones and Barlett.

Jago, R., Wood, L., Zahra, J., Thompson, J. L., \& Sebire, S. J. (2015). Parental Control, Nurturance, Self-Efficacy, and Screen Viewing among 5-to 6-Year-Old Children: A Cross-Sectional Mediation Analysis To Inform Potential Behavior Change Strategies. Childhood Obesity, 11, 139-147. 
Jansen, P. W., Giallo, R., Westrupp, E. M., Wake, M., \& Nicholson, J. M. (2013). Bidirectional associations between mothers' and fathers' parenting consistency and child BMI. Pediatrics, 132, e1513-e1520.

Johnson, G. H., \& Anderson, G. H. (2010). Snacking definitions: impact on interpretation of the literature and dietary recommendations. Critical Reviews in Food Science and Nutrition, 50, 848-871.

Johnson, L., Van Jaarsveld, C. H. M., \& Wardle, J. (2011). Individual and family environment correlates differ for consumption of core and non-core foods in children. British Journal of Nutrition, 105), 950-959.

Keij, I. (2000). Standaarddefinitie allochtonen. Hoe doet het CBS dat nu? (Standard definition immigrants. How does Statistics Netherlands do this?). Index, 10, 24-25.

Kerr, M. A., McCrorie, T. A., Rennie, K. L., Wallace, J. M., \& Livingstone, M. B. E. (2010). Snacking patterns according to location among Northern Ireland children. International Journal of Pediatric Obesity, 5, 243-249.

Kerr, M. A., Rennie, K. L., McCaffrey, T. A., Wallace, J. M. W., Hannon-Fletcher, M. P., \& Livingstone, M. B. E. (2009). Snacking patterns among adolescents: a comparison of type, frequency and portion size between Britain in 1997 and Northern Ireland in 2005. British Journal of Nutrition, 101, 122-131.

Khandpur, N., Blaine, R. E., Fisher, J. O., \& Davison, K. K. (2014). Fathers' child feeding practices: a review of the evidence. Appetite, 78, 110-121.

Kitzmann, K. M., \& Beech, B. M. (2006). Family-based interventions for pediatric obesity: methodological and conceptual challenges from family psychology. Journal of Family Psychology, 20, 175-189.

Kocken, P. L., Schönbeck, Y., Henneman, L., Janssens, A. C., \& Detmar, S. B. (2012). Ethnic differences and parental beliefs are important for overweight prevention and management in children. A cross-sectional study in The Netherlands. BMC Public Health, 12, 867.

Kremers, S. P. J., Sleddens, E. F. C., Gerards, S. M. P. L., Gubbels, J. S., Rodenburg, G., Gevers, D. W. M., \& van Assema, P. (2013). General and Food-Specific Parenting: Measures and Interplay. Childhood Obesity, 9, S22-S31.

Kremers, S. P. J. (2010). Theory and practice in the study of influences on energy balancerelated behaviors. Patient Education and Counseling, 79, 291-298. 
Kröller, K., \& Warschburger, P. (2008). Associations between maternal feeding style and food intake of children with a higher risk for overweight. Appetite, 51, 166-172.

Kröller, K., \& Warschburger, P. (2009). Maternal feeding strategies and child's food intake: considering weight and demographic influences using structural equation modeling. International Journal of Behavioral Nutrition and Physical Activity, 6, 78.

Lally, P., Cooke, L., McGowan, L., Croker, H., Bartle, N., \& Wardle, J. (2012). Parents' misperceptions of social norms for pre-school children's snacking behaviour. Public Health Nutrition, 15, 1678-1682.

Landeta, J. (2006). Current validity of the Delphi method in social sciences. Technological Forecasting and Social Change, 73, 467-482.

Landis, J. R., \& Koch, G. G. (1977). The measurement of observer agreement for categorical data. Biometrics, 33, 159-174.

Larsen, J. K., Hermans, R. C. J., Sleddens, E. F. C., Engels, R. C. M. E., Fisher, J. O., \& Kremers, S. P. J. (2015). How parental dietary behavior and food parenting practices affect children's dietary behavior. Interacting sources of influence? Appetite, 89, 246-257.

Larson, N., \& Story, M. (2013). A review of snacking patterns among children and adolescents: what are the implications of snacking for weight status? Childhood Obesity, 9, 104-115.

Lipsey, M. W. (1990). Design sensitivity: Statistical power for experimental research. Newbury Park, CA: Sage.

Lloyd, A. B., Lubans, D. R., Plotnikoff, R. C., Collins, C. E., \& Morgan, P. J. (2014). Maternal and paternal parenting practices and their influence on children's adiposity, screen-time, diet and physical activity. Appetite, 79, 149-157.

Lobstein, T., Baur, L., \& Uauy, R. (2004). Obesity in children and young people: a crisis in public health. Obesity Reviews, 5, 4-85.

Lohaus, A., Vierhaus, M., \& Ball, J. (2009). Parenting styles and health-related behavior in childhood and early adolescence. Results of a longitudinal study. The Journal of Early Adolescence, 29, 449-475.

Loth, K. A., MacLehose, R. F., Fulkerson, J. A., Crow, S., \& Neumark-Sztainer, D. (2013). Foodrelated parenting practices and adolescent weight status. A population based study. Pediatrics, 131, e1443-e1450. 
Loth, K. A., MacLehose, R. F., Fulkerson, J. A., Crow, S., \& Neumark-Sztainer, D. (2014). Are food restriction and pressure-to-eat parenting practices associated with adolescent disordered eating behaviors? International Journal of Eating Disorders, 47, 310-314.

Lytle, L. A., Varnell, S. Murray, D. M., Story, M., Perry, C., Birnbaum, A. S. \& Kubik, M. Y. (2003). Predicting adolescents' intake of fruits and vegetables. Journal of Nutrution Education and Behavior, 35, 170-175.

Maccoby, E. E., \& Martin, J. A. (1983). Socialization in the context of the family: parent-child interaction. In: Hetherington, E. M., Mussen, P.H. Handbook of child psychology: socialization, personality, and social development (pp. 1-101). New York, NY: Wiley.

Macdiarmid, J., Loe, J., Craig, L. C. A., Masson, L. F., Holmes, B., \& McNeill, G. (2009). Meal and snacking patterns of school-aged children in Scotland. European Journal of Clinical Nutrition, 63, 1297-1304.

Mackerras, D., \& Rutishauser, I. (2005). 24-hour national dietary survey data: how do we interpret them most effectively? Public Health Nutrition, 8, 657-665.

Mallan, K. M., Daniels, L. A., Nothard, M., Nicholson, J. M., Wilson, A., Cameron, C. M., et al. (2014). Dads at the dinner table. A cross-sectional study of Australian fathers' child feeding perceptions and practices. Appetite, 73, 40-44.

Mâsse, L. C., \& Watts, A. W. (2013). Stimulating innovations in the measurement of parenting constructs. Childhood obesity, 9, S5-S13.

Melbye, E. L., Øgaard, T., \& Øverby, N. C. (2013a). Associations between parental feeding practices and child vegetable consumption. Mediation by child cognitions? Appetite, 69, 23-30.

Melbye, E. L., Øgaard, T., Øverby, N. C., \& Hansen, H. (2013b). Parental food-related behaviors and family meal frequencies: associations in Norwegian dyads of parents and preadolescent children. BMC Public Health, 13, 820.

Mena, N. Z., Gorman, K., Dickin, K., Greene, G., \& Tovar, A. (2015). Contextual and Cultural Influences on Parental Feeding Practices and Involvement in Child Care Centers among Hispanic Parents. Childhood Obesity, 11, 347-354.

Monge-Rojas, R., Smith-Castro, V., Colon-Ramos, U., Garita-Arce, C., Sánchez-Lopez, M., \& Chinnock, A. (2010). Parental feeding styles and adolescents' healthy eating habits. Structure and correlates of a Costa Rican questionnaire. Appetite, 55, 253-262. 
Morawska, A., \& West, F. (2013). Do parents of obese children use ineffective parenting strategies? Journal of Child Health Care, 17, 375-386.

Morgan, P. J., Lubans, D. R., Callister, R., Okely, A. D., Burrows, T. L., Fletcher, R., \& Collins, C. (2011). The 'Healthy Dads, Healthy Kids' randomized controlled trial: efficacy of a healthy lifestyle program for overweight fathers and their children. International Journal of Obesity, 35, 436-447.

Musher-Eizenman, D., \& Holub, S. (2007). Comprehensive Feeding Practices Questionnaire: validation of a new measure of parental feeding practices. Journal of Pediatric Psychology, 32, 960-972.

Musher-Eizenman, D. R., \& Kiefner, A. (2013). Food parenting: a selective review of current measurement and an empirical examination to inform future measurement. Childhood obesity, 9, S32-S39.

Myers, R. H. (1990). Classical and modern regression with applications. Belmont: Duxbury Press.

Netherlands Nutrition Centre (2011). Richtlijnen voedselkeuze. (Guidelines for food choices). The Hague: Voedingscentrum

Niermann, C., Krapf, F., Renner, B., Reiner, M., \& Woll, A. (2014). Family health climate scale (FHC-scale). Development and validation. The International Journal of Behavioral Nutrition and Physical Activity, 11, 30.

Nunnally, J. C., \& Bernstein, I. H. (1994). Psychometric theory. New York: McGraw-Hill.

Nyberg, G., Sundblom, E., Norman, Å., Bohman, B., Hagberg, J., \& Elinder, L. S. (2015). Effectiveness of a Universal Parental Support Programme to Promote Healthy Dietary Habits and Physical Activity and to Prevent Overweight and Obesity in 6-Year-Old Children: The Healthy School Start Study, a Cluster-Randomised Controlled Trial. PLoS One, 10, e0116876.

O'Connor, T. M., Hughes, S., Watson, K. B., Baranowski, T., Nicklas, T. A., Fisher, J. O., . . . Shewchuk, R. M. (2010). Parenting practices are associated with fruit and vegetable consumption in pre-school children. Public health nutrition, 13, 91-101.

Ogden, J., Reynolds, R., \& Smith, A. (2006). Expanding the concept of parental control: a role for overt and covert control in children's snacking behaviour? Appetite, 47, 100-106. 
Ostbye, T., Krause, K. M., Stroo, M., Lovelady, C. A., Evenson, K. R., Peterson, B. L., . . . Zucker, N. L. (2012). Parent-focused change to prevent obesity in preschoolers: results from the KAN-DO study. Preventive Medicine, 55, 188-195.

Patrick, H., Hennessy, E., McSpadden, K., \& Oh, A. (2013). Parenting styles and practices in children's obesogenic behaviors: scientific gaps and future research directions. Childhood obesity, 9, S73-S86.

Pearson, N., Salmon, J., Campbell, K., Crawford, D., \& Timperio, A. (2011). Tracking of children's body-mass index, television viewing and dietary intake over five-years. Prev Med, 53, 268-270.

Piernas, C., Barquera, S., \& Popkin, B. M. (2014). Current patterns of water and beverage consumption among Mexican children and adolescents aged 1-18 years: analysis of the Mexican National Health and Nutrition Survey 2012. Public Health Nutrition, 17, 2166-2175.

Piernas, C., \& Popkin, B. M. (2010). Trends In Snacking Among US Children. Health Affairs, 29, 398-404.

Pinard, C. A., Yaroch, A. L., Hart, M. H., Serrano, E. L., McFerren, M. M., \& Estabrooks, P. A. (2012). Measures of the home environment related to childhood obesity: a systematic review. Public Health Nutrition, 15, 97-109.

Portney, L. G., \& Watkins, M. P. (2000). Foundations of clinical research. Applications to practice. Upper Saddle River, NJ: Prentice Hall.

Power, T. G. (2013). Parenting dimensions and styles: a brief history and recommendations for future research. Childhood obesity, 9, S14-S21.

Power, T. G., Sleddens, E. F. C., Berge, J., Connell, L., Govig, B., Hennessy, E., . . St. George, S. M. (2013). Contemporary research on parenting: conceptual, methodological, and translational issues. Childhood obesity, 9, S87-S94.

Pulley, C., Galloway, A. T., Webb, R. M., \& Payne, L. O. (2014). Parental child feeding practices. How do perceptions of mother, father, sibling, and self vary? Appetite, 80 , 96-102.

Raaijmakers, L. G. M., Gevers, D. W. M., Teuscher, D., Kremers, S. P. J., \& van Assema, P. (2014). Emotional and instrumental feeding practices of Dutch mothers regarding foods eaten between main meals. BMC Public Health, 14, 171. 
Rangan, A. M., Randall, D., Hector, D. J., Gill, T. P., \& Webb, K. L. (2008). Consumption of 'extra' foods by Australian children: types, quantities and contribution to energy and nutrient intakes. European Journal of Clinical Nutrition, 62, 356-364.

Rebholz, C. E., Chinapaw, M. J. M., van Stralen, M. M., Bere, E., Bringolf, B., De Bourdeaudhuij, I., . . . te Velde, S. J. (2014). Agreement between parent and child report on parental practices regarding dietary, physical activity and sedentary behaviours: the ENERGY cross-sectional survey. BMC Public Health, 14, 918.

Reilly, J. J., \& Kelly, J. (2011). Long-term impact of overweight and obesity in childhood and adolescence on morbidity and premature mortality in adulthood: systematic review. International Journal of Obesity, 35, 891-898.

Reilly, J. J., Methven, E., McDowell, Z. C., Hacking, B., Alexander, D., Stewart, L., \& Kelnar, C. J. H. (2003). Health consequences of obesity. Archives of Disease in Childhood, 88, 748-752.

Rennie, K. L., Johnson, L., \& Jebb, S. A. (2005). Behavioural determinants of obesity. Best Practice \& Research Clinical Endocrinology \& Metabolism, 19, 343-358.

Rhee, K. E., Coleman, S. M., Appugliese, D. P., Kaciroti, N. A., Corwyn, R. F., Davidson, N. S., . . . Lumeng, J. C. (2009). Maternal feeding practices become more controlling after and not before excessive rates of weight gain. Obesity, 17, 1724-1729.

Rijksinstituut voor Volksgezondheid en Milieu (RIVM) (2011). NEVO-tabel. Nederlands Voedingsstoffenbestand 2011 (Dutch Food Composition Database 2011). The Hague: RIVM.

Rijksoverheid (2014). Alles is gezondheid... Het Nationaal Programma Preventie 2014 - 2016. Den Haag: Rijksoverheid.

Rockell, J. E., Parnell, W. R., Wilson, N. C., Skidmore, P. M. L., \& Regan, A. (2011a). Nutrients and foods consumed by New Zealand children on schooldays and non-schooldays. Public Health Nutition, 14, 203-208.

Rockell, J. E., Skidmore, P. M. L., Parnell, W. R., \& Wilson, N. (2011b). What children eat during afternoons and evenings: is it important? Public Health Nutrition, 14, 557-562.

Rodenburg, G., Kremers, S. P. J., Oenema, A., \& van de Mheen, D. (2014). Associations of parental feeding styles with child snacking behaviour and weight in the context of general parenting. Public Health Nutrition, 17, 960-969. 
Rodenburg, G., Oenema, A., Kremers, S. P. J., \& van de Mheen, D. (2013). Clustering of dietand activity-related parenting practices: cross-sectional findings of the INPACT study. The international journal of behavioral nutrition and physical activity, 10, 36.

Rollins, B. Y., Loken, E., Savage, J. S., \& Birch, L. L. (2014). Maternal controlling feeding practices and girls' inhibitory control interact to predict changes in BMI and eating in the absence of hunger from 5 to 7 y. The American Journal of Clinical Nutrition, 99, 249-257.

Rosnow, R. L., \& Rosenthal, R. (1989). Statistical procedures and the justification of knowledge in psychological science. American Psychologist, 44, 1276-1284.

Rothausen, B. W., Matthiessen, J., Andersen, L. F., Brockhoff, P. B., \& Tetens, I. (2013). Dietary patterns on weekdays and weekend days in 4-14-year-old Danish children. British Journal of Nutrition, 109, 1704-1713.

Ruiter, E. L. M., Fransen, G. A. J., Molleman, G. R. M., van der Velden, K., \& Engels, R. C. M. E. (2015). The effectiveness of a web-based Dutch parenting program to prevent overweight in children 9-13 years of age: study protocol for a two-armed cluster randomized controlled trial. BMC Public Health, 15, 148.

Schneider, F., van Osch, L., \& de Vries, H. (2012). Identifying factors for optimal development of health-related websites: a delphi study among experts and potential future users. Journal of medical Internet research, 14, e18.

Schmitz, K. H., Lytle, L. A., Phillips, G. A., Murray, D. M., Birnbaum, A. S., \& Kubik, M. Y. (2002). Psychosocial correlates of physical activity and sedentary leisure habits in young adolescents: the Teens Eating for Energy and Nutrition at School study. Preventive medicine, 34, 266-278.

Schokker, D. F., Visscher, T. L. S., Nooyens, A. C. J., van Baak, M. A., \& Seidell, J. C. (2007). Prevalence of overweight and obesity in the Netherlands. Obesity Reviews, 8, 101108.

Schönbeck, Y., Talma, H., van Dommelen, P., Bakker, B., Buitendijk, S. E., Hirasing, R. A., \& van Buuren, S. (2011). Increase in prevalence of overweight in Dutch children and adolescents: a comparison of nationwide growth studies in 1980, 1997 and 2009. PLoS One, 6, e27608.

Sheiham, A. (2001). Dietary effects on dental diseases. Public Health Nutrition, 4, 569-591. 
Sherry, B., Jefferds, M. E., \& Grummer-Strawn, L. M. (2007). Accuracy of adolescent selfreport of height and weight in assessing overweight status. A literature review. Archives of Pediatrics \& Adolescent Medicine, 161, 1154-1161.

Singh, A. S., Mulder, C., Twisk, J. W. R., van Mechelen, W., \& Chinapaw, M. J. M. (2008). Tracking of childhood overweight into adulthood: a systematic review of the literature. Obesity Reviews, 9, 474-488.

Singh, A. S., Vik, F. N., Chinapaw, M. J. M., Uijtdewilligen, L., Verloigne, M., Fernández-Alvira, J. M., . . Brug, J. (2011). Test-retest reliability and construct validity of the ENERGY-child questionnaire on energy balance-related behaviours and their potential determinants: the ENERGY-project. International Journal of Behavioral Nutrition and Physical Activity, 8, 136.

Sleddens, E.F.C., O'Connor, T. M., Watson, K. B., Hughes, S. O., Power, T. G., Thijs, C., . . . Kremers, S. P. J. (2014). Development of the Comprehensive General Parenting Questionnaire for caregivers of 5-13 year olds. International Journal of Behavioral Nutrition and Physical Activity, 11, 15.

Sleddens, E. F.C., Gerards, S. M.P.L., Thijs, C., de Vries, N. K., \& Kremers, S. P.J. (2011). General parenting, childhood overweight and obesity-inducing behaviors: A review. International Journal of Pediatric Obesity, 6, e12-e27.

Sleddens, E. F. C., Kremers, S. P. J., De Vries, N. K., \& Thijs, C. (2010). Relationship between parental feeding styles and eating behaviours of Dutch children aged 6-7. Appetite, $54,30-36$.

Slimani, N., Ferrari, P., Ocké, M., Welch, A., Boeing, H., Liere, M., . . Riboli, E. (2000). Standardization of the 24-hour diet recall calibration method used in the european prospective investigation into cancer and nutrition (EPIC): general concepts and preliminary results. European Journal of Clinical Nutrition, 54, 900-917.

Smith, A., Kellet, E., \& Schmerlaib, Y. (1998). The Australian Guide to Healthy Eating. Canberra: Commonwealth Department of Health and Family Services.

Statistics Netherlands (2015). International Standard Classification of Education. Retrieved 1 March, 2015, from http://www.cbs.nl/nl$\mathrm{NL} / \mathrm{menu} / \mathrm{methoden/classificaties/overzicht/isced/} \mathrm{default.htm}$

Statistics Netherlands (2014). Statline Database. Accessed 1 July, 2014 at http://statline.cbs.nl/. 
Statistics Netherlands (2014). Statline Database. Accessed 1 July, 2015 at http://statline.cbs.nl/.

Tabachnick, B. G., \& Fidell, L. S. (2001). Using Multivariate Statistics Boston: Allyn \& Bacon. Taylor, A., Wilson, C., Slater, A., \& Mohr, P. (2011a). Parent-and child-reported parenting. Associations with child weight-related outcomes. Appetite, 57, 700-706.

Taylor, A., Wilson, C., Slater, A., \& Mohr, P. (2011b). Parenting and child body mass index. Longitudinal investigation of maternal and paternal influence. Australian Journal of Psychology, 63, 198-206.

Terwee, C. B., Bot, S. D. M., de Boer, M. R., van der Windt, D. A. W. M., Knol, D. L., Dekker, J., . . . de Vet, H. C. W. (2007). Quality criteria were proposed for measurement properties of health status questionnaires. Journal of Clinical Epidemiology, 60, 3442.

Terwee, C. B., Mokkink, L. B., Knol, D. L., Ostelo, R. W. J. G., Bouter, L. M., \& de Vet, H. C. W. (2012). Rating the methodological quality in systematic reviews of studies on measurement properties: a scoring system for the COSMIN checklist. Quality of Life Research, 21, 651-657.

The International Organization for Standardization Standards (2015). Retrieved 14 January, 2015, from http://www.iso.org/iso/home/standards.htm.

The Netherlands Institute for Social Research (SCP) (2015). Statusscores. Retrieved 1 August, 2014, from http://www.scp.nl/Onderzoek/Lopend_onderzoek/A_Z_alle_lopende_onderzoeken/ Statusscores.

Totland, T. H., Gebremariam, M. K., Lien, N., Bjelland, M., Grydeland, M., Bergh, I. H., . . . Andersen, L. F. (2013a). Does tracking of dietary behaviours differ by parental education in children during the transition into adolescence? Public Health Nutrition, $16,673-682$.

Totland, T. H., Lien, N., Bergh, I. H., Bjelland, M., Gebremariam, M. K., Klepp, K. I., \& Andersen, L. F. (2013b). The relationship between parental education and adolescents' soft drink intake from the age of 11-13 years, and possible mediating effects of availability and accessibility. British Journal of Nutrition, 110, 926-933.

Tschann, J. M., Gregorich, S. E., Penilla, C., Pasch, L. A., de Groat, C. L., Flores, E., ... Butte, N. F. (2013). Parental feeding practices in Mexican American families. Initial test of an 
expanded measure. International Journal of Behavioral Nutrition and Physical Activity, 10, 6 .

Van Ansem, W. J. C., Schrijvers, C. T. M., Rodenburg, G., \& van de Mheen, D. (2014). Maternal educational level and children's healthy eating behaviour: role of the home food environment (cross-sectional results from the INPACT study). International Journal of Behavioral Nutrition and Physical Activity, 11, 113.

Van Assema, P., Glanz, K., Martens, M., \& Brug, J. (2007). Differences between parents' and adolescents' perceptions of family food rules and availability. Journal of Nutrition Education and Behavior, 39, 84-89.

Van Assema, P., Brug, J., Ronda, G., \& Steenhuis, I. (2001). The relative validity of a short Dutch questionnaire as a means to categorize adults and adolescents to total and saturated fat intake. Journal of Human Nutrition and Dietetics, 14, 377-390.

van Buuren, S. (2004). Afkapwaarden van de Body-mass index voor de bepaling van ondergewicht bij Nederlandse kinderen. (Body-mass index cut-off values for underweight in Dutch children). Nederlands Tijdschrift voor Geneeskunde, 148, 19671972.

Van der Horst, K., Kremers, S. P. J., Ferreira, I., Singh, A. S., Oenema, A., \& Brug, J. (2007a). Perceived parenting style and practices and the consumption of sugar-sweetened beverages by adolescents. Health Education Research, 22, 295-304.

Van Lippevelde, W., te Velde, S. J., Verloigne, M., De Bourdeaudhuij, I., Manios, Y., Bere, E., . . . Maes, L. (2013). Associations between home- and family-related factors and fruit juice and soft drink intake among 10- to 12-year old children. The ENERGY project. Appetite, 61, 59-65.

Van Rossum, C. T. M., Fransen, H. P., Verkaik-Kloosterman, J., Buurma-Rethans, E. J. M., \& Ocké, $\quad$ M. C. (2011). Dutch National Food Consumption Survey 2007-2010. Diet of children and adults aged 7 to 69 years. Bilthoven: RIVM.

Van Strien, T., Van Niekerk, R., \& Ouwens, M. A. (2009). Perceived parental food controlling practices are related to obesogenic or leptogenic child life style behaviors. Appetite, 53, 151-154.

Vaughn, A. E., Tabak, R. G., Bryant, M. J., \& Ward, D. S. (2013). Measuring parent food practices: a systematic review of existing measures and examination of instruments. International Journal of Behavioral Nutrition and Physical Activity, 10, 61. 
Vaughn, A. E., Ward, D. S., Fisher, J. O., Faith, M. S., Hughes, S. O., Kremers, S. P. J., . . . Power, T. G. (2015). Fundamental constructs in food parenting practices: a content map to guide future research. Nutrition Reviews, 74, 98-117

Ventura, A. K., \& Birch, L. L. (2008). Does parenting affect children's eating and weight status? International Journal of Behavioral Nutrition and Physical Activity, 5, 15

Vereecken, C. A., Haerens, L., De Bourdeaudhuij, I., \& Maes, L. (2010a). The relationship between children's home food environment and dietary patterns in childhood and adolescence. Public Health Nutrition, 13, 1729-1735.

Vereecken, C. A., Rovner, A., \& Maes, L. (2010b). Associations of parenting styles, parental feeding practices and child characteristics with young children's fruit and vegetable consumption. Appetite, 55, 589-596.

Vereecken, C. A., Keukelier, E., \& Maes, L. (2004). Influence of mother's educational level on food parenting practices and food habits of young children. Appetite, 43, 93-103.

Vereecken, C. A., Van Damme, W., \& Maes, L. (2005). Measuring attitudes, self-efficacy, and social and environmental influences on fruit and vegetable consumption of 11-and 12-year-old children: reliability and validity. Journal of the American Dietetic Association, 105, 257-261.

Vollmer, R. L., \& Mobley, A. R. (2013). Parenting styles, feeding styles, and their influence on child obesogenic behaviors and body weight. A Review. Appetite, 71, 232-241.

Wang, Z., Zhai, F., Zhang, B., \& Popkin, B. M. (2012). Trends in Chinese snacking behaviors and patterns and the social-demographic role between 1991 and 2009. Asia Pacific Journal of Clinical Nutrition, 21, 253-262.

Wardle, J., Sanderson, S., Guthrie, C. A., Rapoport, L., \& Plomin, R. (2002). Parental feeding style and the inter-generational transmission of obesity risk. Obesity Research, 10, 453-462.

Webber, L., Cooke, L., Hill, C., \& Wardle, J. (2010). Child adiposity and maternal feeding practices: a longitudinal analysis. The American Journal of Clinical Nutrition, 92, 14231428.

West F, Sanders M.R., Cleghorn G.J., \& Davies P.S.W. (2010). Randomised clinical trial of a family-based lifestyle intervention for childhood obesity involving parents as the exclusive agents of change. Behaviour Research and Therapy, 48, 1170-1179.

Willet, W. C. (1998). Nutritional epidemiology. New York: Oxford University press. 
Willis, G. B. (1999). Cognitive interviewing. A "how to" guide.

Wood, D., Bruner, J. S., \& Ross, G. (1976). The role of tutoring in problem solving. Journal of Child Psychology and Psychiatry, 17, 89-100.

World Health Organization (WHO) (2003). Diet, nutrition and the prevention of chronic diseases: report of a joint WHO/FAO expert consultation. Geneva: WHO.

Youngblut, J. M., \& Casper, G. R. (1993). Single-item indicators in nursing research. Research in Nursing \& Health, 16, 459-465.

Zarnowiecki, D. M., Dollman, J., \& Parletta, N. (2014). Associations between predictors of children's dietary intake and socioeconomic position: a systematic review of the literature. Obesity reviews, 15, 375-391 
Appendices 


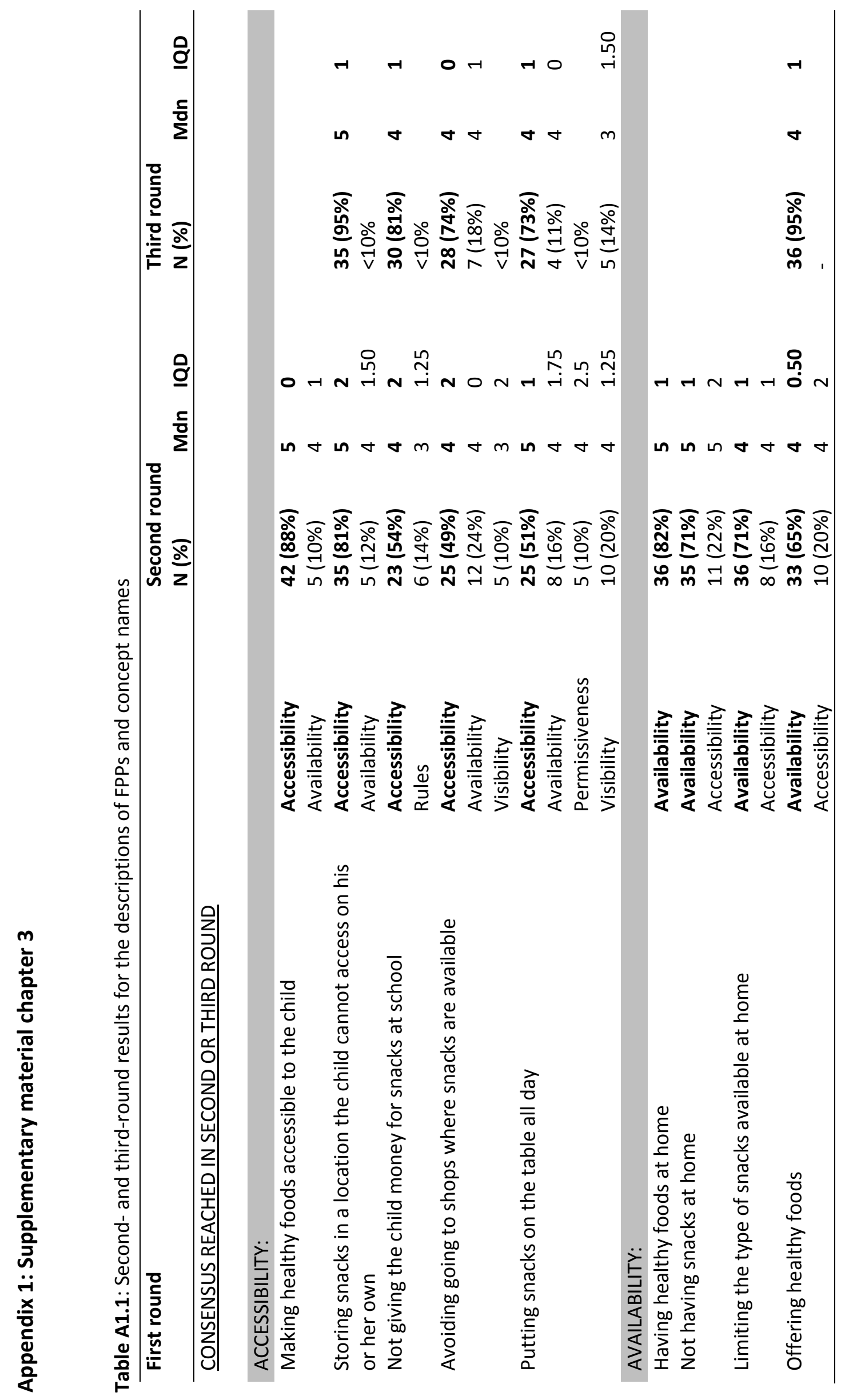




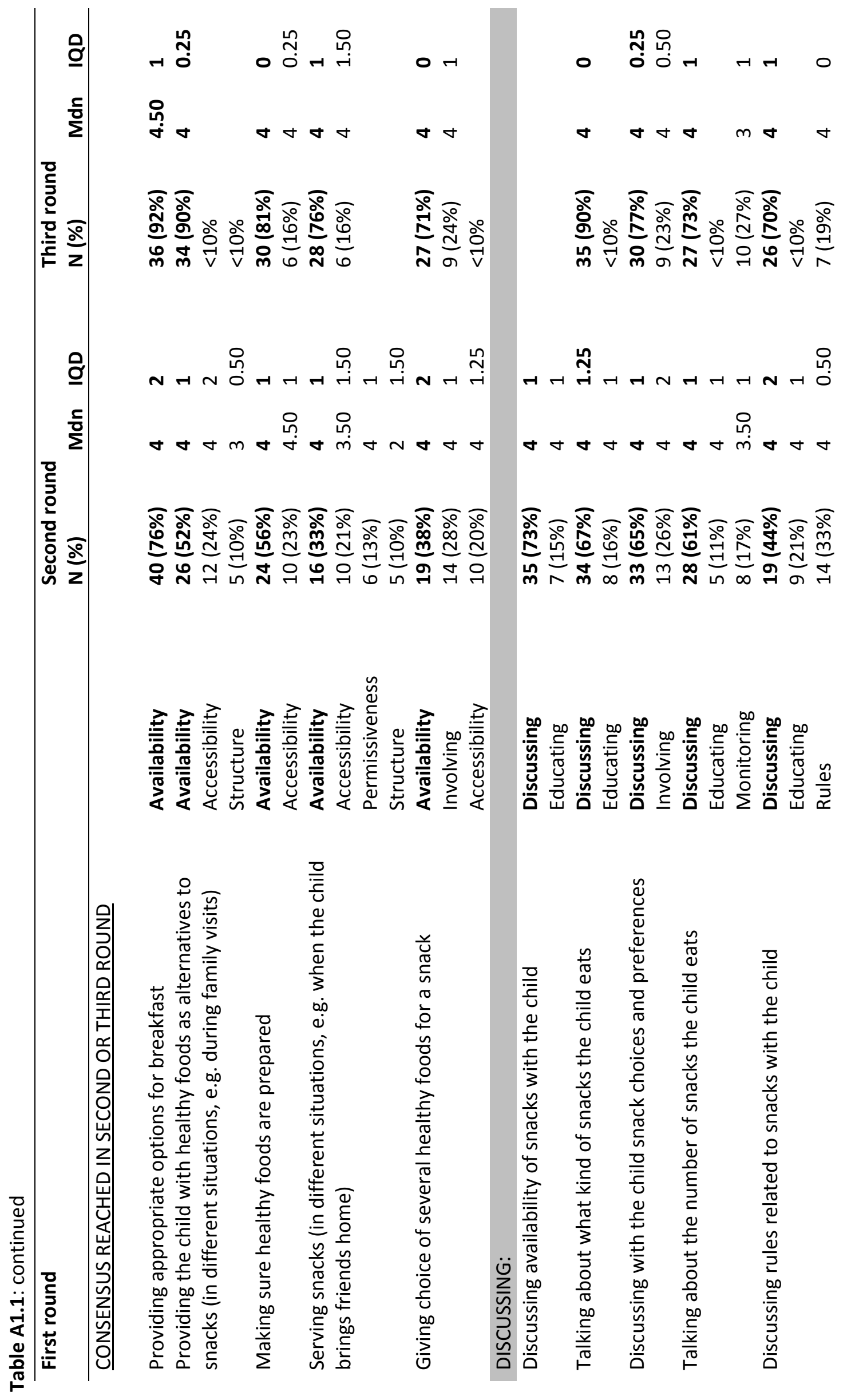




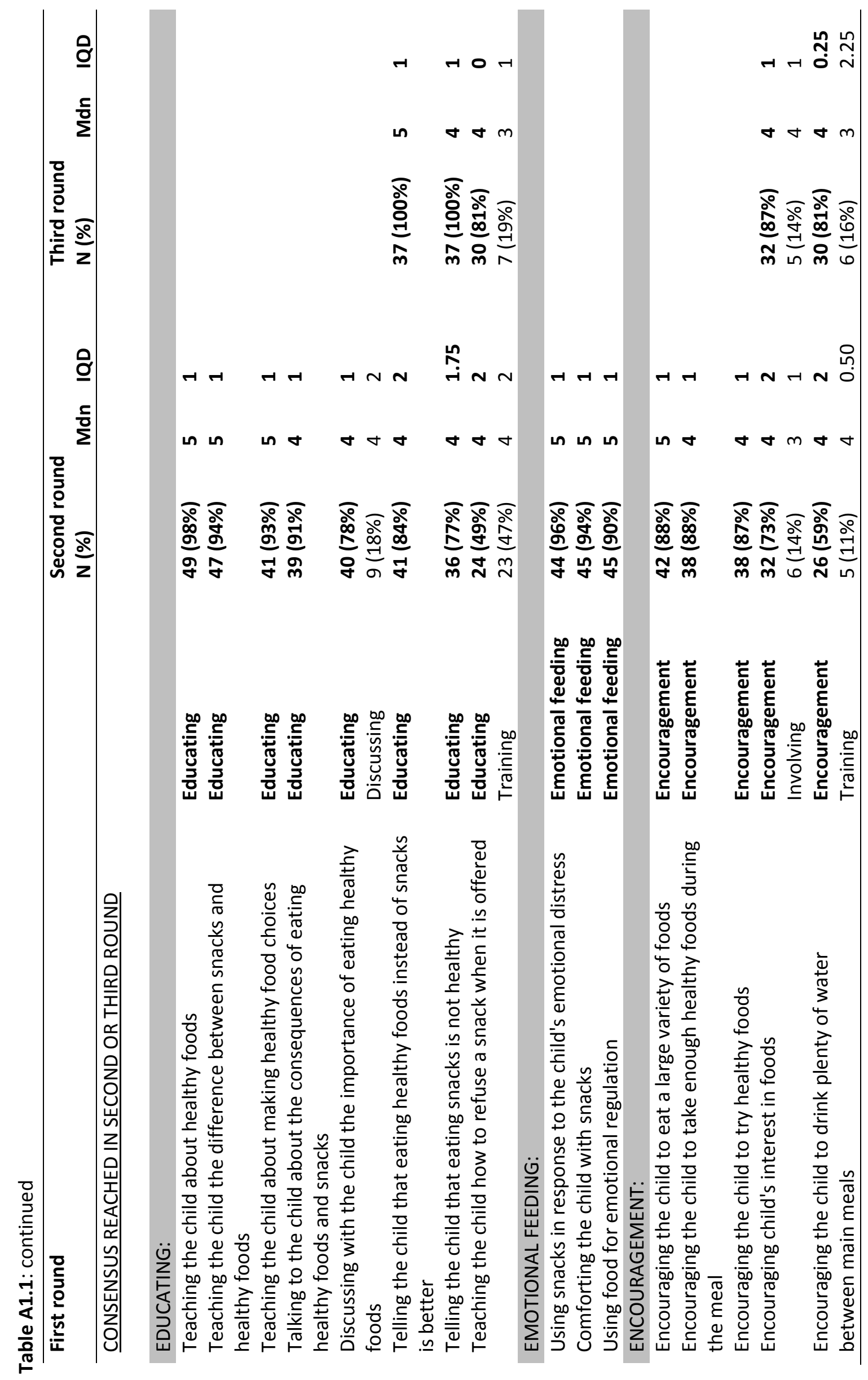




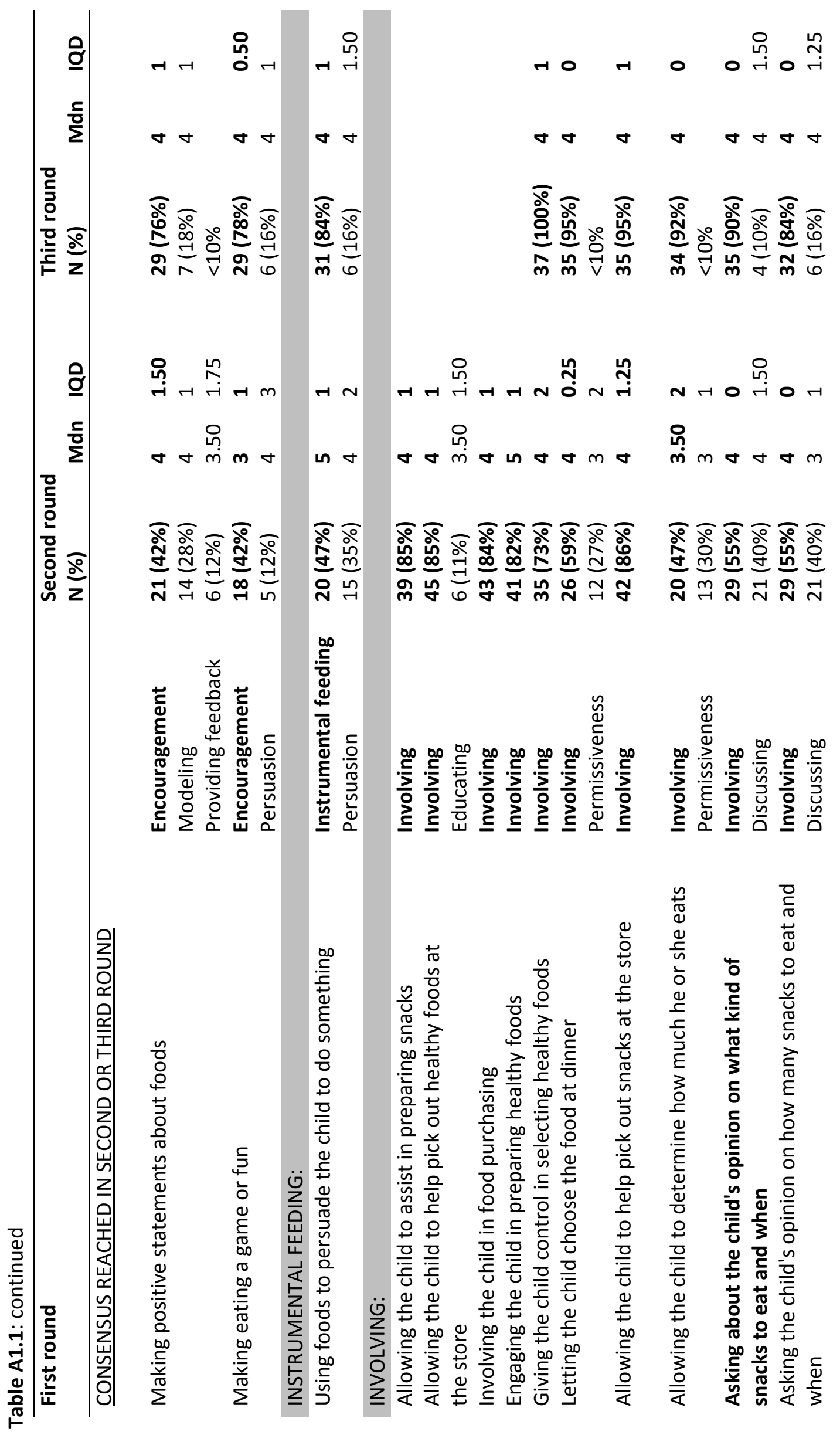




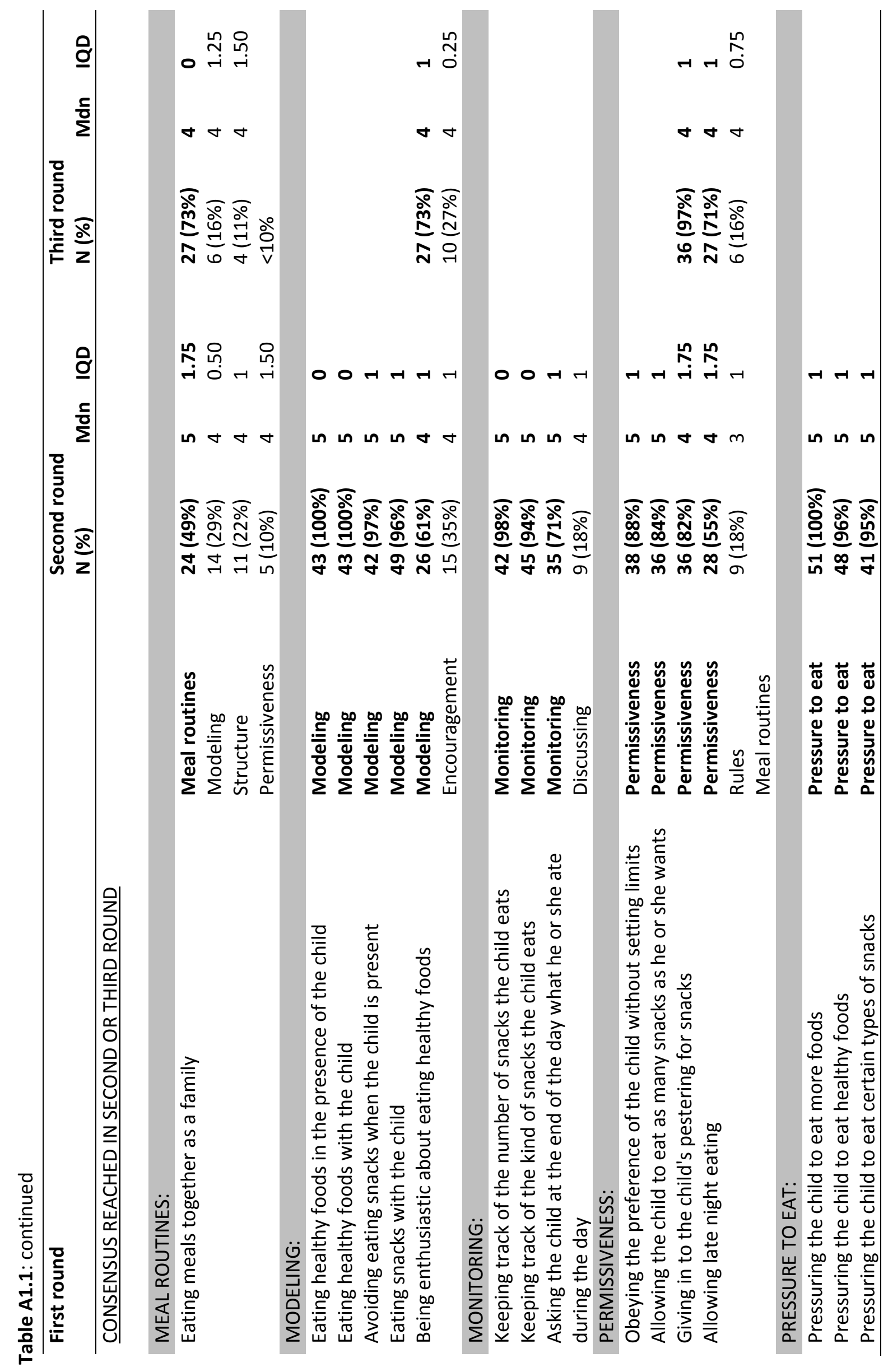




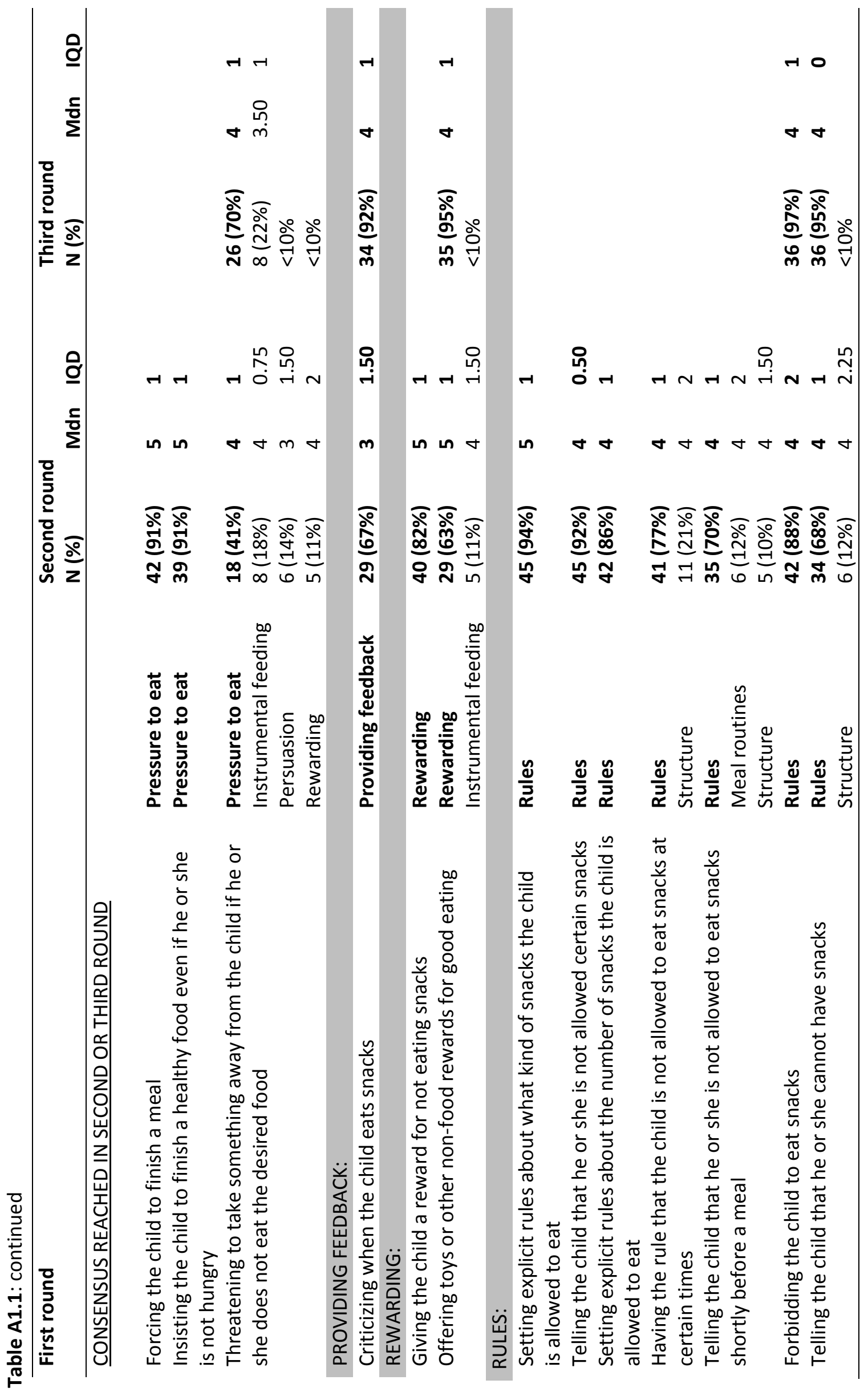




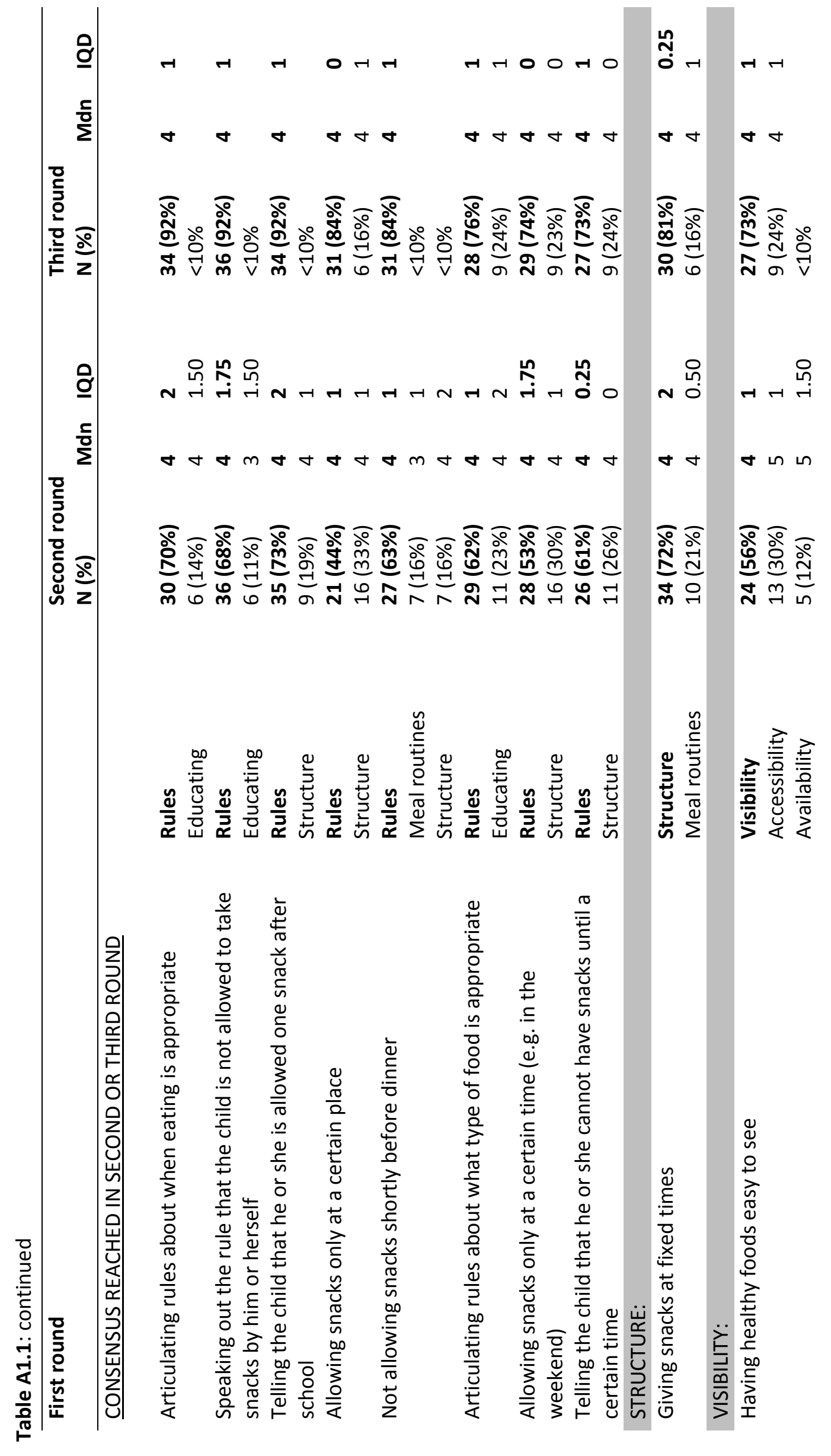




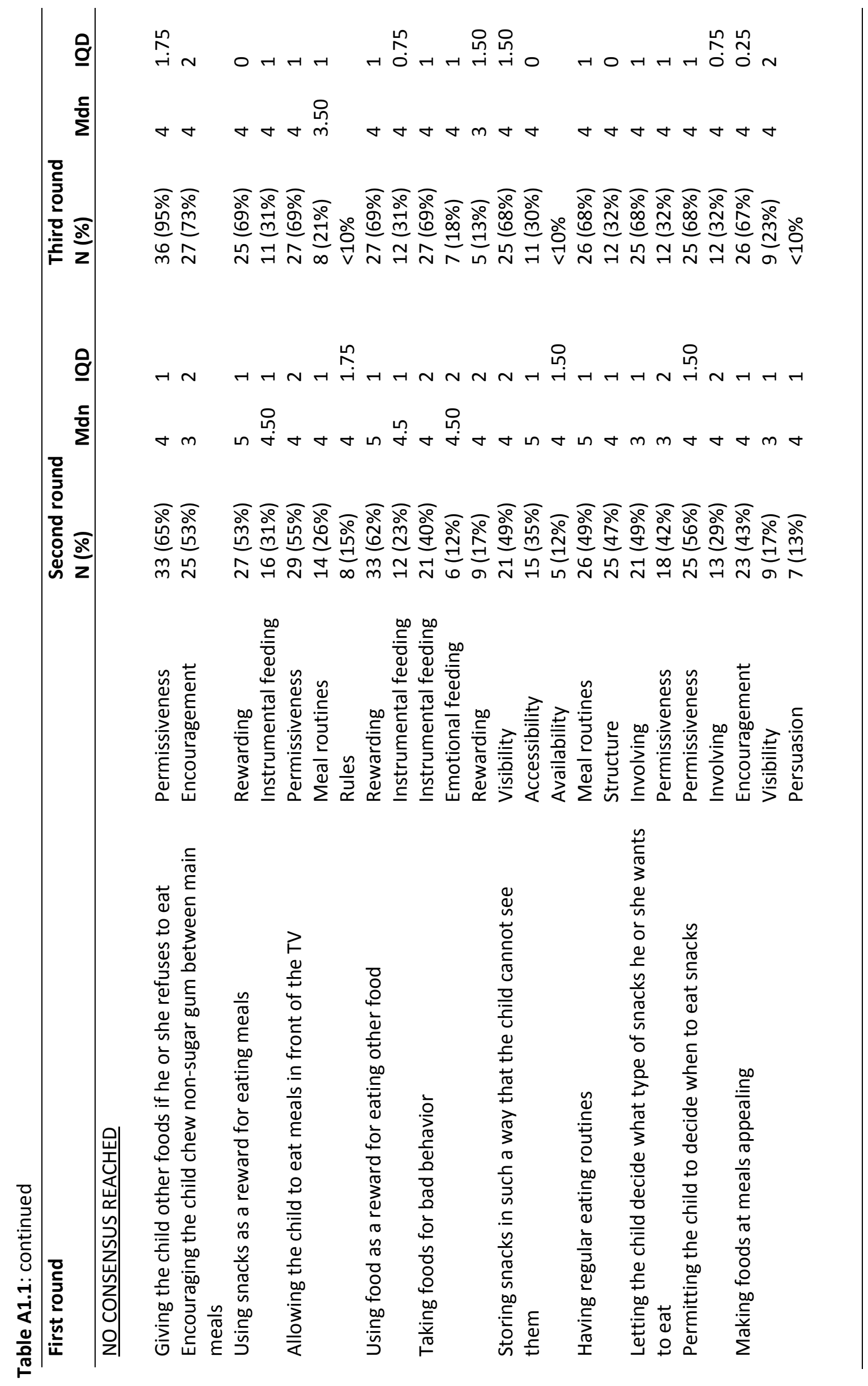




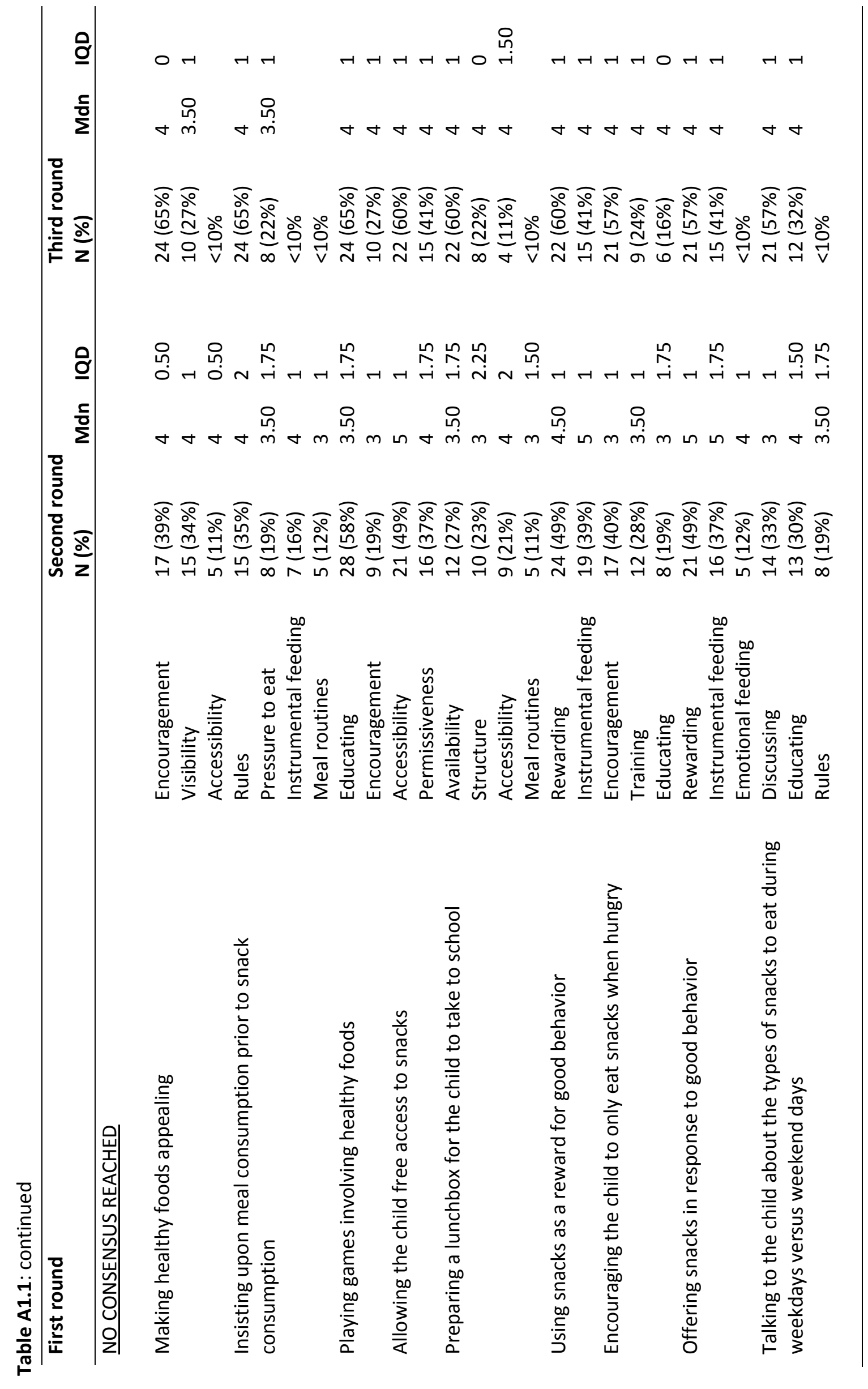




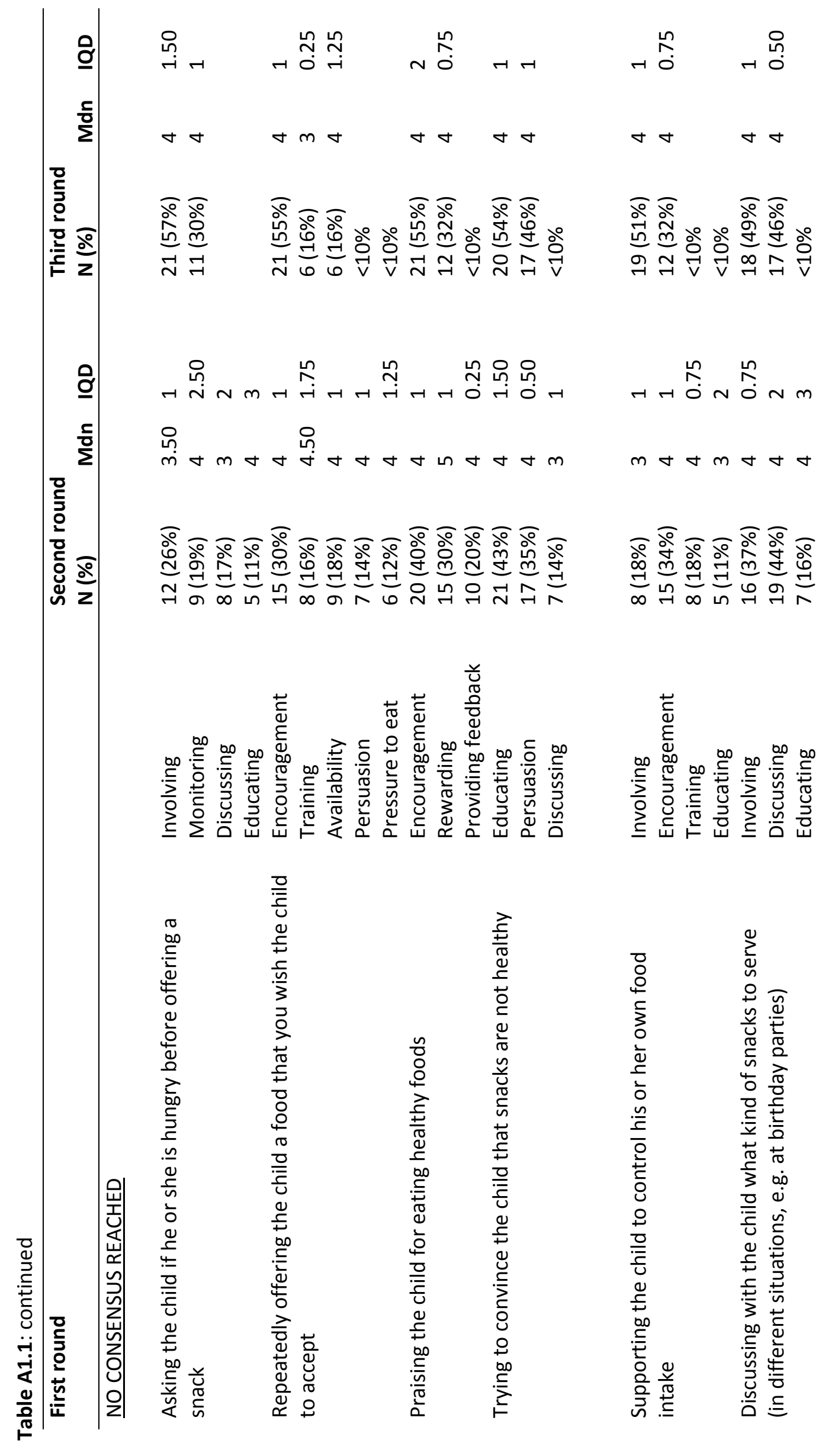




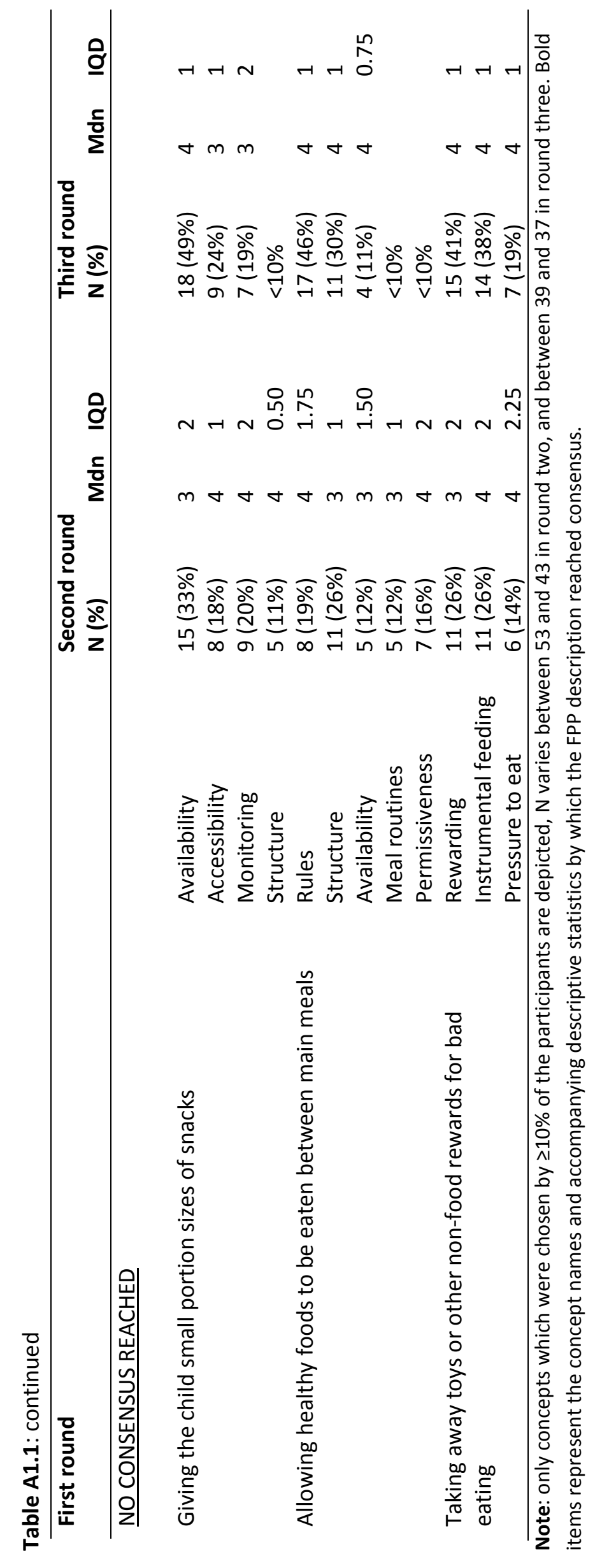




\section{Appendix 2: Supplementary material chapter 4}

\begin{tabular}{|c|c|c|c|c|c|}
\hline $\begin{array}{l}\text { (Availability of unhealthy foods) } \\
\text { 1. Parents could limit the availability of EDSFs in the house. } \\
\text { For example, by limiting the amount and diversity of EDSFs in } \\
\text { the house. }\end{array}$ & 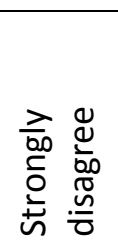 & 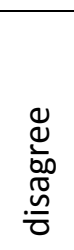 & 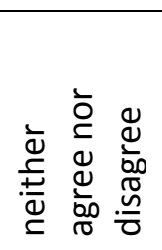 & $\frac{ఖ}{\frac{d}{40}}$ & 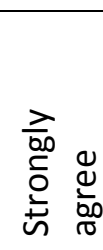 \\
\hline I limit the availability of EDSFs in the house for [child's name] & $\bigcirc$ & $\bigcirc$ & $\bigcirc$ & $\bigcirc$ & 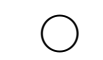 \\
\hline $\begin{array}{l}\text { (Accessibility of unhealthy foods) } \\
\text { 2. Parents could make EDSFs easily accessible to their child. } \\
\text { For example, by storing EDSFs in places where their child can } \\
\text { easily get at them. }\end{array}$ & 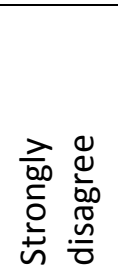 & $\begin{array}{l}\Phi \\
\frac{\Phi}{20} \\
\frac{\mathscr{T}}{0} \\
\frac{\mathscr{N}}{0}\end{array}$ & 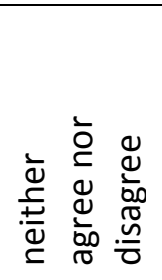 & $\underset{\frac{\Phi}{40}}{\frac{\Phi}{4}}$ & 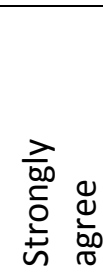 \\
\hline I make sure that [child's name] | & $\bigcirc$ & $\bigcirc$ & $\bigcirc$ & $\bigcirc$ & $\bigcirc$ \\
\hline $\begin{array}{l}\text { (Discussing) } \\
\text { 3. Parents could talk to their children about EDSF intake. } \\
\text { For example, by talking about the kind of EDSFs their child } \\
\text { likes or the kinds that are being bought. }\end{array}$ & 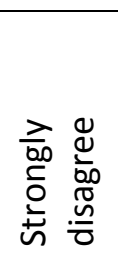 & 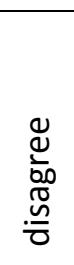 & 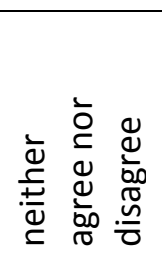 & 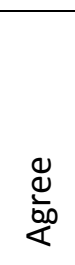 & 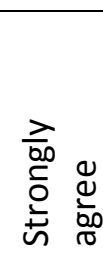 \\
\hline I talk to [child's name] about eating & $\bigcirc$ & 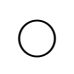 & $\bigcirc$ & $\bigcirc$ & $\bigcirc$ \\
\hline $\begin{array}{l}\text { (Emotional feeding) } \\
\text { 4. Parents could give their child EDSFs to make the child feel } \\
\text { better. } \\
\text { For example, by comforting or calming down the child with } \\
\text { EDSFs if he/she is in pain or is distressed, or by giving EDSFs } \\
\text { to cheer the child up. }\end{array}$ & 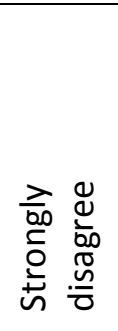 & $\begin{array}{l}\searrow \\
\frac{0}{20} \\
\frac{0}{0} \\
\frac{\mathscr{n}}{0}\end{array}$ & 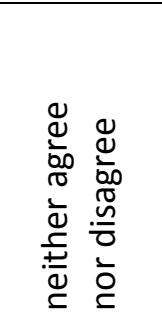 & 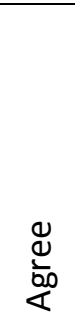 & 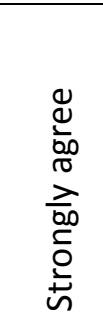 \\
\hline I give [child's name] EDSFs to $\mathrm{m}$ & $U$ & $\bigcirc$ & ) & $U$ & $U$ \\
\hline $\begin{array}{l}\text { (Avoiding unhealthy modelling) } \\
\text { 5. Parents could consciously refrain from eating EDSFs when } \\
\text { their child is around. } \\
\text { For example, by eating EDSFs after their child has been put to } \\
\text { bed. }\end{array}$ & 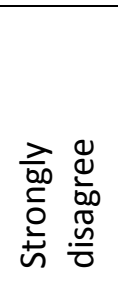 & 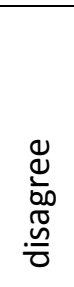 & 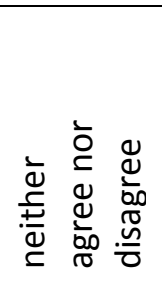 & $\frac{\Phi}{\frac{\Phi}{\alpha 0}}$ & 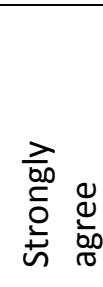 \\
\hline $\begin{array}{l}\text { I consciously refrain from eating EDSFs when [child's name] } \\
\text { is around. }\end{array}$ & $C$ & $\bigcirc$ & $\bigcirc$ & $\bigcirc$ & \\
\hline
\end{tabular}


(Instrumental feeding)

6. Parents could give their child EDSFs as a reward for good behavior.

For example, by telling the child he/she has to eat dinner, fruit, or vegetables first before getting EDSFs, or by rewarding the child if he/she has done well (e.g. at school)

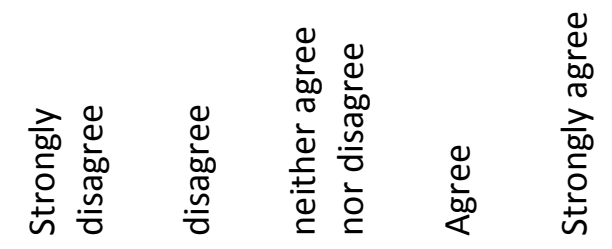

I give [child's name] EDSFs to reward him/her for good behavior.

(Rules)

7. Parents could set rules for their child about eating EDSFs.

For example, the rule that their child first has to ask for candy before getting it, that their child is not allowed to eat EDSFs just before a meal, or that he/she is not allowed to eat particular types of candy.

\begin{tabular}{|c|c|c|c|}
\hline 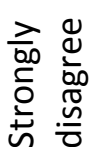 & 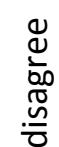 & 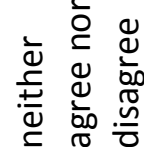 & 0 \\
\hline
\end{tabular}

I have rules for [child's name] about eating EDSFs.

(Structure)

8. Parents could provide structure with regard to EDSFs. For example, by giving EDSFs only on specific occasions or at fixed times, for example when the child comes home from school.

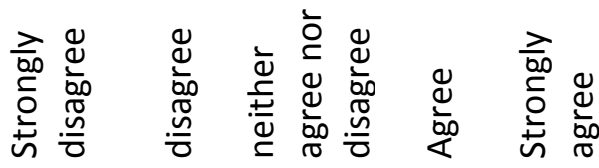

I provide structure regarding EDSFs.

(Pressure to eat)

9. Parents could insist that their child eats or finishes a food item

For example by making their child stay at the dinner table until the plate is empty or by insisting that their child eats fruit.

I insist that [child's name] eats or finishes a food item

(Providing feedback)

10. Parents could give their child feedback on his/her eating behavior.

For example, by criticizing their child for eating EDSFs or saying that he/she has had enough EDSFs for the day.

I respond to [child's name]'s eating behavior by providing him/her with feedback

(Permissiveness)

11. Parents could be flexible about their child's eating behavior.

For example by setting few limits for the amount of EDSFS their child is allowed to eat.

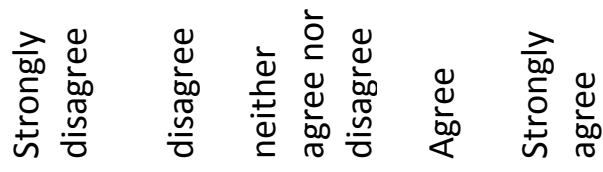
I am flexible about [child's name]'s eating behavior

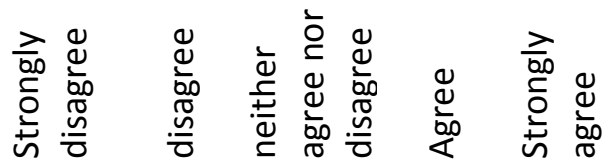
$\bigcirc \quad \bigcirc \quad \bigcirc \quad \bigcirc$ 
(Availability healthy foods)

12. Parents could make sure that healthy foods are available for their child at home.

For example by bringing fruit and vegetables home or by keeping a variety of healthy foods for their child.

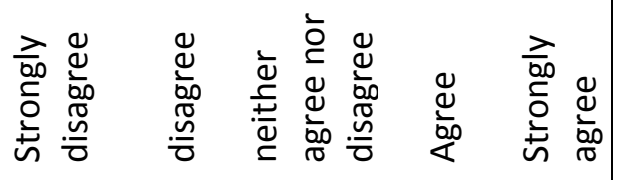

I make sure healthy foods are available at home for [child's name]

(Accessibility healthy foods)

13. Parents could make sure their child has easy access to healthy foods.

For example by storing healthy foods in a place that is easily accessible to their child, or by having healthy foods, such as fruit, available in ready-to-eat form.

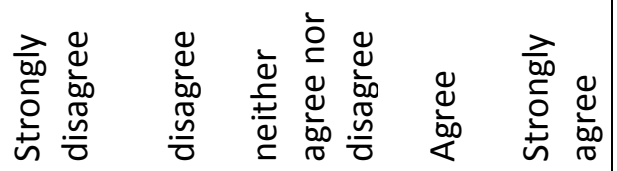

I make sure [child's name] has easy access to healthy foods

(Encouragement)

14. Parents could encourage their child to eat healthy food.

For example, by encouraging their child to eat enough vegetables during the meal, by being positive about healthy foods, or by encouraging their child to eat a variety of foods.

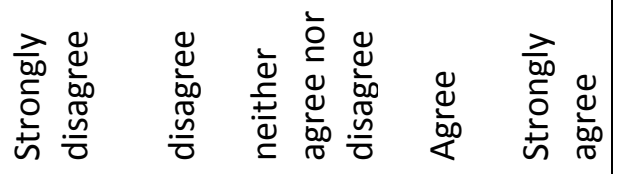

I encourage [child's name] to eat healthy food

(Visibility)

15. Parents could make sure healthy foods are visible for their child.

For example by putting a fruit bowl in a place where the child can clearly see it.

\begin{tabular}{|c|c|c|c|}
\hline 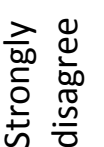 & 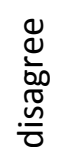 & 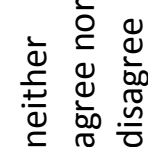 & 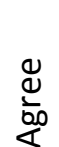 \\
\hline
\end{tabular}

I make sure healthy foods are visible for [child's name]

(Rewarding)

16. Parents could reward their child for healthy eating behavior (rewarding with something else than EDSFs). For example by complimenting their child on eating healthy food or by giving their child a sticker for eating healthy food.

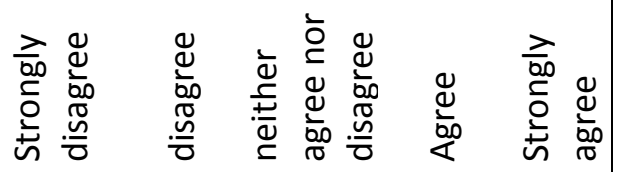
I reward [child's name]'s healthy eating with something else than EDSFs

(Healthy modelling)

17. Parents could intentionally eat healthy foods in front of their child.

For example by eating fruit when their child is around or by talking enthusiastically about healthy foods when their child is around.

I intentionally eat healthy foods in front of [child's name] 
(Educating)

18. Parents could teach their child about food.

For example, by explaining that eating healthy food is better than eating EDSFs or that eating EDSFs is bad for their teeth or that they might become overweight by eating EDSFs.

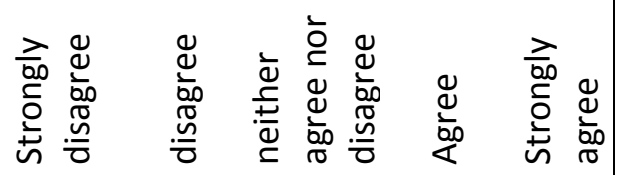

I teach [child's name] things about food

(Involving)

19. Parents could involve their child in food-related activities.

For example, by taking their child along when doing the groceries, letting them choose what to have for dinner, or letting them assist with preparing the food or setting the table.

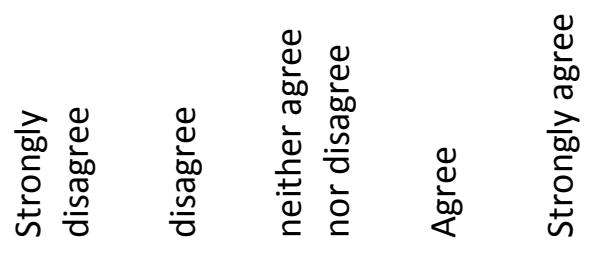

I involve [child's name] in food-related activities

(Meal routines)

20. Parents could ensure healthy mealtime habits.

For example by having meals together with the whole family or by eating at the dinner table.

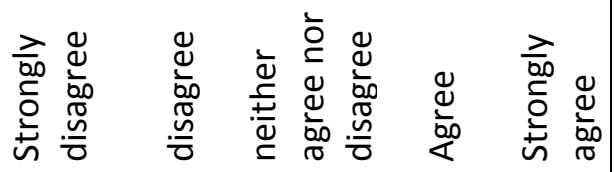

I ensure healthy mealtime habits

(Monitoring)

21. Parents could monitor what their child is eating during the day.

For example, by checking how much EDSFs their child has eaten or by asking their child what he or she ate.

I monitor what [child's name] is eating during the day

Note: the questionnaire has been translated by a bilingual translator but has not been cross-culturally validated. 


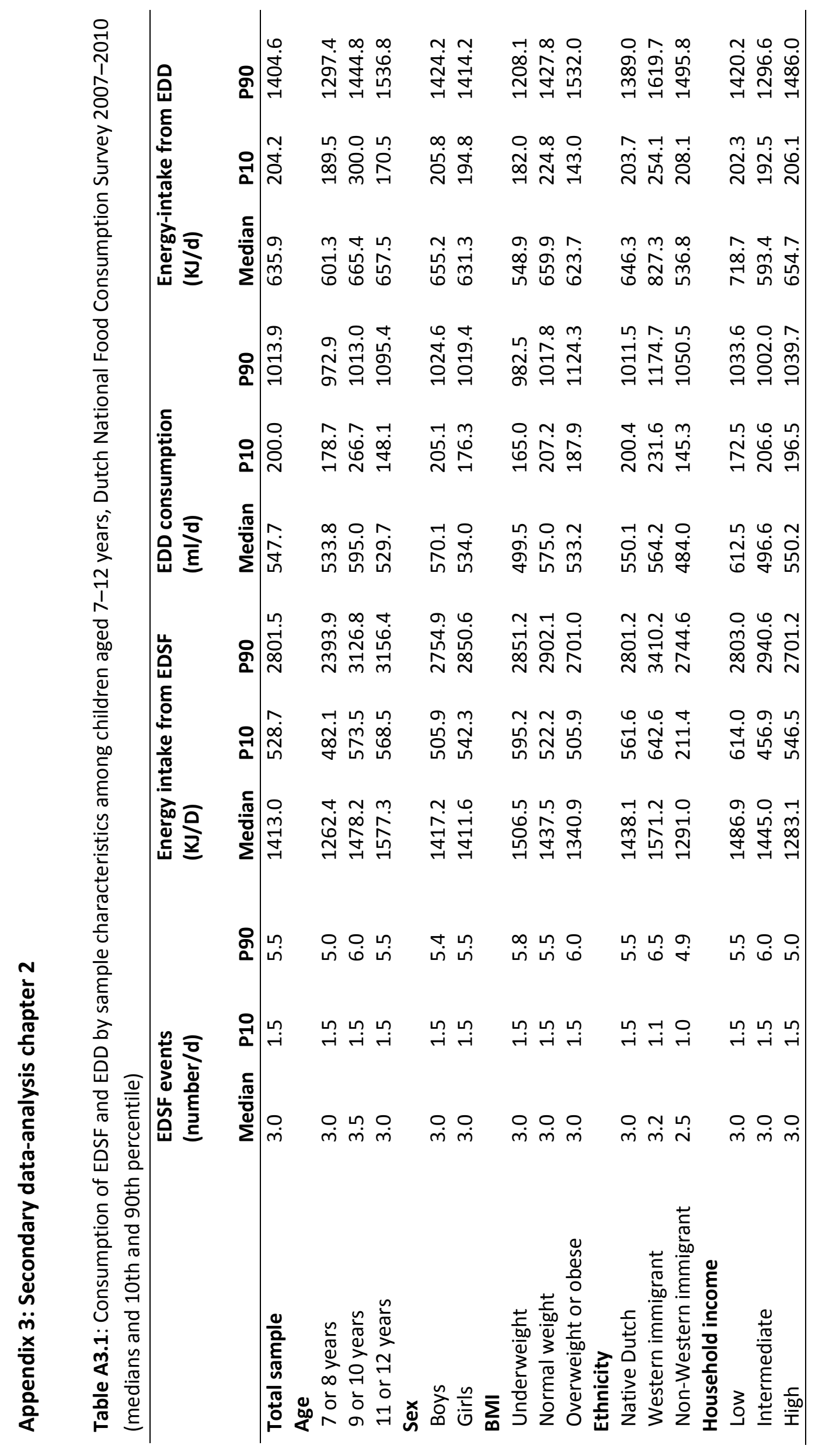




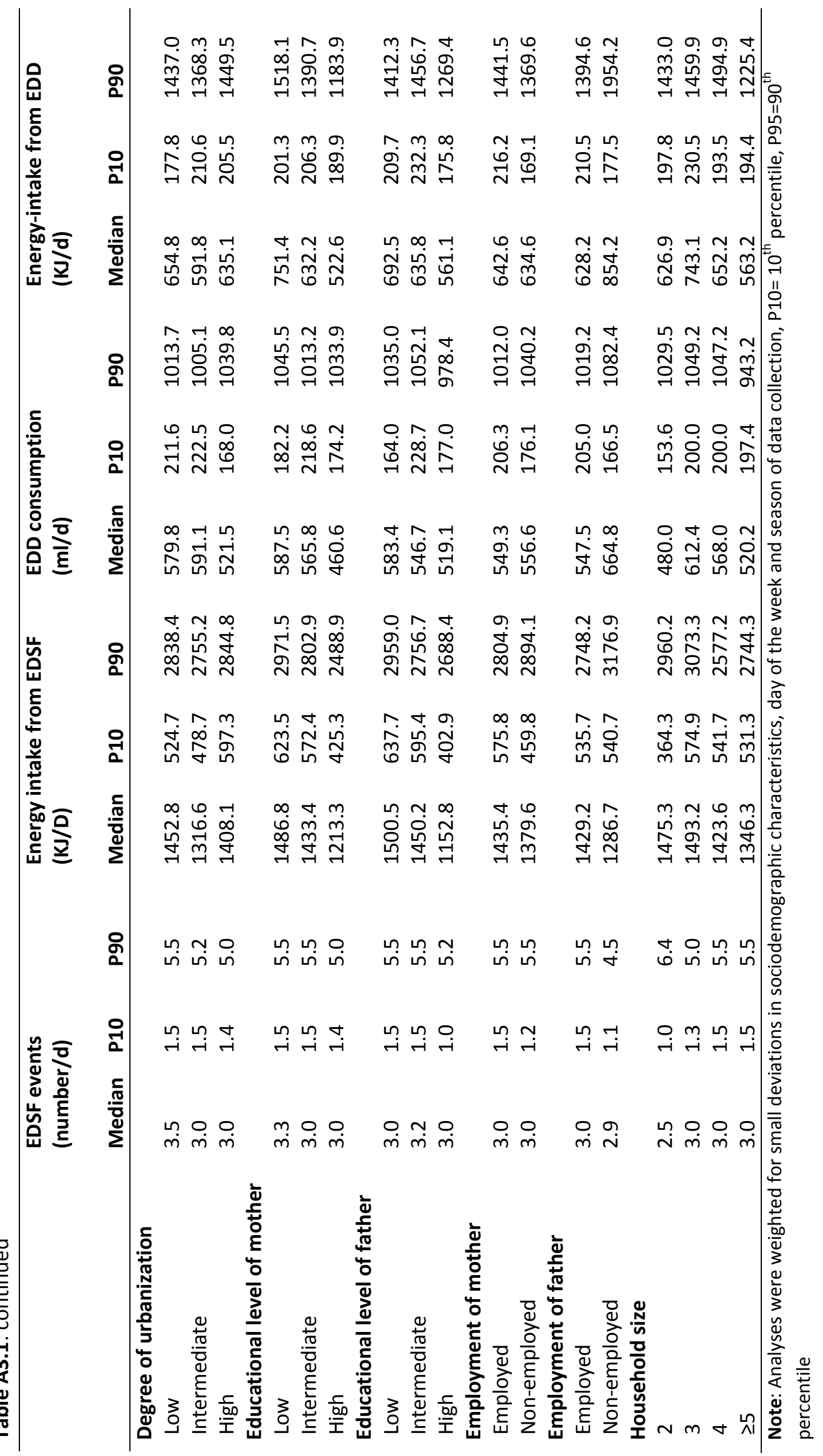


Summary 
The main purpose of the project reported in this dissertation was to advance research and the development of theory around parental influences - in particular food parenting practices (FPPs) - in the context of child snacking. The ultimate goal of the six studies that are included was to identify priorities and starting points for intervention developers addressing children's diets.

Excessive intakes of energy-dense snack foods (EDSDs) are undesirable when it comes to children's health. A leading WHO report on diet and nutrition points out that one of the consequences of children's excessive intakes of such foods includes weight gain and obesity. The adverse effects underscore the need to examine the actual consumption of snack foods among children and investigate opportunities to help children and their parents to decrease it. As such, one of the aims of the research reported in this dissertation was to unravel the consumption of EDSFs among Dutch children. Researchers increasingly recognize the importance of parental influences (i.e. general parenting and FPPs) with regard to children's diets. General parenting refers to an emotional climate of attitudes in which communication toward the child takes place and in which parental behaviors are expressed. General parenting is commonly conceptualized by using two dimensions (i.e. responsiveness and demandingness). FPPs are defined as goal-directed parental behaviors directed at influencing children's dietary behavior (e.g. modeling food intake, monitoring food intake, and restricting the intake of certain foods). Empirical evidence on parenting in relation to children's nutrition behaviors points out that that general parenting and FPPs are linked to children's diet and weight. However, parenting practices have been conceptualized and examined in numerous ways worldwide, which has probably led to inconsistent results. In addition, the interplay between different FPPs, and the interplay of FPPs used by fathers and mothers within one family, has scarcely been taken into account. Hence, another aim of the dissertation was to improve the understanding of parental influences, by revisiting the current conceptualization of FPPs and the development of an instrument. Consequently, the co-occurrence of parenting practices (i.e. the co-occurrence of multiple FPPs within a parent and the co-occurrence of FPPs between parents in one family) was investigated. Since there is a need for a greater understanding of the factors that influence the use of FPPs, in particular the ones that are susceptible to change, the final aim was to explain parent's use 
of practices around snacking using a set of predisposing (e.g. parent's personality) and sociocognitive variables (e.g. attitude, self-efficacy).

Chapter 2 describes the intake of EDSFs and energy-dense drinks (EDDs) among Dutch 7 to 12 year olds, based on the Dutch national food consumption survey. Children were found to have 3.3 (SD=1.6) snack food events per day on average, yielding 1569.7 (SD=928.7) kJ. The average EDD consumption of the sample was $594.2(\mathrm{SD}=342.3) \mathrm{ml} / \mathrm{d}$, yielding 737.2 $(S D=495.9) \mathrm{kJ}$. Accordingly, the total daily energy intake from these energy-dense foods and drinks was 2306.8 (SD 1113.8) kJ/d (about $550 \mathrm{kcal} /$ day) on average. The high number of children with excessive intakes illustrates the need for actions. In particular, children of low educated parents and after school snacking should be targeted.

Chapter 3 shows the results of an international Delphi study among subject experts that was conducted to revisit current conceptualization and create consensus in operationalization of FPPs. The three round Delphi study resulted in a list with descriptions of FPPs around snacking and 21 constructs matching these descriptions. A conceptual framework of four factors, derived from the general parenting literature (i.e. nurturance, structure, behavioral control, and coercive control), was proposed to classify the constructs identified. The results of this study could serve as a starting point for the development of instruments and may boost the process of consensus development concerning terminology around FPPs.

Chapter 4 describes the systematic development of a questionnaire for measuring FPPs in the context of snacking. The results from the Delphi study laid the foundation of the newly developed instrument. Based on a questionnaire survey, acceptable test-retest reliabilities and evidence for the discriminative value of constructs were found. The instrument is comprehensive but brief and therefore offers the opportunity to study dynamics across FPPs, for example by taking a clustering approach.

Chapter 5 illustrates the co-occurrence of FPPs by the identification of four clusters of parents based on their use of the FPPs operationalized in the study of chapter 4 . A sample of Dutch parents were recruited from a research panel and invited to fill out a questionnaire. The following clusters emerged: "high covert control and rewarding", "low covert control 
and non-rewarding", "high involvement and supportive" and "low involvement and indulgent". Several background factors characterized membership of the clusters, including parent's age, gender and children's age and snack intake. Most importantly, parents in the "high involvement and supportive" cluster were found to have children with the lowest snack intakes, compared to children of parents in any other cluster. Most saliently, parents within this cluster tended to be involved in communicating about food and created a supportive home food environment. In addition, they often applied relatively strict rules regarding snacking. The number of parents not being highly involved and supportive regarding children's snacking should be reduced.

Chapter 6 shows an exploration of how the co-occurrence of general parenting and FPPs between parents within in one family may affect children's intake of snack foods. In particular, the impact of incongruence between parents regarding general parenting and restrictive snacking rules on children's intake of snack foods was assessed. To this end, a cross-sectional questionnaire survey was conducted. The study showed that high levels of parental incongruence regarding snacking rules impair the negative association between father's restrictive rules and children's snacking. This exploratory examination of incongruence between parents suggests that restrictive rules may help to prevent excessive snack consumption in children only when both parents apply them.

Chapter $\mathbf{7}$ describes which factors (i.e. predisposing factors such as personality and general parenting and socio-cognitive factors such as self-efficacy and attitude) explain the use of FPP patterns identified in chapter 5 . The study built on that study by using the same sample and data. Overall, self-efficacy and outcome expectations were among the strongest predictors of parent's use of parenting practices. With regard to the predisposing factors, the general parenting construct of nurturance strongly predicted whether parents were likely to apply the pattern of "high covert control and rewarding". This evidence indicates that intervention developers might focus at increasing self-efficacy and educating parents about what constitute effective and ineffective parenting practices. In order to create sustainable change in FPPs, creating a positive general parenting climate seems to be essential. 
Chapter 8 summarizes the main findings of the different studies and discusses methodological considerations of the studies. Furthermore, it describes implications for research, theory, and practice, leading to several recommendations. From the studies presented, it can be concluded that most children in the Netherlands consume EDSFs and EDDs excessively. Moreover, the Delphi study initiated a process towards consensus on terminology and conceptualization of FPPs, as indicated by subsequent initiatives. The cooccurrence of FPPs was acknowledged and addressed in two studies, showing that different patterns of use of FPPs exist and that this combination of practices might be more valuable to study than individual practices. In addition, fathers and mothers within a family may be incongruent regarding parenting, which could be countereffective. Finally, socio-cognitive factors are strong predictors of parent's FPPs and could be targeted in programs to change parent's use of practices. Thus, fundamental work was conducted to stimulate theory development, while the empirical studies contributed to the understanding of parental influences on child snacking. The newly developed questionnaire created the opportunity to investigate more of such unexplored key issues in food parenting to continue advancing research is this area. 
Samenvatting 
Het hoofddoel van het project in dit proefschrift was om onderzoek en theorieontwikkeling rondom ouderlijke invloeden - in het bijzonder voedingsgerelateerde ouderschapsprakijken (VOP'en) - op het snackgedrag van kinderen te bevorderen. Het ultieme doel van de zes geïncludeerde studies was om prioriteiten en aanknopingspunten voor interventieontwikkelaars te identificeren.

Overmatige consumptie van energiedichte tussendoortjes is ongezond voor kinderen. Een invloedrijk rapport over voeding, gepubliceerd door de Wereldgezondheidsorganisatie (WHO), geeft aan dat de consumptie van dergelijke voedingsmiddelen onder andere kan leiden tot gewichtstoename en obesitas. Deze nadelige gevolgen benadrukken het belang om de consumptie van energiedichte tussendoortjes door kinderen te onderzoeken en mogelijkheden te bestuderen om kinderen en hun ouders te helpen het te verlagen. Daarom is het nauwkeurig onderzoeken van de inname van energiedichte tussendoortjes een van de doelen van dit proefschrift. In toenemende mate erkennen onderzoekers dat ouderlijke invloed (d.w.z. algemene opvoeding en VOP'en) belangrijk zijn ten aanzien van het eetgedrag van kinderen. Algemene opvoeding verwijst naar een 'emotioneel klimaat bestaande uit attitudes van ouders' in de thuissituatie. In dit klimaat vindt interactie tussen ouder en kind plaats. Veelal wordt algemene opvoeding geconceptualiseerd door middel van twee dimensies (d.w.z. responsiviteit en gedragscontrole). VOP'en zijn gedefinieerd als doelgericht gedrag van ouders, gericht op het beïnvloeden van het eetgedrag van hun kind(eren) (bijvoorbeeld grenzen stellen aan de inname van bepaalde soorten voedingsproducten of het vertonen van voorbeeldgedrag). Empirisch bewijs van de relatie tussen opvoeding en het eetgedrag laat zien dat algemene opvoeding en VOP'en beide gerelateerd zijn aan eetgedrag en gewicht van kinderen. Deze ouderschapspraktijken zijn wereldwijd echter op verschillende manieren geconceptualiseerd en gemeten, wat mogelijk voor inconsistente resultaten heeft gezorgd. Bovendien zijn de wisselwerking tussen verschillende ouderschapspraktijken en tussen ouderschapspraktijken die worden toegepast door vaders en moeders binnen één gezin zelden in beschouwing genomen. Om deze redenen was een ander doel van dit proefschrift om de kennis over ouderlijke invloeden ten aanzien van tussendoortjesconsumptie te vergroten door de huidige conceptualisatie van VOP'en te herzien en door de ontwikkeling van een meetinstrument. Vervolgens is de wisselwerking van VOP'en (d.w.z. de wisselwerking van de verschillende praktijken van een 
ouder en tussen ouders binnen een gezin) onderzocht. Omdat er behoefte is aan inzicht in de factoren die het gebruik van ouderschapspraktijken beïnvloeden, en dan met name de factoren die veranderbaar zijn, was het laatste doel om het gebruik van ouderschapspraktijken ten aanzien van tussendoortjes te verklaren door middel van een groep predisponerende (bv. persoonlijkheid van de ouder) en sociaal-cognitieve (bv. attitude, eigen-effectiviteit) factoren.

Hoofdstuk 2 beschrijft de inname van energiedichte tussendoortjes en dranken onder Nederlandse kinderen van 7 tot en met 12 jaar, gebaseerd op de Nederlandse voedselconsumptiepeiling. Gemiddeld hadden kinderen 3.3 (SD=1.6) tussendoortjesmomenten per dag waarin 1569.7 (SD=928.7) kJ geconsumeerd werd. De gemiddelde consumptie van energiedichte dranken was 594.2 ( $\mathrm{SD}=342.3$ ) $\mathrm{ml} / \mathrm{dag}$, wat resulteerde in een inname van $737.2(\mathrm{SD}=495.9) \mathrm{kJ}$. Zodoende was de totale energie-inname van deze energiedichte producten gemiddeld 2306.8 (SD=1113.8) kJ/dag (ongeveer 550 $\mathrm{kcal} / \mathrm{dag})$. Het groot aantal kinderen met overmatige inname benadrukken dat acties om gezonde voedingsgewoonten onder kinderen te bevorderen noodzakelijk zijn. Deze acties zouden zich vooral op kinderen van laag opgeleide ouders en snacken na school moeten richten.

Hoofdstuk 3 presenteert de resultaten van de internationale Delphi studie onder deskundigen in het veld, die was uitgevoerd om de huidige conceptualisatie te herzien en voor consistentie te zorgen in de operationalisatie van voedingsgerelateerde ouderschapspraktijken. De uit drie ronden bestaande Delphi studie resulteerde in een lijst met beschrijvingen van ouderschapspraktijken rondom tussendoortjesconsumptie en 21 constructen die de inhoud ervan dekken. Om de geïdentificeerde constructen te classificeren is een conceptueel raamwerk met vier factoren voorgesteld (d.w.z. zorgzaamheid, structuur, gedragscontrole, en dwangmatige controle). Deze factoren zijn afgeleid van onderzoek naar algemene opvoeding. De resultaten van de studie kunnen aanknopingspunten bieden voor de ontwikkeling van instrumenten en zou het proces van overeenstemming over terminologie rondom VOP'en kunnen stimuleren. 
Hoofdstuk 4 beschrijft de systematische ontwikkeling van een vragenlijst voor het meten van ouderschapspraktijken in de context van snackconsumptie. De resultaten van de Delphi studie vormden de basis voor dit nieuw ontwikkeld instrument. Gebaseerd op een vragenlijstonderzoek, werden acceptabele test-hertest betrouwbaarheidsstatistieken en bewijs voor de discriminerende waarde van de constructen gevonden. Het instrument omvat een breed scala aan ouderschapspraktijken, maar is beknopt waardoor het mogelijkheden biedt om de dynamiek van praktijken te onderzoeken, bijvoorbeeld door middel van een clusteranalyse.

Hoofdstuk 5 illustreert het complementaire optreden van VOP'en door de identificatie van vier clusters van ouders. Deze clusters zijn gebaseerd op het gebruik van VOP'en die in hoofdstuk 4 zijn geoperationaliseerd. Een steekproef onder Nederlandse ouders was gerekruteerd via een onderzoekspanel en uitgenodigd om een vragenlijst in te vullen. De volgende clusters werden gevonden: "hoge verborgen controle en belonen", "lage verborgen controle en belonen", "hoge betrokkenheid en ondersteunend", en "lage betrokkenheid en toegeeflijk". Verschillende achtergrondkenmerken karakteriseerde clusterlidmaatschap, waaronder de leeftijd en het geslacht van de ouder, en de leeftijd en tussendoortjesconsumptie van het kind. In het bijzonder werd gevonden dat ouders binnen het "hoge betrokkenheid en ondersteunend" cluster kinderen met de laagste tussendoortjesconsumptie hadden. Meest kenmerkend voor ouders in dit cluster was dat zij geneigd waren om te communiceren over voeding en een ondersteunende thuisomgeving rondom voeding te creëren. Daarnaast pasten deze ouders vaak relatief strikte regels ten aanzien van tussendoortjes toe. Het aantal ouders dat geen hoge betrokkenheid heeft en niet ondersteunend is ten aanzien van de tussendoortjesconsumptie van kinderen zou verminderd moeten worden.

Hoofdstuk 6 beschrijft een exploratie van hoe het complementaire optreden van algemene opvoeding en ouderschapspraktijken tussen ouders binnen een gezin de tussendoortjesconsumptie van kinderen zou kunnen beïnvloeden. Specifiek werd de invloed van inconsistentie in algemene opvoeding en restrictieve regels ten aanzien van tussendoortjes tussen ouders op de snackconsumptie van kinderen onderzocht. Hiervoor werd een cross-sectioneel vragenlijstonderzoek uitgevoerd. De studie liet zien dat hoge 
niveaus van ouderlijke inconsistentie ten aanzien van snackregels de negatieve associatie tussen vader's restrictieve regels en de tussendoortjesconsumptie van kinderen verzwakt. Dit onderzoek naar inconsistentie tussen ouders suggereert dat restrictieve regels overmatige snackconsumptie door kinderen zouden kunnen voorkomen, maar alleen wanneer beide ouders deze hanteren.

Hoofdstuk 7 beschrijft welke factoren (d.w.z. predisponerende factoren zoals persoonlijkheid en algemene opvoeding, en sociaal-cognitieve factoren zoals eigeneffectiviteit en attitude) patronen van VOP'en die zijn geïdentificeerd in hoofdstuk 5 verklaren. Van alle factoren, waren eigen-effectiviteit en uitkomstverwachtingen de sterkste voorspellers van het gebruik van ouderschapspraktijken. Met betrekking tot alleen de predisponerende factoren, voorspelde het algemene opvoedingsconstruct zorgzaamheid sterk de kans op het patroon van "hoge betrokkenheid en ondersteunend" onder ouders. Dit bewijs laat zien dat interventieontwikkelaars zich kunnen richten op het vergroten van eigen-effectiviteit en ouders zouden moeten voorlichten over wat effectieve en ineffectieve ouderschapspraktijken zijn. Om tot langdurige verandering in ouderschapspraktijken te komen, lijkt het noodzakelijk te zijn om daarnaast ook te richten op algemene opvoeding, zoals zorgzaamheid.

Hoofdstuk 8 vat de belangrijkste bevindingen van de verschillende studies samen en bediscussieerd de methodologische overwegingen van deze studies. Daarnaast worden de implicaties voor onderzoek en de praktijk beschreven, welke leiden tot verschillende aanbevelingen. Uit de studies die zijn gepresenteerd in dit proefschrift kan worden geconcludeerd dat de meeste kinderen in Nederland energiedichte- tussendoortjes en dranken overmatig consumeren. Daarnaast heeft de Delphi studie een proces ten aanzien van overeenstemming in terminologie en conceptualisatie van VOP'en in gang gezet, zoals blijkt uit initiatieven die hierna volgenden. Het complementaire optreden van ouderschapspraktijken is erkend in twee studies die lieten dat verschillende patronen van ouderschapspraktijken bestaan en dat het mogelijk waardevoller is om deze combinatie van praktijken te onderzoeken, in plaats van individuele praktijken. Daarnaast kunnen vaders en moeders inconsistent zijn met betrekking tot opvoeding, wat de positieve effecten ervan kan tegenwerken. Tot slot werd gevonden dat sociaal-cognitieve factoren sterke voorspellers zijn 
van patronen ten aanzien van VOP'en. Interventieprogramma's zouden zich dan ook op deze factoren kunnen richten. $\mathrm{Er}$ is dus fundamenteel werk verricht om theorieontwikkeling te stimuleren, terwijl de empirische studies bijdroegen aan het begrip van ouderlijke invloeden op het snackgedrag van kinderen. De ontwikkelde vragenlijst heeft ervoor gezorgd dat meer van dit soort nog niet geëxploreerde, maar belangrijke invalshoeken rondom ouderschapspraktijken onderzocht kunnen worden om de bevordering van het onderzoek in dit veld voort te zetten. 
Curriculum vitae 


\section{Biography}

Dorus Gevers was born in Heesch, the Netherlands, on November 10, 1987. After completing secondary school, he studied Health Sciences at Maastricht University. In 2010, he finished this programme cum laude and started pursuing a Master's degree in Public Health, with a specialization in Health Education and Promotion. He achieved this degree cum laude in 2011. During his training at Maastricht University, he belonged to the top 3\% students in four consecutive academic years (i.e. 2007-2008, 2008-2009, 2009-2010, and 2010-2011). In October of 2011 he began his PhD project at the department of Health Promotion and worked there for four years. In September of 2015 he started working as an epidemiologist at the West Brabant Public Health Service. Since April 2016 he has been working as a researcher at Utrecht University on a serious game aimed at preventing childhood obesity.

\section{Publications}

dd 01-05-2016

\section{Publications presented in this dissertation}

Gevers, D. W. M., Kremers, S. P. J., de Vries, N. K., \& van Assema, P. (2014). Clarifying concepts of food parenting practices. A Delphi study with an application to snacking behavior. Appetite, 79, 51-57.

Gevers, D. W. M., Kremers, S. P. J., de Vries, N. K., \& van Assema, P. (2015). Intake of energydense snack foods and drinks among Dutch children aged 7-12 years: how many, how much, when, where and which? Public Health Nutrition, 1-10.

Gevers, D. W. M., Kremers, S. P. J., de Vries, N. K., \& van Assema, P. (2015). Patterns of Food Parenting Practices and Children's Intake of Energy-Dense Snack Foods. Nutrients, 7, 4093-4106.

Gevers, D. W. M., van Assema, P., Sleddens, E. F. C., de Vries, N. K., \& Kremers, S. P. J. (2015). Associations between general parenting, restrictive snacking rules, and adolescent's snack intake. The roles of fathers and mothers and interparental congruence. Appetite, 87, 184-191. 


\section{Other publications:}

Gevers, D. W. M., Kremers, S. P. J., de Vries, N. K., van Assema, P. (2014). Voedingsspecifieke opvoedingspraktijken meetbaar maken. VoedingNu, 16, 29.

Gevers, D. W. M., Raaijmakers, L. G. M., Bessems, K. M. H. H., Teuscher, D., Kremers, S. P. J., \& van Assema, P. (2015). Restrictive rules of Dutch mothers regarding their children's dietary intake between meals. Eating behaviors, 18, 62-65.

Kremers, S. P. J., Sleddens, E. F. C., Gerards, S. M. P. L., Gubbels, J. S., Rodenburg, G., Gevers, D. W. M., \& van Assema, P. (2013). General and Food-Specific Parenting: Measures and Interplay. Childhood Obesity, 9, S22-S31.

Raaijmakers, L. G. M., Gevers, D. W. M., Teuscher, D., Kremers, S. P. J., \& van Assema, P. (2014). Emotional and instrumental feeding practices of Dutch mothers regarding foods eaten between main meals. BMC Public Health, 14, 171. 
Dankwoord 
Het geeft een goed gevoel om na vier jaar het proefschrift te kunnen afronden en aan iedereen het resultaat van het promotieonderzoek te laten zien. Zonder de hulp van velen was dit proefschrift niet geworden zoals het nu is. Ik wil daarom iedereen die daaraan heeft bijgedragen heel erg bedanken.

Allereerst mijn promotoren en copromotor: Nanne, Stef en Patricia, bedankt voor de kans die jullie me gaven om dit onderzoek uit te voeren en te promoveren. Nanne, je kwam vaak met goede gedachten over hoe we het best het onderzoek konden voortzetten en opbouwen. Je had altijd overzicht over het grote geheel waardoor ik binnen vier jaar zo goed als alles heb kunnen afronden. Bedankt ook voor je kritische blik op mijn werk. De manuscripten zijn hier sterk door verbeterd. Stef, als ik je 'begeleiderschap' zou uitdrukken in termen van algemene opvoeding scoor je hoog op autonomy support; naar mijn idee een goede opvoeding voor een promovendus. Ik waardeer je kennis, gedrevenheid en optimisme. Vooral je kracht om resultaten in perspectief te plaatsen hebben me enorm vooruit geholpen in het onderzoek. Vanaf de start tot en met het eind maakte jij tijdens congressen en symposia 'reclame' voor mijn onderzoek (en nu nog). Dank je wel daarvoor! Patricia, wanneer ik door een grote hoeveelheid keuzemogelijkheden niet meer snel genoeg vooruitkwam, dwong je me regelmatig keuzes te maken. Dat heeft ervoor gezorgd dat de kwantiteit van het onderzoek op peil bleef en ik nu eerder beslissingen kan nemen. Ik heb van je geleerd om planmatig en systematisch te werken. Daarnaast had je oog voor detail waardoor de manuscripten er perfect uit kwamen te zien. Ik heb veel ruimte gekregen om het promotieonderzoek vorm te geven. Het algemene onderzoeksdoel was niet voor niets 'stimuleren van onderzoek en theorieontwikkeling'! Dat was misschien wel het meest leerzame uit de hele periode. Veel dank daarvoor!

Ook wil graag de beoordelingscommissie bedanken voor het lezen en beoordelen van het proefschrift.

Dit tastbare boekje is niet het enige wat het werken binnen de vakgroep Gezondheidsbevordering heeft opgeleverd. Oud-collega's, dankjewel voor jullie enthousiasme. Met name de VOT- en voedingsoverleggen inspireerde en gaven me motivatie om toepassingen binnen mijn eigen onderzoek te vinden. Ik kon bij iedereen 
terecht voor advies of hulp. Mijn voorkeur voor droge humor werd door verschillende collega's gedeeld waardoor van tijd tot tijd ook wat afleiding mogelijk was.

Paranimfen, Bart en Michel, dank je wel voor jullie morele steun voor en tijdens de verdediging. Ik kon altijd bij jullie terecht met praktische zaken rondom het promoveren en drukken van het proefschrift. Jullie hebben beide ervaring met promoveren waardoor ik me geen betere paranimfen kon wensen.

Familie, schoonfamilie en vrienden: dank je wel voor jullie interesse in mijn onderzoek, gedeelde blijdschap als een manuscript was goedgekeurd en waardering die jullie hadden voor het op en neer reizen naar Maastricht. Soms klonken er wat kritische geluiden over mijn eigen eetgewoonten, (heel) af en toe niet helemaal onterecht. In ieder geval weten jullie nu waar het aan zou kunnen liggen;). Pap, mam, Inge, Kim, Rob, Erik, Hanny, Tommy, Anne en Paul: bedankt voor jullie aanmoedigingen! Opa's en Oma's, bedankt voor het oppassen zodat ik mijn proefschrift kon afronden!

Kim, ondanks dat Maastricht niet bij ons om de hoek is heb jij nooit getwijfeld en me altijd gestimuleerd om daar te promoveren. Je hebt me vaak geholpen om de lange dagen vol te houden. Ik ben je daar erg dankbaar voor. We hebben samen heel veel leuke vakanties, dagjes weg, uitjes en andere hele mooie momenten gehad. Ook dat heeft er aan bijgedragen dat ik met genoeg energie mijn promotieonderzoek kon doen. De afronding van het proefschrift was pittig, toen heb je me enorm geholpen door veel uit handen te nemen. Luuk, hoeveel broertjes of zusjes je er bijkrijgt valt te bezien, maar stelling negen zou wel eens van toepassing kunnen zijn! Dank jullie wel! 
